\title{
The Implications of Degrees of Belief in Free Will
}

by

Sanyar Sohrabi

\begin{abstract}
A thesis submitted to the Faculty of Graduate and Postdoctoral Affairs in partial fulfillment of the requirements for the degree of
\end{abstract}

Master of Cognitive Science

in

Cognitive Science

Carleton University

Ottawa, Canada

(C) 2021

Sanyar Sohrabi 


\begin{abstract}
Belief in free will (whatever free will may exactly be) seems to influence our attitudes and behaviors, from cognition all the way up to meta-cognition. Several researchers recognized the importance of this area a little more than a decade ago and set up camps within the boundaries of philosophy and psychology to examine belief in free will in the general public. But as could be expected, this area, like every other up-and-coming field of study, has its fair share of problems. This thesis is, first, a critique of the prominent instruments being employed in the field, and second, presents a novel approach that bypasses the many problems that exist within the current literature. Subsequently, after employing our proposed free will item along with several other measures, we were able to demonstrate that different degrees of belief in free will only sometimes influence laypeople's attitudes and behaviors.
\end{abstract}

Keywords: free will, belief in free will, implications of beliefs in free will 


\section{Acknowledgments}

My deepest gratitude goes to my advisor, Andrew Brook, without whom I would be living an entirely different life with an entirely different thesis-I am tremendously fortunate to have worked under the guidance of a contemporary philosopher. I am also grateful to Myrto Mylopoulos for her penetrating suggestions and remarkable philosophical guidance. Thanks also goes to Deepthi Kamawar and for her many comments and suggestions on earlier drafts of this work, as well as going the extra mile to ensure that I met my deadlines. And I must especially thank Chunyun Ma for her helpful advice on the analyses presented in this thesis. Last, and most important, I am greatly thankful to my family, Ahmad Sohrabi, Shahin Fakhraei, and Tanya Sohrabi, for their continued love and encouragement. This work would not be what it is without the support of the aforementioned people, that is why I have chosen to use plural pronouns throughout the thesis. And, of course, it should go without saying that I alone am responsible for all remaining errors and shortcomings. 


\section{TABLE OF CONTENTS}

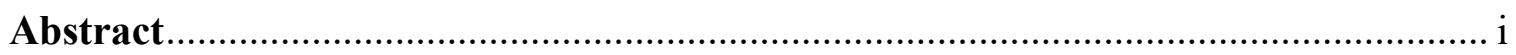

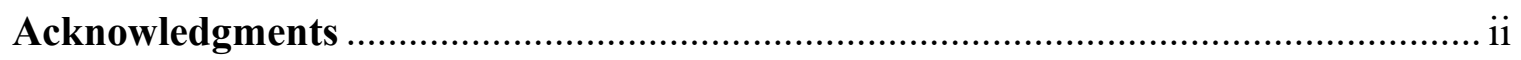

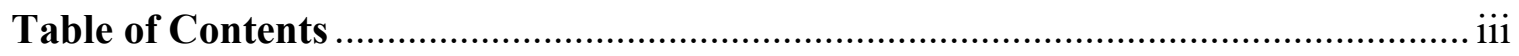

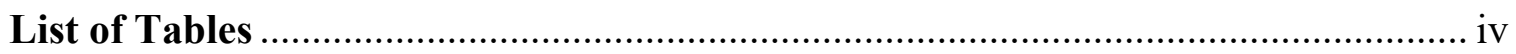

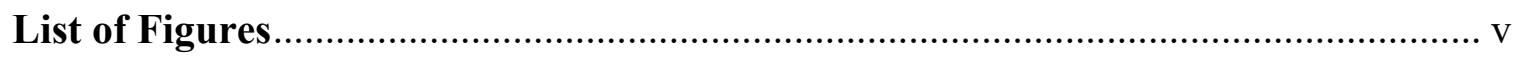

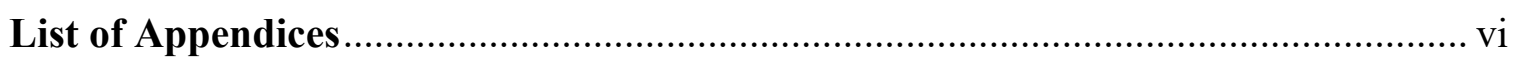

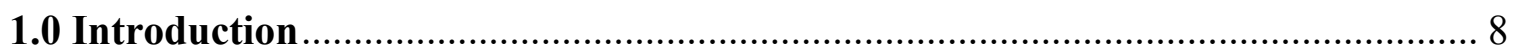

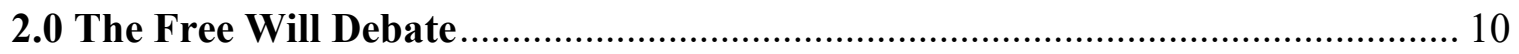

2.1 Main Viewpoints on Free Will .................................................................... 11

3.0 Measuring Degrees of Belief in Free Will ....................................................... 13

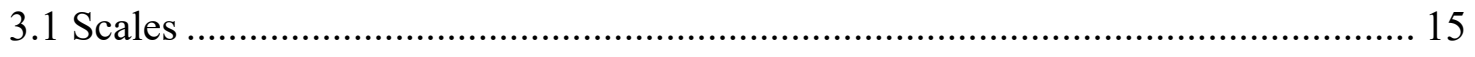

3.1.1 The Free Will and Determinism-Plus (FAD-Plus) ...................................... 15

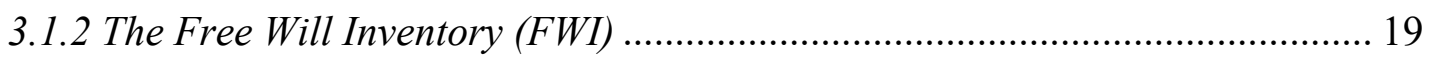

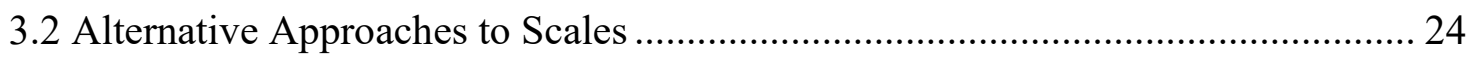

4.0 The Classical Belief in Free Will item (CBFW item) ......................................... 29

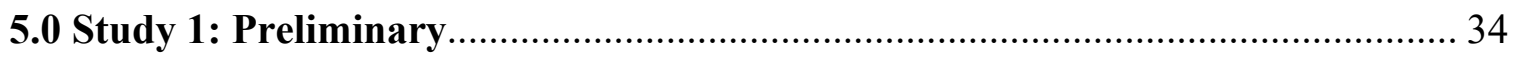

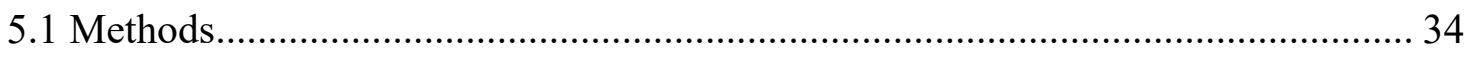

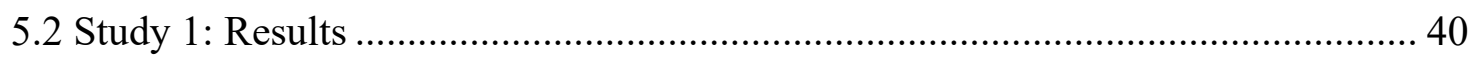

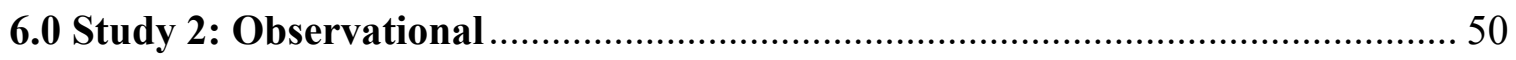

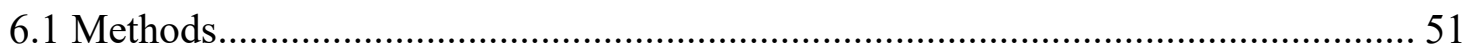

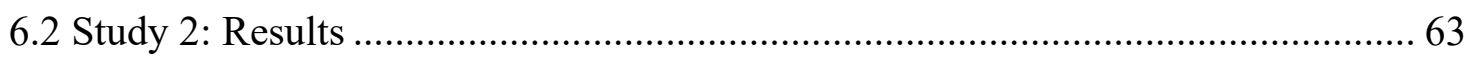

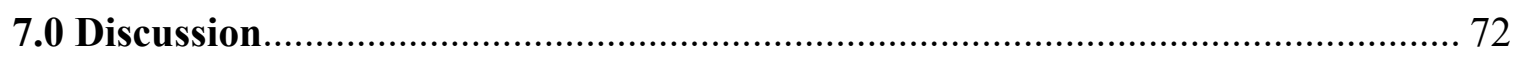




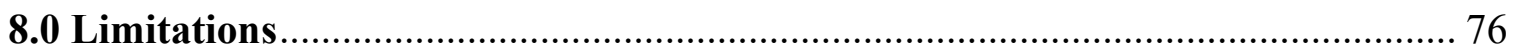

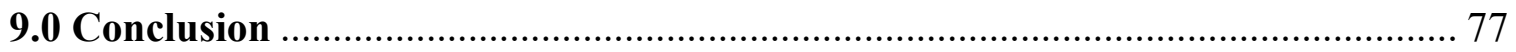

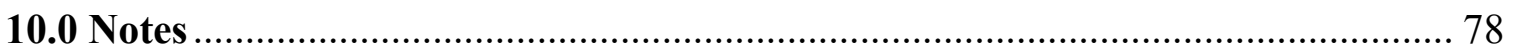

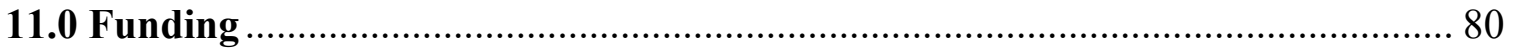

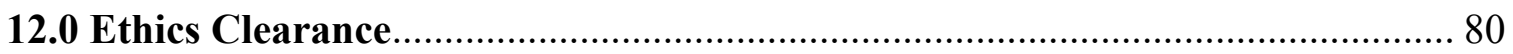

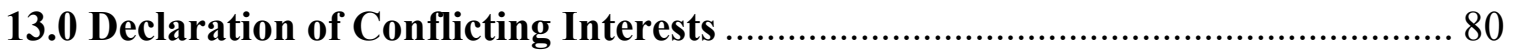

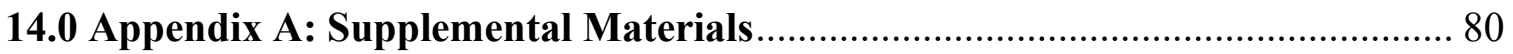

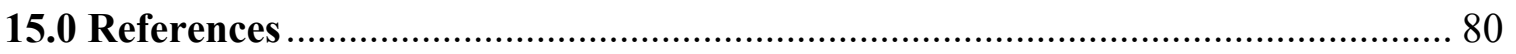

\section{LIST OF TABLES}

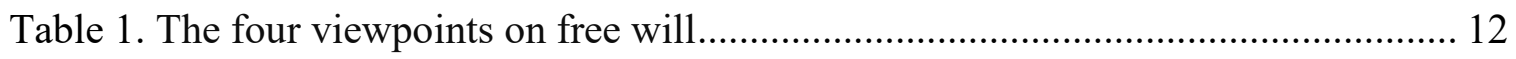

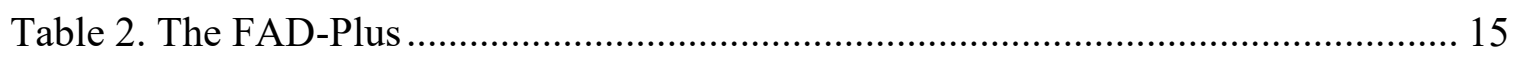

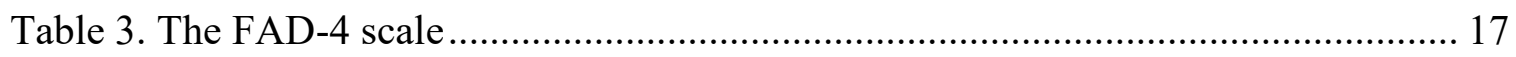

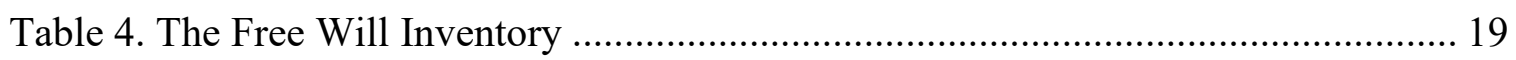

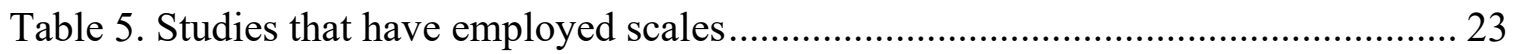

Table 6. Studies in the field that did not manipulate ................................................... 24

Table 7. Mean and standard deviation of demographic information, Study 1 .................. 39

Table 8. Number of participants excluded in Study 1 ................................................. 40

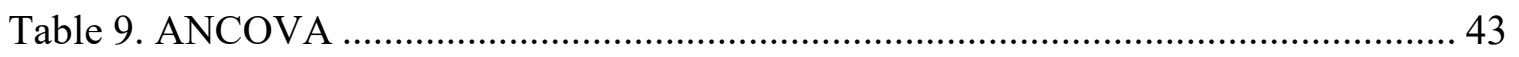

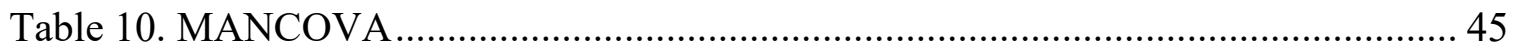

Table 11. Mean and standard deviation of demographic information, Study $2 \ldots \ldots \ldots \ldots \ldots . . .55$

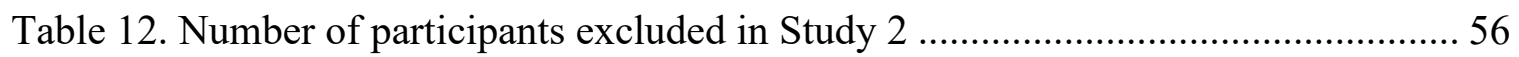

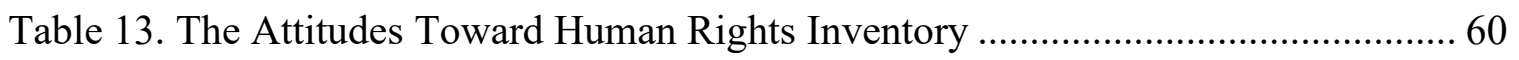




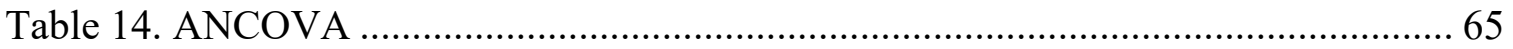

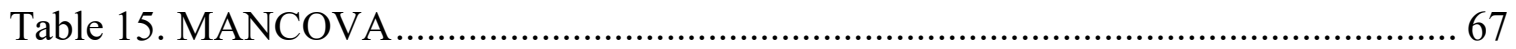

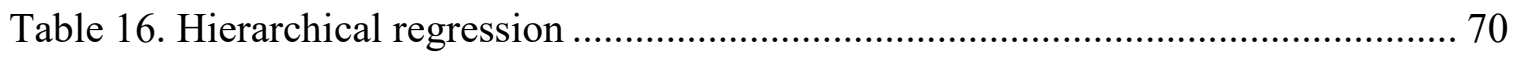

Table 17. Fit indices for the structural equation model ............................................... 72

\section{LIST OF FIGURES}

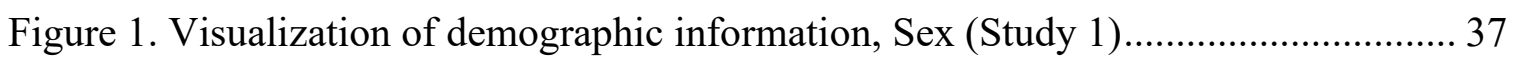

Figure 2. Visualization of demographic information, Education (Study 1) ..................... 38

Figure 3. Visualization of demographic information, Ethnicity (Study 1) ..................... 38

Figure 4. Visualization of demographic information, Religion (Study 1) ........................ 39

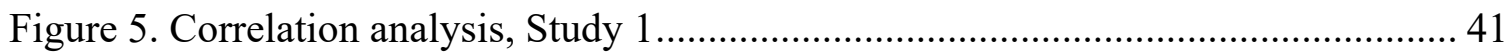

Figure 6. Mean and standard deviation of the degrees of classical belief in free will..... 42

Figure 7. Simulation-based null distribution of CBFW3 and Sex ................................. 46

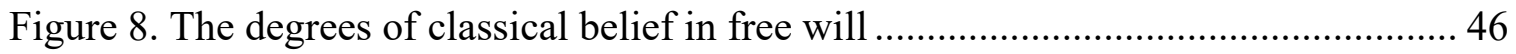

Figure 9. Check the validity of the assumptions for CBFW1 .................................... 48

Figure 10. Check the validity of the assumptions for CBFW2 ..................................... 48

Figure 11. Check the validity of the assumptions for CBFW3 .................................... 49

Figure 12. Check the validity of the assumptions for the CBFW scale ......................... 49

Figure 13. Single-variable mediation model............................................................ 52

Figure 14. Visualization of demographic information, Sex (Study 2)............................ 53

Figure 15. Visualization of demographic information, Religion (Study 2) .................... 54

Figure 16. Visualization of demographic information, Ethnicity (Study 2) .................... 54

Figure 17. Visualization of demographic information, Education (Study 2) .................. 55

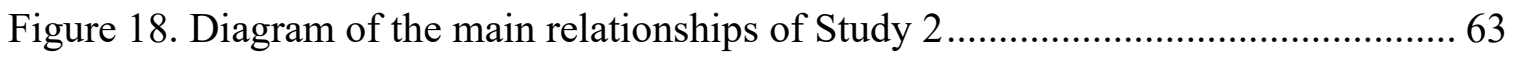


Figure 19. Mean and Standard deviation of the degrees of classical belief in free will ... 64

Figure 20. Simulation-based null distribution of CBFW2 and Sex ............................. 66

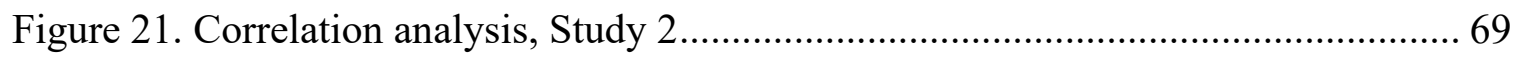

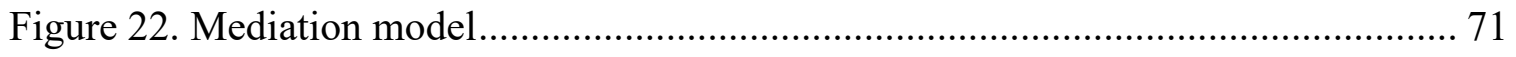

Figure 23. Structural equation model for Study 2 ............................................... 72

\section{LIST OF APPENDICES}

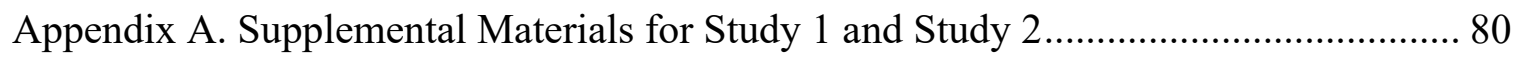




\subsection{Introduction}

What makes the nature of free will so fascinating is that if we go back far enough, the thought of not being in complete control of our actions had not even crossed our early ancestors' minds (whether they called it free will, responsibility, control, or etc.). We can see the thumbprint of this by going over history and cringing at their customary retributive behaviors, which are considered more and more disturbing every day. However, different from the more recent notions on free will, which have tried to take mental health, severe limitations, and factors beyond our control into account, laypeople's sense of freedom, as well as most legal systems, have fallen behind. And so, for this reason alone, it is imperative to investigate laypeople's beliefs in free will (BFW) the way it is, without any foundation to the notions offered by philosophers over the years.

Unfortunately, the recent area of study that has sought to explore BFW in the general public has done so by mapping people's beliefs onto the free will debate (1) and/or doing so in such a way that has failed to account for alternative ways of thinking about free will (2). What is wrong with these approaches? For one, and as indicated above, researchers should not be attempting to assess laypeople's views of the free will debate-explicitly or even implicitly - in light of them not being familiar with the myriad theories and approaches to free will. Second, laypeople have varied and basic BFW, and because of this, the measures should try to classify and clarify their differences. Yet, these are only two of the main problems, there are others too (as will be discussed in section 3.0). So, how should BFW be measured? In its most basic sense, whenever belief in any phenomenon is being investigated in the general public, the following condition should be met: there should be a common understanding of and consensus on the phenomenon. However, for an area of 
study that has been with us for more than a decade, we believe that this basic condition is not being met:

(a) there is no solid consensus on the notion of free will among philosophers and scholars, (b) no general understanding of it in the general public.

Seeing as philosophers have been discussing the notion for a long time, there are certainly many lessons this new area of study can learn from the free will debate, but in order to state them, a quick overview of the current debate on free will has to be presented. This overview will outline the theoretical framework future work on free will requires for conducting better research, and also bring to attention just how different laypeople's BFW are compared to the philosophical stances. Afterwards, the substantial problems within the field on BFW are explained in detail with the hopes of highlighting the limitations and challenges these studies have faced. And to conclude, we have conducted two studies. The first introduces a novel approach that avoids the many theoretical problems in the field, specifically, an item designed to truly center on laypeople's beliefs in free will, or what we call classical belief in free will (CBFW) - the varied and basic common beliefs people have when they believe themselves to be in control of their decisions. The second study sets out to determine the social ramifications of holding different degrees of CBFW. To do this, we have employed a cheating and donation task with the aim of assessing pro- and anti-social behavior, a personal liberties scale to measure attitudes directed toward a subpart of human rights, and an item designed to evaluate people's attitudes about incarceration, along with our proposed $\mathrm{CBFW}$ item so as to investigate any potential associations that may exist between them. At the outset, we were reluctant to make any speculations about the social ramifications of CBFW since there is such a mixed literature surrounding BFW. So far, 
most studies have shown that BFW are positively correlated with prosocial attitudes and behaviors (e.g., Baumeister, Masicampo, \& DeWall, 2009; Vohs \& Schooler, 2008), minus retributive attitudes (e.g., Shariff et al., 2014). Hence, it came as a surprise when our findings suggested a conflicting picture.

\subsection{The Free Will Debate}

It only takes a minute or so to realize how odd and frustrating the notion of free will is. Could it be our intentions, desires, or choices? Is it being able to do what one chooses? Is it having different choices available to one? And so on and on it goes. It is a profoundly tricky and puzzling matter and has led many intellectuals to ponder about the term itself and how to study it (for a detailed evaluation of the various approaches to naturalizing free will, see Mylopoulos \& Lau, 2014). Since there is disagreement on the nature of free will, a simple sketch of the traditional notion over which some of the viewpoints have quarreled needs to be drawn. Think of an action that could be thought of as free. There are usually four steps prior to that action:

1. A Stimulus

2. Unconscious processes

3. Random thoughts occurring + Formation and consideration of those thoughts

4. Deliberation + Making a final choice

5. Action

So, what is the traditional view of free will? It simply states that for one or more of these five steps, primarily steps four and five, more than one course of events is able to take place, or, put differently, there is more than one possible future. This, then, for the traditionalists implies that in order for free will to exist, complete causal determinism has to be false (e.g., Kane, 1996). 
The traditional notion seems straightforward enough, yet only two of the four viewpoints are engaged with it-libertarianism and hard determinism (see next section). The two other viewpoints, compatibilism and hard incompatibilism, are not concerned with the theory of determinism and are largely centered on humans, and whether or not we are psychologically and/or morally free. Sadly, even up till now, it is hard to see how researchers expect to measure a belief about something that is almost as complicated as consciousness.

\subsection{Main Viewpoints on Free Will}

There are four strong viewpoints on the nature and existence of free will. The first group, known as libertarianism, sees free will as a special ability that enables human beings to break the causal chain in the world. According to libertarians, an action is free if it is indeterministically caused (Libet, 2004), or at least directed (Kane, 1996), by an agent. Furthermore, if we have free will, as the libertarian assumes, this for the libertarian suggests that free will and complete causal determinism are incompatible. Now, on the other side, we have our second group that also believes free will and determinism are incompatible, a position labeled hard determinism, a term coined by William James (1890). Hard determinists believe that everything happening in the world is the result (effect) of an earlier event (cause). In their view, free will is not possible as it departs from the natural laws. Adding that due to the actual past, there can only be one future (e.g., van Inwagen, 1983). So, once more, we see that libertarians and hard determinists are primarily concerned with the traditional notion of free will.

The third group, known as compatibilism or soft determinism, also claims that our decisions are determined, but they contend that determinism does not rule out free will. 
Compatibilists discard the traditional notion of free will and adopt their own definition; compatibilist theories of free action maintain that free will can exist if mentally healthy people act intentionally in the absence of compulsive factors (e.g., Dennett, 2003; Frankfurt, 1971). And last but not least, the fourth and most recent viewpoint goes a step further and rejects free will altogether, that is, even if the world is indeterministic, there is no free will. Derk Perboom termed this view hard incompatibilism, firmly stating that determinism and indeterminism are both incompatible with free will and moral responsibility (Pereboom, 2002). At this point, in an attempt to clarify the differences between the viewpoints, we have shown in the form of a diagram, a basic classification of theories based on their views on the ontology and function of free will (Table 1). And, although there is a lot more to be said, for now, we wish to stay neutral on the debate. ${ }^{1}$

\section{Table 1}

The four viewpoints on free will and their thoughts on its existence and function

\begin{tabular}{|c|c|c|c|c|}
\hline Viewpoints & $\begin{array}{l}\text { Libertarianism } \\
\text { (Incompatibilism) }\end{array}$ & $\begin{array}{l}\text { Soft Determinism } \\
\text { (Compatibilism) }\end{array}$ & $\begin{array}{l}\text { Hard Determinism } \\
\text { (Incompatibilism) }\end{array}$ & $\begin{array}{l}\text { Hard Incompatibilism } \\
\text { (Incompatibilism) }\end{array}$ \\
\hline $\begin{array}{c}\text { Free Will } \\
\text { and } \\
\text { Determinism }\end{array}$ & $\begin{array}{c}\text { Incompatible } \\
\text { (Determinism is False) }\end{array}$ & Compatible & Incompatible & Incompatible \\
\hline $\begin{array}{c}\text { Free Will } \\
\text { and } \\
\text { Indeterminism }\end{array}$ & Compatible & Incompatible & $\begin{array}{c}\text { Compatible } \\
\text { (Indeterminism is } \\
\text { False) }\end{array}$ & Incompatible \\
\hline $\begin{array}{l}\text { Existence/ } \\
\text { Ontology }\end{array}$ & $\begin{array}{c}\text { Real } \\
\text { (Robert Kane) }\end{array}$ & $\begin{array}{c}\text { Real } \\
\text { (Daniel Dennett) }\end{array}$ & $\begin{array}{c}\text { Not real } \\
\text { (William James) }\end{array}$ & $\begin{array}{c}\text { Eliminative } \\
\text { (Derk Pereboom) }\end{array}$ \\
\hline $\begin{array}{l}\text { Function/ } \\
\text { Benefit }\end{array}$ & Yes & Yes & No & No \\
\hline
\end{tabular}

We see that each group has laid out a consistent framework, so why can they not agree to disagree? Well, largely because of the nature of the notion, where different viewpoints 
are trying to define free will in terms of two very different concepts. The first is the traditional notion of free will that has intertwined with determinism, primarily trying to figure out whether complete causal determinism is true. This notion mainly concerns libertarians and hard determinists. The second notion, led by compatibilists and hard incompatibilists, stresses the moral and psychological aspect of the debate.

The fact that these two concepts are by and large unknown to the general public is one that must be considered in the underlying theme of the studies within the field — but as you may have guessed by now, it has not been. The measures that assess laypeople's beliefs in free will should ask questions in such a way that, if a subject answers yes or $n o$, it is because they genuinely do or do not believe people to have free will, not because they believe or do not believe some particular reason for saying yes or no (libertarianism or compatibilism for yes, determinism and hard incompatibilism for no).

\subsection{Measuring Degrees of Belief in Free Will}

A resolution of the free will debate may take a while, but it is clear that what free will is to laypeople, and what it is to experts who have studied and thought about the notion, are parallel to what the theory of evolution would be for two equivalent crowds. Some have probably only heard the name, some think that the theory of evolution states that we are descendants of chimpanzees, some have studied the theory and are baffled by its complex simplicity, and some are actively and eagerly exploring the origins of the first selfreplicating molecule (the first gene) — although we have yet to figure out which of the viewpoints on free will will be the creationism of the free will debate. We hope that manipulative and observational studies on beliefs in free will (BFW) will turn out to be a 
much different and shorter story, assuming that studying laypeople's BFW is a lot easier than studying free will itself.

In 2008, when Vohs and Schooler demonstrated that upon reading passages endorsing determinism, people tended to cheat more, they raised an interesting question: what social ramifications might BFW have in the general public? This, in turn, led to an attractive area of study, with over one hundred studies further exploring the question. However, the field has now somewhat split, with half of the literature manipulating beliefs, similar to Vohs and Schooler's work, and the other half conducting observational studies on the relationship between BFW and various behaviors and trait characteristics. The second area of study is the one we are interested in, because manipulations are not true to our development in the real world. ${ }^{2}$ To be sure, some may argue that in order to make any causal claims about a belief, we would need to manipulate that belief. And this is a valid point. However, in this thesis, we are seeking correlational and not causal relationships.

Regardless of this, both areas of study face analogous problems, in particular, the instruments being employed to measure BFW almost entirely fail to carve up what we want to know about laypeople's beliefs. Not only do we need instruments that assess beliefs in free will rather than free will theory, but also measures that are able to account for the varied nature of laypeople's intuitions. In order to effectively clarify the worries mentioned thus far, we shall start by illustrating the specific problems with the most commonly used measures in the literature, the scales, and then proceed to explaining the overarching challenges that lead to these specific problems in the following section. 


\section{Table 2}

The FAD-Plus (Delroy L. Paulhus \& Jasmine M. Carey, 2011)

\section{FAD-Plus}

1. I believe that the future has already been determined by fate.

2. People's biological makeup determines their talents and personality.

3. Chance events seem to be the major cause of human history.

4. People have complete control over the decisions they make.

5. No matter how hard you try, you can't change your destiny.

6. Psychologists and psychiatrists will eventually figure out all human behavior.

7. No one can predict what will happen in this world.

8. People must take full responsibility for any bad choices they make.

9. Fate already has a plan for everyone.

10. Your genes determine your future.

11. Life seems unpredictable — just like throwing dice or flipping a coin.

12. People can overcome any obstacles if they truly want to.

13. Whatever will be, will be - there's not much you can do about it.

14. Science has shown how your past environment created your current intelligence and personality.

15. People are unpredictable.

16. Criminals are totally responsible for the bad things they do.

17. Whether people like it or not, mysterious forces seem to move their lives.

18. As with other animals, human behavior always follows the laws of nature.

19. Life is hard to predict because it is almost totally random.

20. Luck plays a big role in people's lives.

21. People have complete free will.

22. Parents' character will determine the character of their children.

23. People are always at fault for their bad behavior.

24. Childhood environment will determine your success as an adult.

25. What happens to people is a matter of chance.

26. Strength of mind can always overcome the body's desires.

27. People's futures cannot be predicted.

\section{Subscales}

Free Will: 4, 8, 12, 16, 21, 23, 26

Scientific Determinism: 2, 6, 10, 14, 18, 22, 24

Fatalistic Determinism: 1, 5, 9, 13, 17

Unpredictability: 3, 7, 11, 15, 19, 20, 25, 27

\subsection{Scales}

\subsubsection{The Free Will and Determinism-Plus (FAD-Plus)}

The Free Will and Determinism-Plus scale (Paulhus \& Carey, 2011) consists of 27 questions designed to measure free will belief and closely related constructs (Table 2). The questions are categorized into four subscales: Free Will, Fatalistic Determinism, Scientific 
Determinism, and Unpredictability. The participants rate the extent to which they agree with each statement from 1 (strongly disagree) to 5 (strongly agree). The purpose of the Unpredictability subscale is to explore broader relationships between the three beliefs (Paulhus \& Carey, 2011), hence, we shall focus on the other three subscales.

The Scientific Determinism subscale. Believers in free will, determinism, and fate have different views on decision making, that is why it is crucial to make each subscale as distinct as possible. The Scientific Determinism subscale of the FAD-Plus will not be able to accomplish this task in the slightest. Consider its seven items. At a first glance, they may all look like items that only determinists would agree to, but this would only be true if determinism suggested one of two scenarios to be true: that development occurs either through nature or nurture, and not both (nor their interactions). It is needless to say that this is false, as most people, and determinists in particular, would contend that nature and nurture go hand in hand. Thus, when you have items concentrating exclusively on one of them—your genes, your past environment, or childhood environment, for example—it will lead to a lot of hesitation and confusion, especially when words like determine and will determine are employed in the sentence. And so, as a consequence, the items are not actually capturing the theory of determinism, but rather debunked scientific notions.

The Free Will subscale. The Free Will subscale faces comparable problems; the subscale fails to properly control for alternative ways of thinking of what free will is. Questions 8, 16, and 23 bring responsibility into the picture. To begin with, responsibility might seem like something believers in free will uniquely hold, except that the items fail to consider the other groups' opinion on the matter. Determinists, for instance, might disagree with the backward-looking justification of blame and punishment, but still 
completely recognize the need for prevention in the forward-looking sense. Yet, fate believers' attitudes toward responsibility are more complicated and should at least be considered. Furthermore, by using the immediate term free will, question 21 results in the same problems philosophers and scholars are confronted with in the free will debate by preventing us from knowing what participants are really responding to-akin to weighing a black box within a black box. And, lastly, it is not apparent what question 26 is meant to assess.

\section{Table 3}

The FAD-4 scale (Delroy L. Paulhus \& Adam Margesson, 1994)

\section{FAD-4}

\section{The Scientific Determinism subscale}

1. People's biological makeup influences their talents and personality.

2. Bad behavior is caused by bad life circumstances.

3. Psychologists and psychiatrists will eventually figure out all human behaviors.

4. Your genes determine your future.

5. Science has shown how your past environment created your intelligence and personality.

6. Scientists will never be able to predict human behavior precisely. - (Reverse Score)

7. As with other animals, human behavior always follows the laws of nature.

\section{The Free Will subscale}

1. People have complete control over the decisions they make.

2. People must take full responsibility for any bad choices they make.

3. People can overcome any obstacles if they truly want to.

4. Criminals are totally responsible for the bad things they do.

5. People do not choose to be in the situations they end up - it just happens. -

6. We should avoid punishing people because many of them can't help doing what they do. -

7. Strength of mind can always overcome the body's desires. 
In addition, all of the problems stated above also apply to the earlier version of the FADPlus, and then some (Table 3), another prominent scale in the field (FAD-4; Paulhus \& Margesson, 1994). Similar to the FAD-Plus, the items in the Determinism and Free Will subscales of the FAD-4 fail to be either exclusive to the determinist belief or account for alternative ways of thinking about free will. Paulhus and Carey (2011) even later said that

Despite some recent success, the FAD -4 had psychometric weaknesses. Subscale reliabilities sometimes slipped below .60 and several items exhibited double loadings and even cross-loadings [for instance, when a variable/question (e.g., Your genes determine your future) loads onto two or more factors/subscales (e.g., The Scientific Determinism subscale and the Free Will subscale), so they are not actually measuring what they are saying they are measuring], and as a result, it was never published. Although the subscale intercorrelations were modest, we suspected that they were contaminated by the cross-loadings. Therefore, we remained uncertain about the true relations among our four constructs (...) [and that the analyses] suggested that free will items cluster separately from two distinct types of determinism, namely, scientific and fatalistic. (p. 96)

Now, as it happens, the second prominent scale of the field, the Free Will Inventory (FWI; Nadelhoffer et al., 2014), is a tad better equipped to deal with these problems, though perhaps not the fatalistic aspect. 


\section{Table 4}

The Free Will Inventory (Nadelhoffer, Shepard, Nahmias, Sripada, \& Ross, 2014)

\section{FWI Part 1}

\section{The Free Will Subscale}

1. People always have the ability to do otherwise. (Round 1)

2. People always have free will. (R1)

3. How people's lives unfold is completely up to them. (R2)

4. People ultimately have complete control over their decisions and their actions. (R2)

5. People have free will even when their choices are completely limited by external circumstances. (R4)

The Determinism Subscale

6. Everything that has ever happened had to happen precisely as it did, given what happened before. (R4)

7. Every event that has ever occurred, including human decisions and actions, was completely determined by prior events. (R2)

8. People's choices and actions must happen precisely the way they do because of the laws of nature and the way things were in the distant past. (R2)

9. A supercomputer that could know everything about the way the universe is now could know everything about the way the universe will be in the future. (R4)

10. Given the way things were at the Big Bang, there is only one way for everything to happen in the universe after that. (R4)

The Dualism/Anti-Reductionism Scale

11. The fact that we have souls that are distinct from our material bodies is what makes humans unique. (R3)

12. Each person has a non-physical essence that makes that person unique. (R4)

13. The human mind cannot simply be reduced to the brain. (R4)

14. The human mind is more than just a complicated biological machine. (R4)

15. Human action can only be understood in terms of our souls and minds and not just in terms of our brains. (R4)

\subsubsection{The Free Will Inventory (FWI)}

There are 29 items in the Free Will Inventory (Table 4). The participants are instructed to rate their agreement on a 7-point Likert scale ranging from 1 (Strongly disagree) to 7 (Strongly agree). Nadelhoffer and colleagues (2014) designed the FWI in two parts: the first part examines general belief in free will and related concepts (determinism and dualism/anti-reductionism), while part two seeks to investigate "the complex network of people's associated beliefs and attitudes about free will, determinism, choice, the soul, predictability, responsibility, and punishment" (p. 27). We will only consider the first two subscales in part one of the FWI, Free Will and Determinism, since only the first part is included in all studies throughout the field. 
If one were to quickly skim through the FWI, they would notice that a fatalism subscale is not present, and this leaves us with a major concern. For a start, the authors had four development rounds, and in those rounds, one of the difficulties they were faced with was differentiating between determinism and fatalism:

Round 1: "This suggests one of three possibilities: (1) Although determinism and fatalism are conceptually dissociable, these concepts may not be strongly differentiated in the general population." (p. 32)

Round 2: "In contrast to Round 1, the EFA [(exploratory factor analysis)] results for this round suggest that the general population may make a conceptual distinction between determinism and fatalism.” (p. 33)

Round 3: "Like Round 1 but unlike Round 2, the Round 3 EFA suggested that people tend to conflate determinism and fatalism.” (p. 33)

Round 4: "We used seven items to reflect determinism, and dropped the few fatalism items that sometimes loaded onto factors with determinism items.” (p. 34) Nadelhoffer and colleagues' decision to drop the fatalism subscale could strike someone as simply avoiding the problem. But then, to be fair, one might wonder whether there are indeed more than a handful of determinists in each sample (individuals that are familiar with and accept the concept of determinism). Because of this, it should not come as a surprise that researchers have been encountering difficulties differentiating between fate and determinism believers.

The designers of the FAD-Plus and FWI mentioned some challenges with the two beliefs. In the FAD-Plus, Paulhus and Carey (2011) stated that "one more factor covariance was freed because, in the community sample, Scientific and Fatalistic Determinism were 
significantly correlated $(r=.38, \mathrm{p}<.001)$ " ( $(\mathrm{p} .102)$. Similarly, in the FWI (Nadelhoffer et al., 2014, page 34), it was pointed out by the authors that

... many lessons were learned from the four development rounds. For example, it is not clear if determinism and fatalism, or if free will and moral responsibility, form clear and distinct conceptual categories for most people. It is possible that most people do distinguish determinism from fatalism, and free will from moral responsibility, but given the close relationships between the concepts within these pairs, it may be difficult for psychometric tools to tease apart these concepts (one goal of Part 2 was to examine some of the conceptual relationships between free will and related concepts).

This claim of theirs also raises further doubts about the use of responsibility in the Free Will subscale of the FAD-Plus, another vague and tricky concept.

All the scales in the field consist of a free will and determinism/scientific determinism subscale. However, some have added a fatalism subscale (e.g., FAD-Plus), while others have not included one (e.g., FWI). So, one major problem with the scales is that they cannot distinguish the fatalists' and determinists' responses from one another. This is key as there are many differences between the two. The main difference is that people who believe in determinism hold the idea that not only is the future determined, but every thought, deliberation, choice, and action is also pre-determined by natural laws - being part of the stream of causality. Fate believers, on the other hand, think that the future is determined irrespective of our actions, and that a supernatural deity or force is responsible for setting forth the motion with a purpose in mind. Compatibilism is a nice illustration of why this difference matters, since compatibilists would deny that fatalism is true, but allow 
determinism to be true. Thus, in response to the items, people who believe in fate might also score high on determinism, but not the other way around, i.e., most people that believe in determinism do not believe in the supernatural and/or fate; and so, in scales like the FAD-Plus (Paulhus \& Carey, 2011), the Fatalism and Scientific Determinism subscales have a part-whole relationship and cannot discriminate the two groups effectively.

Alternatively, if fatalism is removed as a subscale (e.g., FWI, Nadelhoffer et al., 2014), people who believe in fate will still score high on the Determinism subscale as they also believe in a sort of determinism, but then again, their reasons for holding their belief are completely different from the determinists. Additionally, like the FAD-Plus, the Free Will subscale of the FWI, has included the term free will in questions 2 and 5, and also used another vague concept, and that is do otherwise in question 1, allowing the participants to provide us with more black-box-like responses.

Therefore, given these considerations, the studies in the field will not receive distinct results for their respective belief groups, or at best, the degree of significance will not be accurate. As we know, there is not a big gap between a result being statistically significant or non-significant. It is to be hoped that the worries that we have pointed out will not go unnoticed, and future work on free will will explore alternative methods (see section 4.0). At this point, in order to draw attention to this wide-ranging area of study, we have listed the prominent scales in the field, and many of the studies that have used them, in Table 5. Also, many studies have examined the relationship between BFW and various behaviors and trait characteristics, more than half of which have been listed in Table 6; however, as mentioned earlier, a lot of these studies have manipulated participants' beliefs, so we have chosen to only include observational work since they are two separate kinds of study. 


\section{Table 5}

Studies that have employed scales to assess beliefs in free will in the general public

\begin{tabular}{|c|c|c|c|}
\hline Free Will Inventory & Free Will and Determinism & Free Will and Determinism-Plus & Free Will and Determinism \\
\hline (FWI) & (FAD-4) & $(\mathrm{FAD}+)$ & (FWD) \\
\hline Nadelhoffer et al., 2013 & Paulhus and Margesson, 1994 & Paulhus and Carey, 2011 & Rakos et al., 2008 \\
\hline 1) Boudesseul et al., 2016 & 10) Vohs \& Schooler, 2008 & 15) Aarts \& van den Bos, 2011 & 39) Rigoni et al., 2012 \\
\hline 2) Genschow et al., 2017 & 11) Baumeister et al., 2009 (and & 16) Alquist et al., 2013 & 40) Ent \& Baumeister, 2014 \\
\hline 3) Earp et al., 2018 & also the revised FAD-4, 2008) & 17) Carey \& Paulhus, 2013 & 41) Feldman et al., 2014 \\
\hline (Study 3) & 12) Stillman et al., 2010 & 18) Rigoni et al., 2013 & 42) Feldman et al., 2016 \\
\hline 4) Wisniewsk et al., 2019 & 13) Shariff et al., 2014 & 19) Krueger et al., 2014 & 43) Moynihan et al., 2017 \\
\hline 5) Willoughby et al., 2019 & 14) Clark et al., 2017 (Study 1 \& 2) & 20) Lynn et al., 2014 & \\
\hline 6) Crone \& Levy, 2019 & & 21) Clark et al., 2014 & \\
\hline 7) Mercier et al., 2020 & & (Study $1,2, \& 3$ ) & \\
\hline (Study $1 \& 2$ ) & & 22) Shariff et al., 2014 & \\
\hline 8) Genschow et al., 2020 & & 23) Zhao et al., 2014 & \\
\hline \multirow[t]{16}{*}{ 9) Chandrashekar, 2020} & & 24) Feldman et al., 2014 & \\
\hline & & 25) MacKenzie et al., 2014 & \\
\hline & & 26) Carmody \& Gordon, 2014 & \\
\hline & & 27) Boudesseul et al., 2016 & \\
\hline & & 28) Li et al., 2017 (Free Will & \\
\hline & & subscale only) & \\
\hline & & 31) Clark et al., 2017 (Study 4) & \\
\hline & & 32) Moynihan et al., 2017 & \\
\hline & & 33) Caspar et al., 2017 & \\
\hline & & 34)Kondratowicz-Nowak \& & \\
\hline & & Zawadzka, 2018 & \\
\hline & & 35) Willoughby et al., 2019 & \\
\hline & & 36) Crone \& Levy, 2019 & \\
\hline & & 37) Earp et al., 2018 & \\
\hline & & (Study $1 \&$ 2) & \\
\hline & & 38) Seto et al., 2020 & \\
\hline
\end{tabular}




\title{
Table 6
}

Studies in the field that did not manipulate participants' beliefs in free will

\section{Various Studies in the Field}

\author{
1) Experiment 2: Baumeister et al., 2009 \\ 2) Stillman et al., 2010 \\ 3) Aarts \& van den Bos, 2011 \\ 4) Experiment 1: Alquist et al., 2013 \\ 5) Carey \& Paulhus, 2013 \\ 6) Carmody \& Gordon, 2014 \\ 7) Study 1: Shariff et al., 2014 \\ 8) Krueger et al., 2014
}

9) Ent \& Baumeister, 2014

17) Genschow et al., 2017

10) Study 5: Clark et al., 2014

18) Vonasch et al., 2017

11) Study 1: Zhao et al., 2014

19) Li et al., 2017

12) Study 1: MacKenzie et al., 2014

13) Boudesseul et al., 2016

20) Kondratowicz-Nowak \& Zawadzka, 2018

14) Feldman et al., 2016

21) Earp et al., 2018

15) Clark, 2017

22) Chandrashekar, 2020

16) Moynihan et al., 2017

23) Study 1: Mercier et al., 2020

24) Seto et al., 2020

\subsection{Alternative Approaches to Scales}

Moving forward, it looks as if the scales not only have to start accounting for fate believers and determinists in an effective manner, but also the varied nature of laypeople's beliefs in free will. All of this, while at the same time, trying to find out where to place responsibility in the framework. We see that future studies certainly have their work cut out for them if they truly want to get at participant's true beliefs. So, what might laypeople's attitudes about free will be? They are rudimentary and are often associated with religion, culture, personal experiences, and intuitions. Notwithstanding this fact, several researchers have set out to figure out where folk intuitions map onto the free will debate, and their conclusions, we would say, are quite questionable. Some have said that laypeople's beliefs are in line with compatibilism (Cova \& Kitano, 2014; Mele, 2014; Monroe \& Malle, 2010; Nahmias, Morris, Nadelhoffer, \& Turner 2005; 2006; Paulhus \& Carey, 2011); analogously, people seem to regard choices aligned with one's desires and free from constraints to be associated with having free will - a "psychological concept of free will" 
(Monroe \& Malle, 2010; Monroe et al., 2014; see also Stillman et al., 2011). On the other hand, several philosophers have said that an incompatibilist theory of free will is what people have in mind (e.g., Kane, 1999; Strawson, 1986; Vargas, 2006); adding to this claim, some researchers have stated that the general public has incompatibilist intuitions (e.g., Bear \& Knobe, 2015; Rose \& Nichols, 2013).

Yet, the most reasonable conclusion, we believe, was that of Nichols and Knobe (2007), they claimed that "[i]t appears that people have both compatibilist and incompatibilist intuitions" (p. 681). Specifically, “[w]hen asked questions that call for a more abstract, theoretical sort of cognition, people give overwhelmingly incompatibilist answers. But when asked questions that trigger emotions, their answers become far more compatibilist." (p. 664). The reason we believe Nichols and Knobe's method is more appropriate, a method pioneered by Nahmias et al., (2005), is because participants are not just answering questions but reacting to various scenarios, this approach does not use vague philosophical terms, rather offers an outline of what is actually being asked of the participants (Nichols and Knobe, page 669):

Imagine a universe (Universe A) in which everything that happens is completely caused by whatever happened before it. This is true from the very beginning of the universe, so what happened in the beginning of the universe caused what happened next, and so on right up until the present. For example one day John decided to have French Fries at lunch. Like everything else, this decision was completely caused by what happened before it. So, if everything in this universe was exactly the same up until John made his decision, then it had to happen that John would decide to have French Fries. 
Now imagine a universe (Universe B) in which almost everything that happens is completely caused by whatever happened before it. The one exception is human decision making. For example, one day Mary decided to have French Fries at lunch. Since a person's decision in this universe is not completely caused by what happened before it, even if everything in the universe was exactly the same up until Mary made her decision, it did not have to happen that Mary would decide to have French Fries. She could have decided to have something different.

The key difference, then, is that in Universe A every decision is completely caused by what happened before the decision-given the past, each decision has to happen the way that it does. By contrast, in Universe B, decisions are not completely caused by the past, and each human decision does not have to happen the way that it does. Which of these universes do you think is most like ours? (circle one)

In response to this question, $90 \%$ of the participants chose Universe B over Universe A, thus indicating that the vast majority of the participants did not believe in determinism. Several follow-up questions were then presented.

Abstract condition:

In Universe A, is it possible for a person to be fully morally responsible for their actions?

Here, only $14 \%$ of the participants chose Yes, showing that the majority of the participants had incompatibilist intuitions.

Concrete condition: 
In Universe A, a man named Bill has become attracted to his secretary, and he decides that the only way to be with her is to kill his wife and 3 children. He knows that it is impossible to escape from his house in the event of a fire. Before he leaves on a business trip, he sets up a device in his basement that burns down the house and kills his family.

Is Bill fully morally responsible for killing his wife and children?

Shorter concrete version:

In Universe A, Bill stabs his wife and children to death so that he can be with his secretary. Is it possible that Bill is fully morally responsible for killing his family?

The participants' answers turned closer to compatibilism when the questions became more emotionally triggering - with $72 \%$ of the participants choosing Yes in response to the concrete condition, and $50 \%$ for the shorter concrete condition.

We believe that Nichols and Knobe's (2007) finding that laypeople's reactions to the same scenario is different once it is abstract or concrete is rather important. Their item has been used in other studies that have examined BFW in the general public (e.g., Li et al., 2017; Sarkissian et al., 2010). Their depicted scenarios mainly involve the existence of complete causal determinism, and this happens to be a well-defined notion. However, even this approach is still imperfect, by which we mean it heavily faces the mapping problem (page 6) - that there is a consensus on and understanding of the phenomenon among the general public. For some reason, it appears that the authors expected that the general public would have clear intuitions (through contrasting Universe A and B). To begin with, there 
is a big gap between accepting the concept of causality and adhering to philosophical determinism, in fact, if laypeople do indeed have could have done otherwise intuitions, the vast majority of those intuitions would not be grounded upon any scientific theory, and would be just that, intuitions. Bear in mind that hard determinists (e.g., Harris, 2012) and compatibilists (e.g., Dennett, 2003; Frankfurt, 1969) have been disagreeing on the meaning of could have done otherwise for a reason.

On these accounts, the overall method of depicting a deterministic or indeterministic universe for laypeople and instructing them to select the one they believe to be true, and also, questioning whether an individual within the deterministic universe could be held morally responsible, will surely encounter analogous problems to the usage of the problematic scales, e.g., akin to including the terms free will and responsibility or adding a Determinism/Scientific Determinism subscale (Section 3.1). And while it may seem like the emotional aspect of the scenarios might bring to light the difference between the image of a concept (accepting determinism) and the actual use of a concept (adhering to determinism), this would only be the case if laypeople were in fact familiar with the theory of determinism, and moreover, were able to differentiate determinism from fatalism. Therefore, the depicted scenarios of Nichols and Knobe (see also, Nahmias et al., 2005) may not be exploring laypeople's views on free will, but presenting them with a brief and incomplete definition of the theory of determinism, and instantly asking them whether or not they believe the theory to be true, and also, whether an individual could be held morally responsible within the framework of this newly and loosely acquired concept.

Furthermore, similar to the scales in the field, fate believers' attitudes have not been taken into account in Nichols and Knobe's item (2007; see also, Nahmias et al., 2005). That is, 
when the deterministic aspect of free will is included, believers in fatalism ought to be accounted for as most of the results obtained will not represent the determinist population, rather, largely fate believers due to the minimal amount of people actually familiar with the theory of determinism. And so, although Nichols and Knobe's item does a great job of differentiating the traditionalists, in the end, given that there are no believers in traditional free will in the general public, the items face the same problems as the scales (pages 10 and 11).

What is troublesome is that all the worries stated thus far apply to virtually the entire literature. Hence, in outline, seeing as there are different beliefs and viewpoints on the nature of free will, plus the lack of an alternative theories in the general public, it might prove beneficial to sidestep whether subjects believe in determinism when examining BFW. Similarly, folk intuitions on free will are undeniably more varied and ambiguous than the free will debate - extending out to freedom of action, dualism, could have done otherwise, fate, intentions and desires, mentally healthy, and so on and so forth. Many of these concepts are either irrelevant to the current debate or are gathered into four solid viewpoints that laypeople know nothing about. In view of these difficulties, it is evident that observational and manipulative work in the field should not be probing laypeople's attitudes toward the free will debate.

\subsection{The Classical Belief in Free Will item (CBFW item)}

If the arguments listed above and in the last section are sound, then taken all together, they raise serious questions about the methods, conclusions and, most importantly, interpretations of this new area of study (a great many of which are listed in Table 5). Now, there may perhaps be a way of studying BFW among laypeople, but as discussed earlier, it 
has to be truly centered on laypeople's beliefs, that does not require the participants to have any knowledge of the free will debate - the varied and basic common beliefs people have when they believe themselves to be in control of their decisions. The significance of isolating this notion, or what we call classical belief in free will (CBFW), is because it is fairly independent of the contemporary viewpoints on free will. More specifically, CBFW does not require that one know anything about the traditional or compatibilist notions of free will.

Therefore, on these terms, the traditional philosophical notion is the notion of what free will is, held by most philosophers until compatibilism became popular around 70 years ago, Immanuel Kant for example. For those holding this notion, there was no disagreement about what free will is, what it requires, just whether it exists. However, CBFW is a collection of beliefs about free will held by most laypeople, who have little or no philosophical training, and nearly all legal systems: That we have it (whatever it consists of), so we are justified in holding people responsible and, among other things, rewarding them when they do well and punishing them when they break the law. Due to these distinctions, we believe the scales and measures within the field should be seeking to test whether subjects believe that we have free will as articulated by the classical belief.

Here, we propose a simple item to explore CBFW, a measure that is adapted from the Nichols and Knobe's item (2007) and the FWI (Nadelhoffer et al., 2014). This item is a very short and concrete scenario that is minimally emotionally triggering, and, above all, it avoids the many difficulties mentioned throughout the thesis. The only aspect it focuses on is whether or not laypeople believe themselves to be in control of their decisions, and to what extent. 
A man named Bill has become attracted to one of his colleagues. The attraction is mutual, so he decides to leave his wife. Before leaving on a business trip, Bill asks his lawyer to prepare divorce papers and deliver them to his wife.

1. Thinking of the whole of a person's life, could Bill have made a different decision?

2. Does Bill and everyone else who does not suffer from mental illness, extreme poverty, or the like, mostly have control over his decisions?

3. In general, we do what we want, please select somewhat disagree so that we know you are paying attention.

4. Are Bill's decisions, like most people's, completely up to him?

A single scenario may measure differences in different groups of subjects, but it would not measure differences in single subjects as to how they react to different scenarios. Therefore, we decided to see how subjects react to scenarios about different sexes. If there were to be a different balance of answers, that would smoke out some prejudices (by way of comparing participants' responses to the Bill and Olivia scenarios), but while woman to man might smoke out sexism, it would not homophobia or trans or bi phobia or so on and so forth, still this would be better than nothing. ${ }^{3}$ And unfortunately, we will not be able to probe all the possible combinations in one, so including variables in addition to sex will be saved for future work. ${ }^{4}$ 
A woman named Olivia has become attracted to one of her colleagues. The attraction is mutual, so she decides to leave her husband. Before leaving on a business trip, Olivia asks her lawyer to prepare divorce papers and deliver them to her husband.

1. Thinking of the whole of a person's life, could Olivia have made a different decision?

2. Does Olivia and everyone who does not suffer from mental illness, extreme poverty, or the like, mostly have control over her decisions?

3. In general, we do what we want, please select somewhat disagree so that we know you are paying attention.

4. Are Olivia's decisions, like most people's, completely up to her?

On a deeper level, this setup can take place within a deterministic or indeterministic universe, does not include any reference to moral responsibility, or include the term free will. As a result, the scenario should be able to mainly center on measuring laypeople's degrees of CBFW. And, as mentioned before, there is no need to take account of libertarians, hard determinists, compatibilists, or hard incompatibilists because there are almost certainly no participants familiar with the various concepts and theories on free will in each sampled population. Crucially, the multiple follow-up questions will allow us to explore the varied nature of laypeople's BFW: the phrasing of 1 enhances the contrast with 2 - one person in one situation $(\mathrm{CBFW} 1)$ vs. almost anyone in a great many situations (CBFW2). We used "mostly in control" in 2 because in some situations, anyone would be forced to make a decision and would have no choice, or at least no real choice. Question 3 is a rather difficult attention check question and will not of course be included in the 
analyses. Then 4 distinguishes between those who think we have free choice much or most of the time and those who think that we always have it (from now on we will refer to the fourth question as CBFW3).

What is more, we believe that a short concrete item with a slight emotional load should be more appropriate than Nichols and Knobe's deterministic and indeterministic item because it gets at participants' true intuitions. There are a number of problems in their approach, making use of an abstract item might get intertwined with things participants do not understand and prevent us from knowing what their actual views are; and equally, long items will surely lead participants to lose interest and attention and, as a result, lead to incurious and hasty responses. Also, we did not want the participants to be reacting from a desire to condemn Bill because he is immoral, so we wanted to ensure that the scenario was not heavily loaded emotionally. This was probably going on in at least some of the compatibilist responses to Nichols and Knobe's emotionally-loaded scenarios, which, if true, would be a study-destroying confound. Yet, most notably, participants' responses to the three follow-up questions will conceivably allow us to explore the varied nature of laypeople's beliefs, that is to say if their beliefs and intuitions actually vary. And since we will be avoiding the free will debate and its many concepts and theories, we can center on choices, through different angles, and whether or not laypeople believe themselves to be in true control of them (whatever this might exactly mean to them), and because of these reasons, we believe that our item will correctly answer the question: "what degrees of belief in free will does the general public hold?" 


\subsection{Study 1: Preliminary}

Our first study is a preliminary study directed at examining classical belief in free will $(\mathrm{CBFW})$. In order for us to present a valid construct, we checked for biases through employing a female and a male scenario to the participants in a random manner (the Bill and Olivia scenarios), with the addition of tracking the influence of the sex, age, education, and completion time of the participants. Evaluating these variables was a necessary step for our second study-by way of showing that these differences reflect differences in beliefs and not differences in sex or sex-related biases, we were able to move on to investigate the correlations between our CBFW item and various items and tasks (from cheating and helping behavior to attitudes toward human rights and incarceration).

\section{Ethics Statement}

Participants were given a link to Qualtrics (an online survey tool; www.qualtrics.com) and asked to provide consent. They were instructed to complete a survey meant to assess their attitudes about the world and life. Due to mild deception, once the participants had finished doing the survey, they received debriefing and were given the opportunity to withdraw in the secondary consent form. The same procedure was used for Study 2. Both studies were conducted in accordance with the Carleton University Research Ethics Board (see Ethics Clearance for Study 1 and Study 2).

\subsection{Methods}

\section{Analyses}

Pearson correlation coefficient. Pearson's $r$ is a statistical linear measure that evaluates the correlation between two variables: CBFW1, CBFW2, CBFW3, Age, Education, and the sum of the three CBFW questions (i.e., the CBFW scale). 
Analysis of covariance. ANCOVA measures the differences between two or more groups (e.g., Bill-Olivia and Sex) with regard to a dependent variable (e.g., the CBFW scale) by also adjusting for the effect of covariate(s), such as Age, Education, and Completion Time.

Multivariate analysis of covariance. MANCOVA is the multivariate extension of ANCOVA (where there is more than one dependent variable, e.g., the three CBFW questions). In our study, MANCOVA was used as our main analysis given that it has some advantages over MANOVA (e.g., Tabachnick \& Fidell, 2019), including taking into account the effects of dependent as well as covariate variables.

\section{Power Analysis}

Sample size was calculated by G*Power (Faul et al., 2007; 2009), among the analyses, the highest required sample size was for ANCOVA: with an effect size of $0.01,5$ a power of 0.8 , and a significance level of 0.05 , the number of participants needed was 787 . The second highest required sample size was for MANCOVA analysis, with 685 required participants. However, since we planned to remove participants who completed the study in the lower fifth percentile (through Qualtrics), and because our study contained a difficult attention check question, we over-sampled by around $15 \%$, increasing the number from 787 to 900 participants.

\section{Participants}

Nine-hundred participants were recruited via Amazon's Mechanical Turk. Eligibility was limited to subjects based in the United States with a 95\% approval rating and 500 previously approved jobs (i.e., 95\% successful completion rate over 500 different studies). Participants received $\$ 0.50$ to take part in the survey. 


\section{Amazon Mechanical Turk}

Amazon Mechanical Turk (MTurk) has been increasingly used in science experiments and the data obtained through it has been shown to be no less reliable than previous conventional methods (e.g., Buhrmester et al., 2011; Casler et al., 2013); and likewise, while it may be more difficult to administer experimental conditions online, studies have shown that the results obtained are comparable to those acquired in labs (e.g., Crump et al., 2013; Horton et al., 2011; Paolacci et al., 2010). Yet, the current study will be observational and so the results obtained should be even more acceptable. Also, the quality of the data can be further improved by limiting certain demographics (see previous section, Participants), as demonstrated by the increase of statistical power (Thomas \& Clifford, 2017).

\section{Procedures}

The participants were given a link to Qualtrics (an online survey tool), asked to provide consent (see Ethics Clearance), and instructed to read and respond to a short scenario, the CBFW measure, by selecting 1-6 depending on their agreement with the follow-up questions ("Strongly disagree", "Disagree", "Somewhat disagree", "Somewhat agree", "Agree", and "Strongly agree"). We did not offer a "Neutral" option (i.e., 7-point Likert scale) so that participants would be nudged to think and choose between either "somewhat disagree" or "somewhat agree" were they not to be certain about their response-thus also exploiting the benefits of a binary categorical item (e.g., please select "Yes" or "No"). As discussed before, the two scenarios, Bill and Olivia, were randomly presented to the participants to check for potential sex-related prejudices in men and women. 
Finally, MTurk workers who did not correctly fill out the Amazon ID and Age questions, along with those who completed the survey in the lower fifth percentile (under 50 seconds), and participants who failed the attention check question were excluded from the study. After removing participants who failed the exclusion criteria, we were left with a total of 753 participants in Study 1. A summary of demographic information are presented in Figure 1-4 and Table 7, and the number of participants excluded are displayed in Table 8.

\section{Figure 1}

Visualization of demographic information, Sex (Study 1). No participant selected "Not listed/Other" in the Olivia condition
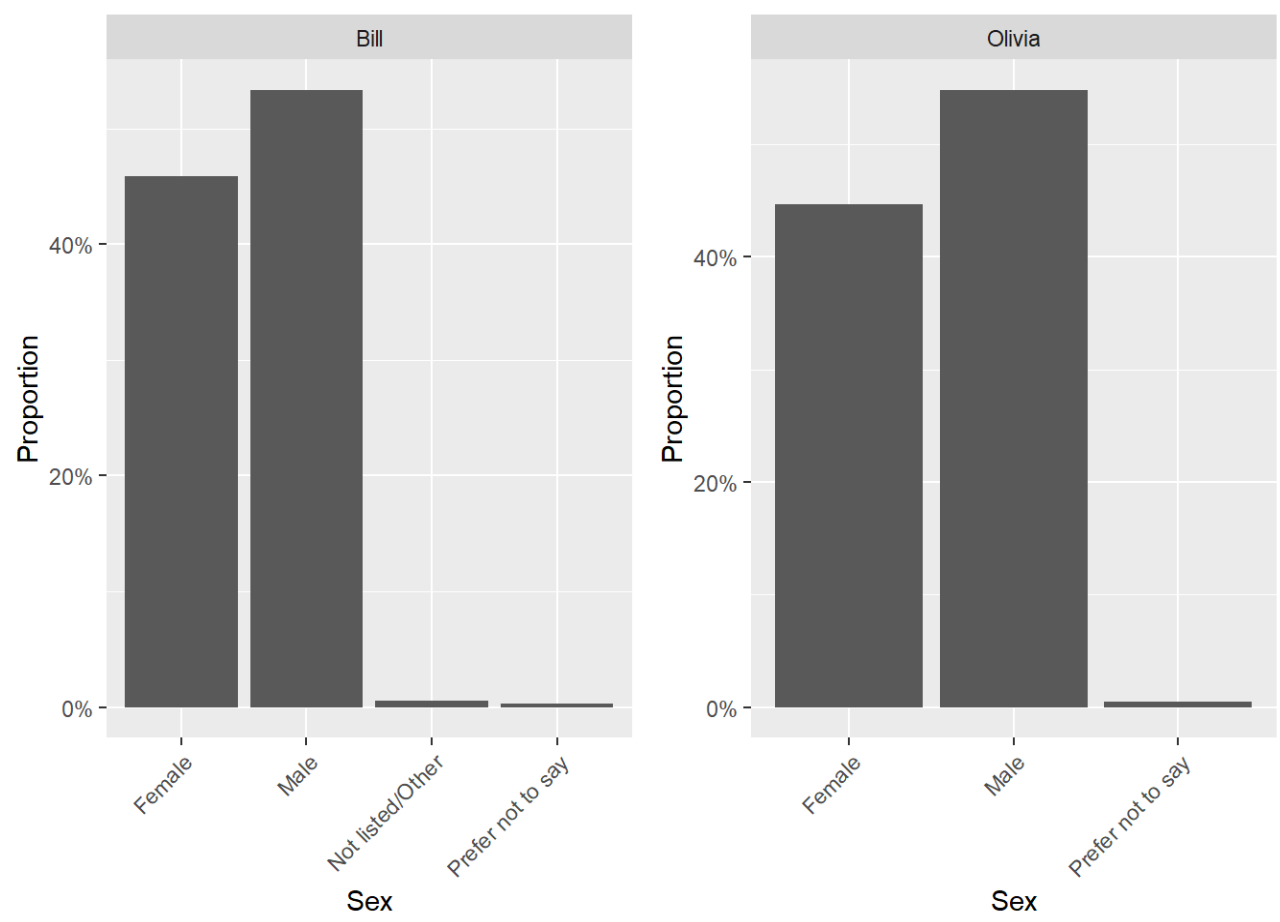


\section{Figure 2}

Visualization of demographic information, Education (Study 1)
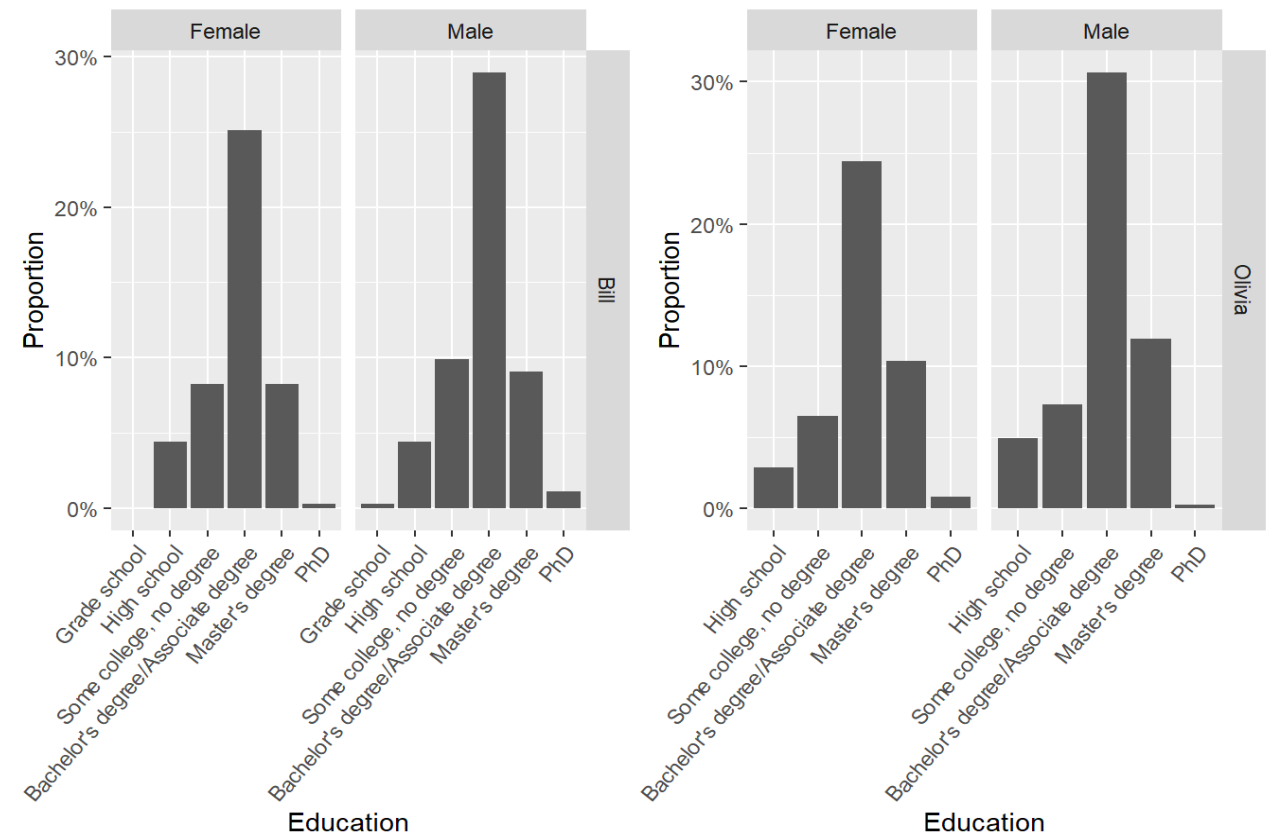

\section{Figure 3}

Visualization of demographic information, Ethnicity (Study 1)
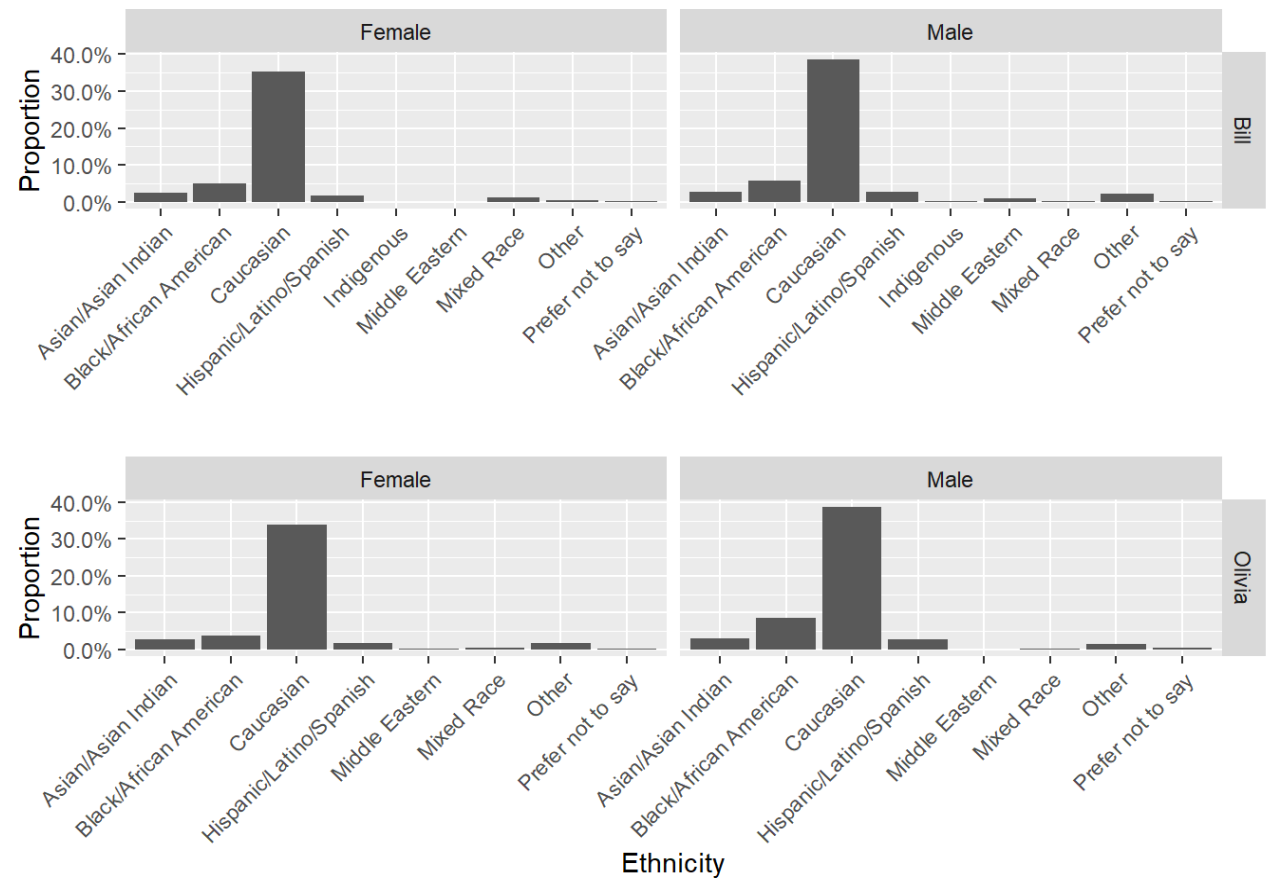


\section{Figure 4}

Visualization of demographic information, Religion (Study 1)
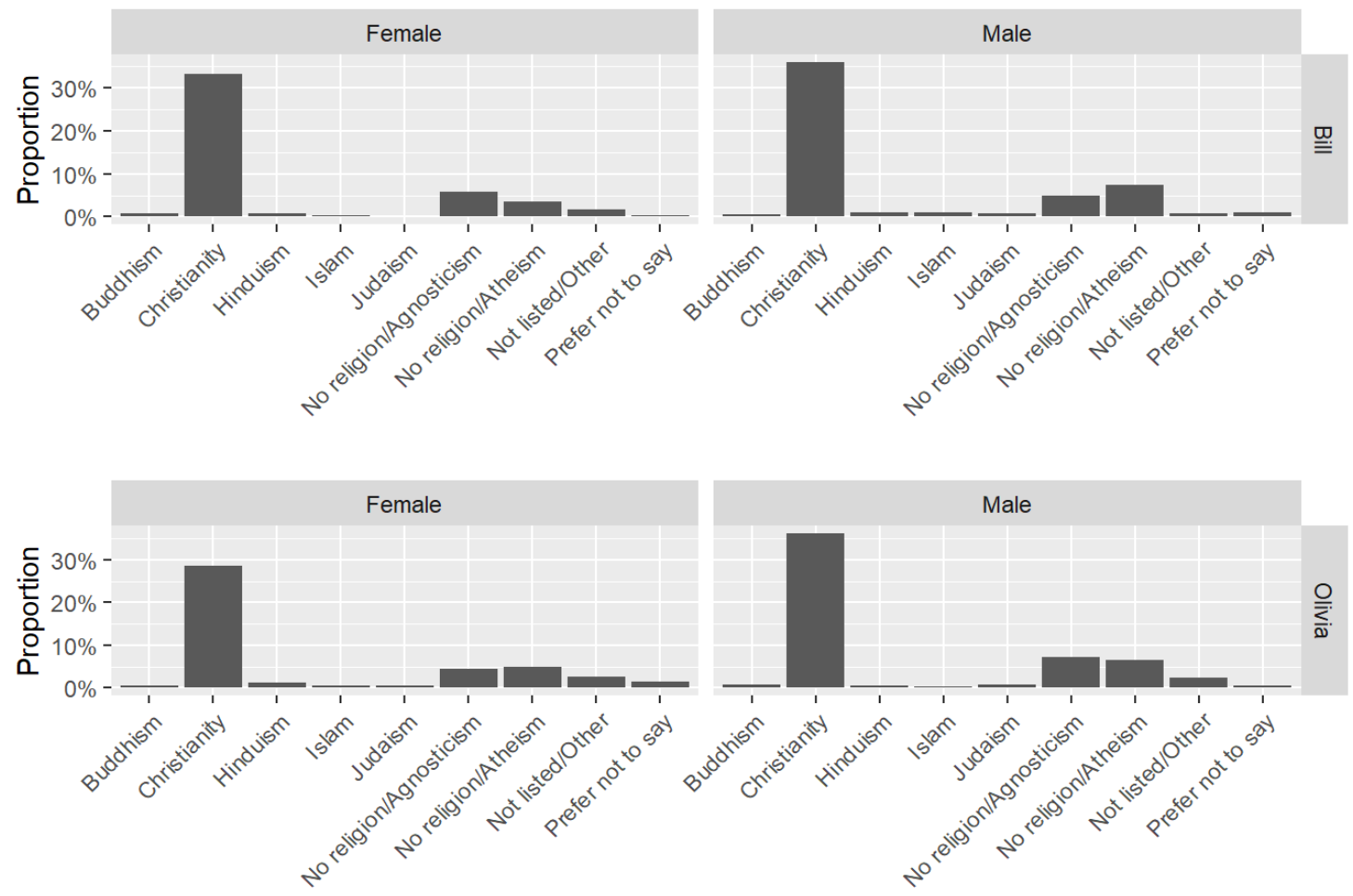

Religion

\section{Table 7}

Mean and standard deviation of demographic information for all participants, Study 1

\begin{tabular}{llllll}
\hline & Participants & Age & Female & Christian & Caucasian \\
\hline Bill scenario & 366 & $40.9 \pm 11.4$ & $45.9 \%$ & $68.3 \%$ & $73.5 \%$ \\
Olivia scenario & 387 & $40.7 \pm 12.7$ & $44.7 \%$ & $64.6 \%$ & $72.4 \%$ \\
\hline
\end{tabular}




\section{Table 8}

Number of participants excluded in Study 1

\section{Total N}

Attention Check

Did not complete study

Lower fifth percentile completion time

Wrong Age

Did not provide consent in follow-up consent form

Wrong ID

\subsection{Study 1: Results}

The data were analyzed using $\mathrm{R}$ (version 3.959), a free statistical programming tool (www.r-project.org). The tidyverse, moderndive, umx, lavaan, infer, lattice, Hmisc, PerformanceAnalytics, readxl, expss, broom, DescTools, jmv, knitr, scales, car, mvnormtest, skimr, and semPlot packages were used for Study 1 and Study 2. While the three classical belief in free will questions (CBFW1, CBFW2, and CBFW3) grasp different angles on decision making, we also conducted a reliability analysis on the three questions, to see if they would make a reliable measure (i.e., scale). The CBFW scale had good (but not great) psychometric characteristics (Cronbach's Alpha $=.74)$, this confirmed our earlier assumption, that people have varied intuitions with respect to free will-even when all three CBFW questions are centered on decisions. This would also explain why there is 
such a mixed literature on BFW and their implications in the general public. So, for these reasons, our main analyses will consist of examining the CBFW questions separately.

Next, we checked for Pearson correlation coefficient among the three CBFW questions, the CBFW scale, Age, and finally Education (Figure 5). The results indicated that all CBFW questions, as well as the CBFW scale, were significantly negatively correlated with Education $(r=-.13, p=.0003 ; r=-.10, p=.0043 ; r=-.11, p=.0022 ; r=-.14, p=.0000$, respectively); while only CBFW1 was significantly correlated with Age $(r=.09, p=$ $.0195)$.

\section{Figure 5}

The correlation between Education, Age, $C B F W 1, C B F W 2, C B F W 3$, and the $C B F W$ scale

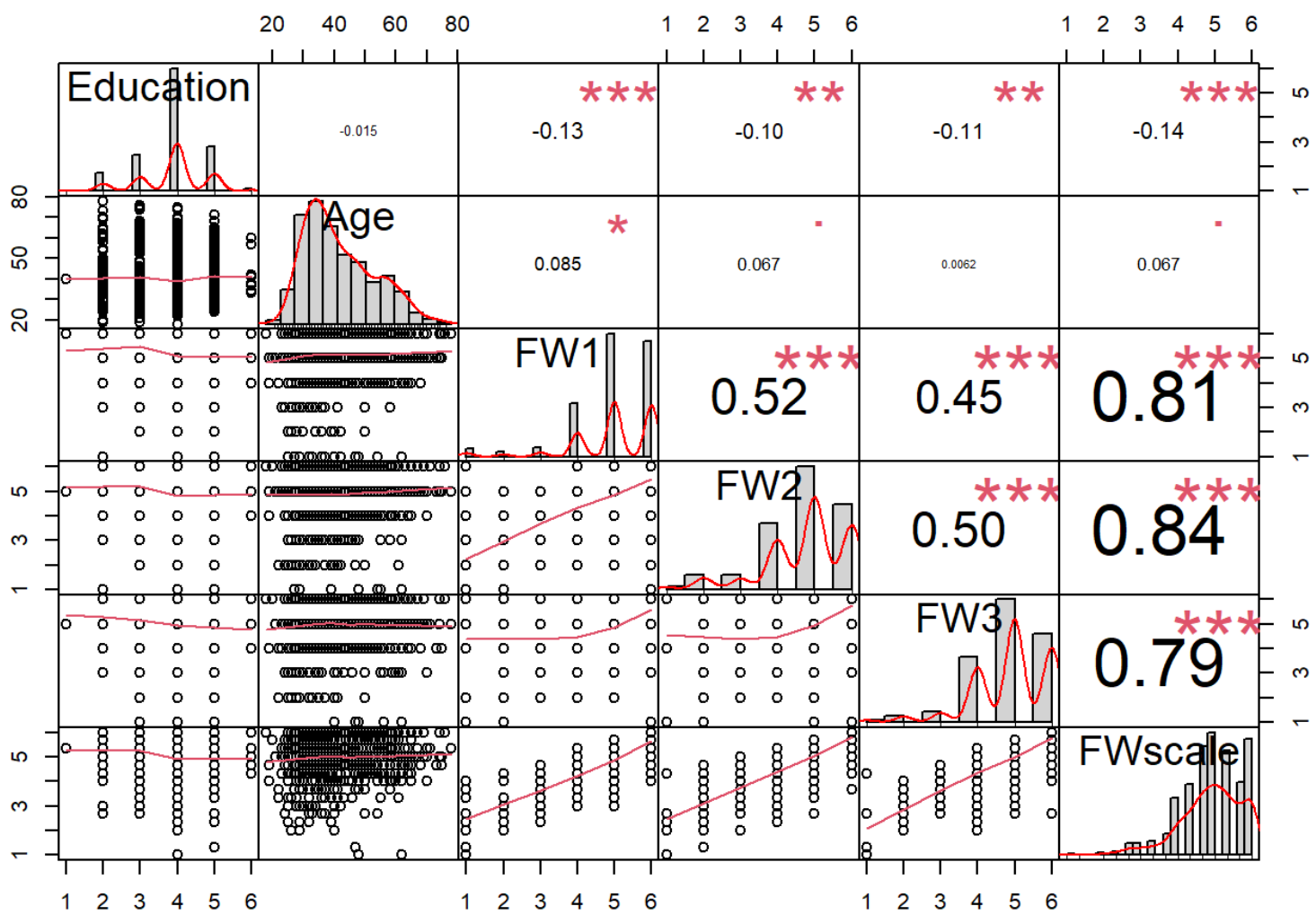


To check for potential sex-related differences and biases, we conducted an ANCOVA analysis. The CBFW scale was included as the dependent variable and Sex and BillOlivia as the independent variables, taking into account their interactions and the roles of Age, Education, and Completion Time (Table 9). Similar to the correlation analysis, the results revealed significant effects of Education and Age $\left(\mathrm{F}_{1,741}=15.94, p=.0000 ; \mathrm{F}_{1,741}\right.$ $=3.96, p=.0469$, respectively). Interestingly, the interactions between Sex and BillOlivia and their main effects were non-significant. Participants' responses to the CBFW measure are displayed in Figure 6.

\section{Figure 6}

Mean and standard deviation of the degrees of classical belief in free will between Sex and the Bill-Olivia scenarios

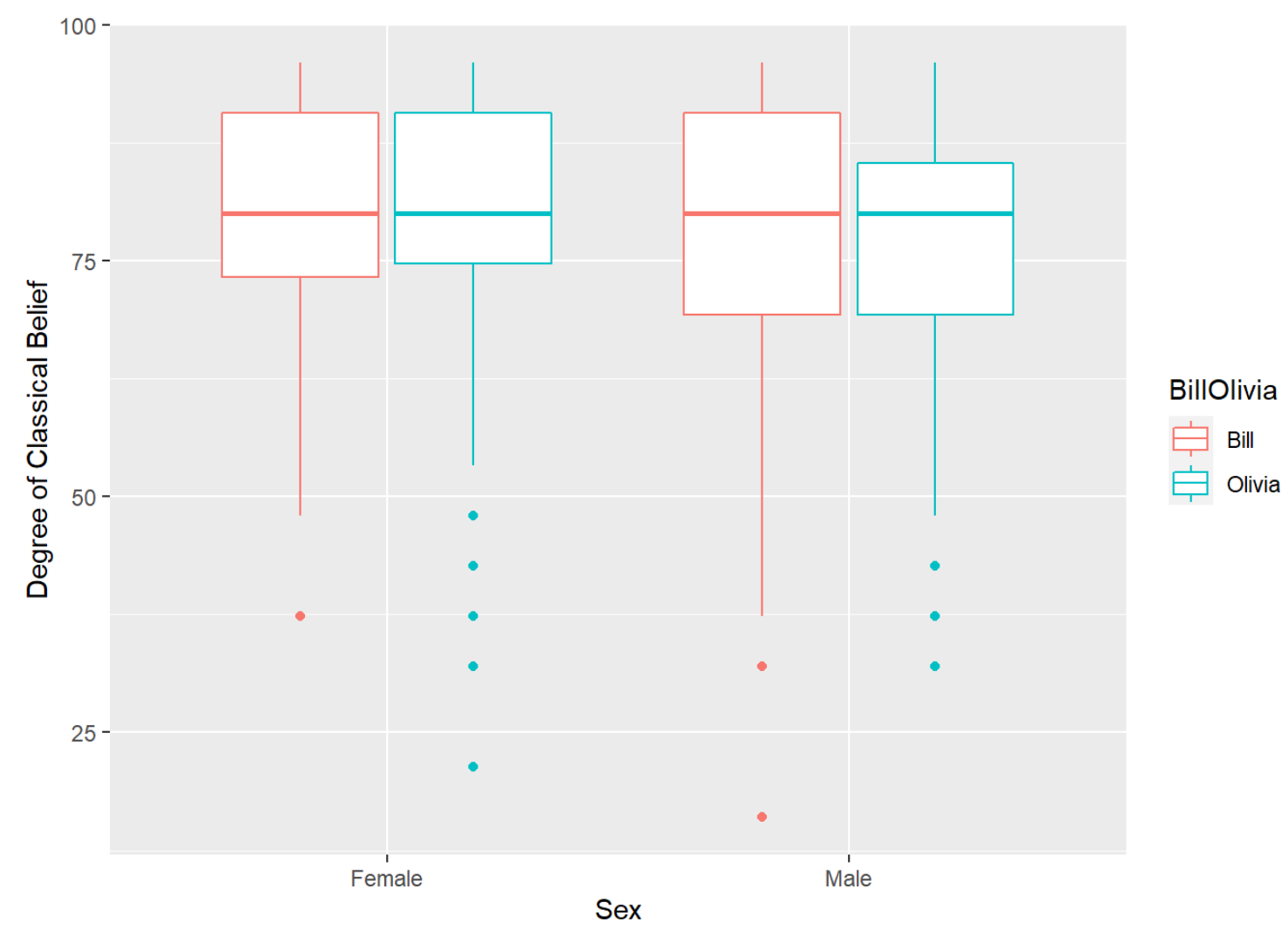




\section{Table 9}

ANCOVA on Sex and Bill-Olivia (independent variables), and CBFW scale (dependent variable), and Education, Age, and Completion Time as covariates

\begin{tabular}{llllll}
\hline & $d f$ & sumsq & meansq & statistic & p.value \\
\hline Education & 1 & 11.386 & 11.386 & 15.94 & 0.0000 \\
Age & 1 & 2.832 & 2.832 & 3.96 & 0.0468 \\
Time & 1 & 2.411 & 2.411 & 3.37 & 0.0666 \\
BillOlivia & 1 & 0.099 & 0.099 & 0.14 & 0.7097 \\
Sex & 1 & 1.696 & 1.696 & 2.37 & 0.1238 \\
BillOlivia:Sex & 1 & 0.231 & 0.231 & 0.32 & 0.5700 \\
Residuals & 741 & 529.358 & 0.714 & NA & NA \\
& & & & & \\
\hline
\end{tabular}

Similar findings came from the MANCOVA analysis on the three CBFW questions (dependent variables) and Sex and Bill-Olivia (independent variables), with Age, Education, and Time as the covariate variables (Table 10). The results showed that effect of education was significant for all three CBFW questions $\left(\mathrm{CBFW} 1: \mathrm{F}_{1.741}=12.865, p=\right.$ $\left..000 ; \mathrm{CBFW} 2: \mathrm{F}_{1.741}=7.885, p=.005 ; \mathrm{CBFW} 3: \mathrm{F}_{1.741}=10.309, p=.001\right)$, and that there was only a significant effect of Age on CBFW1 $\left(\mathrm{F}_{1.741}=5.785, p=.016\right)$; The effect of Age was also marginally significant for CBFW2 $\left(\mathrm{F}_{1.741}=3.504, p=.062\right)$. Lastly, and unexpectedly, there was a significant main effect of participants' completion time on CBFW3 $\left(\mathrm{F}_{1.741}=8.363, p=.004\right)$. And although the Box's $\mathrm{M}$ test turned out to be significant in the MANCOVA analysis $(p=.000)$ - which is a source of concern when conducting a MANCOVA on three similar dependent variables (e.g., the three CBFW questions) - this can usually be ignored since it is a common phenomenon within larger samples, 753 participants (e.g., Tabachnick \& Fidell, 2019). 
In a follow-up regression analysis, we observed that the relationship between CBFW1 and Age remained significant even after adding the mediating effect of Education $(p=$ .021). Also, considering that CBFW3 question was marginally different between Sex ( $p=$ .084), we conducted a hypothesis test on CBFW3 and Sex with 10000 permutations and saw that the relationship remained marginal and non-significant $(p=.096$, Figure 7). Last but most importantly, we came to realize that the vast majority of participants had higher compared to lower degrees of CBFW (Figure 8).

The fact that the CBFW variables were negatively skewed was an indication of nonnormality. So, we checked to see if they were acceptable assumptions for us to work with, by assessing the assumptions for the CBFW questions and the CBFW scale (Figure 9-12), and saw that all variables, apart from CBFW1, were reasonably distributed: the residuals in the plots were normally distributed (i.e., the points in the Q-Q plots were roughly on diagonal lines). Moreover, we conducted Shapiro-Wilk to perform an inferential test of the normality of the CBFW questions and scale. The results indicated that the variables were not normally distributed. This was not a cause for concern as the assumption of normality does not refer to the normality of the overall data (Denis, 2020), especially in larger samples (Tabachnick \& Fidell, 2019). However, above all, as put by Howell (2013, p. 340), "if the populations can be assumed to be symmetric [(e.g., the Bill and Olivia scenario and Sex)], or at least similar in shape (e.g., all negatively skewed), and if the largest variance is no more than four times the smallest, the analysis of variance is most likely to be valid" (see Figure 1 and 14).

Nevertheless, to be on the safe side, we also conducted Spearman's rank-order correlation, on top of Pearson's correlation coefficient, to see if the significance levels of 
the correlation analysis differed. This is common practice for when normality assumption is not met. The results revealed no differences between the two analyses (see Appendix A).

\section{Table 10}

MANCOVA on Sex and Bill-Olivia (independent variables) and the CBFW questions (dependent variables), with Age, Education, and Completion Time as the covariate variables

\begin{tabular}{|c|c|c|c|c|c|c|}
\hline & $\begin{array}{l}\text { Dependent } \\
\text { Variable }\end{array}$ & $\begin{array}{l}\text { Sum of } \\
\text { Squares }\end{array}$ & $d f$ & $\begin{array}{l}\text { Mean } \\
\text { Square }\end{array}$ & $\mathrm{F}$ & $p$ \\
\hline & FW1 & 2.481 & 1 & 2.481 & 2.159 & 0.142 \\
\hline \multirow[t]{3}{*}{ Sex } & FW2 & 1.061 & 1 & 1.061 & 0.885 & 0.347 \\
\hline & FW3 & 2.851 & 1 & 2.100 & 2.993 & 0.084 \\
\hline & FW1 & 1.404 & 1 & 1.404 & 1.222 & 0.269 \\
\hline \multirow[t]{3}{*}{ BillOlivia } & FW2 & 0.835 & 1 & 0.835 & 0.696 & 0.404 \\
\hline & FW3 & 0.213 & 1 & 0.213 & 0.224 & 0.636 \\
\hline & FW1 & 0.148 & 1 & 0.148 & 0.129 & 0.720 \\
\hline \multirow[t]{3}{*}{ Sex:BillOlivia } & FW2 & 0.616 & 1 & 0.616 & 0.514 & 0.473 \\
\hline & FW3 & 1.083 & 1 & 1.083 & 1.137 & 0.287 \\
\hline & FW1 & 6.648 & 1 & 6.648 & 5.785 & 0.016 \\
\hline \multirow[t]{3}{*}{ Age } & FW2 & 4.201 & 1 & 4.201 & 3.504 & 0.062 \\
\hline & FW3 & 0.042 & 1 & 0.042 & 0.044 & 0.834 \\
\hline & FW1 & 14.783 & 1 & 14.783 & 12.865 & 0.000 \\
\hline \multirow[t]{3}{*}{ Education } & FW2 & 9.455 & 1 & 9.455 & 7.885 & 0.005 \\
\hline & FW3 & 9.820 & 1 & 9.820 & 10.309 & 0.001 \\
\hline & FW1 & 0.082 & 1 & 0.082 & 0.071 & 0.789 \\
\hline \multirow[t]{3}{*}{ Time } & FW2 & 1.941 & 1 & 1.941 & 1.619 & 0.204 \\
\hline & FW3 & 7.966 & 1 & 7.966 & 8.363 & 0.004 \\
\hline & FW1 & 851.454 & 741 & 1.149 & & \\
\hline \multirow[t]{2}{*}{ Residuals } & FW2 & 888.517 & 741 & 1.199 & & \\
\hline & FW3 & 705.843 & 741 & 0.953 & & \\
\hline
\end{tabular}




\section{Figure 7}

Simulation-based null distribution of CBFW3 and Sex (hypothesis test)

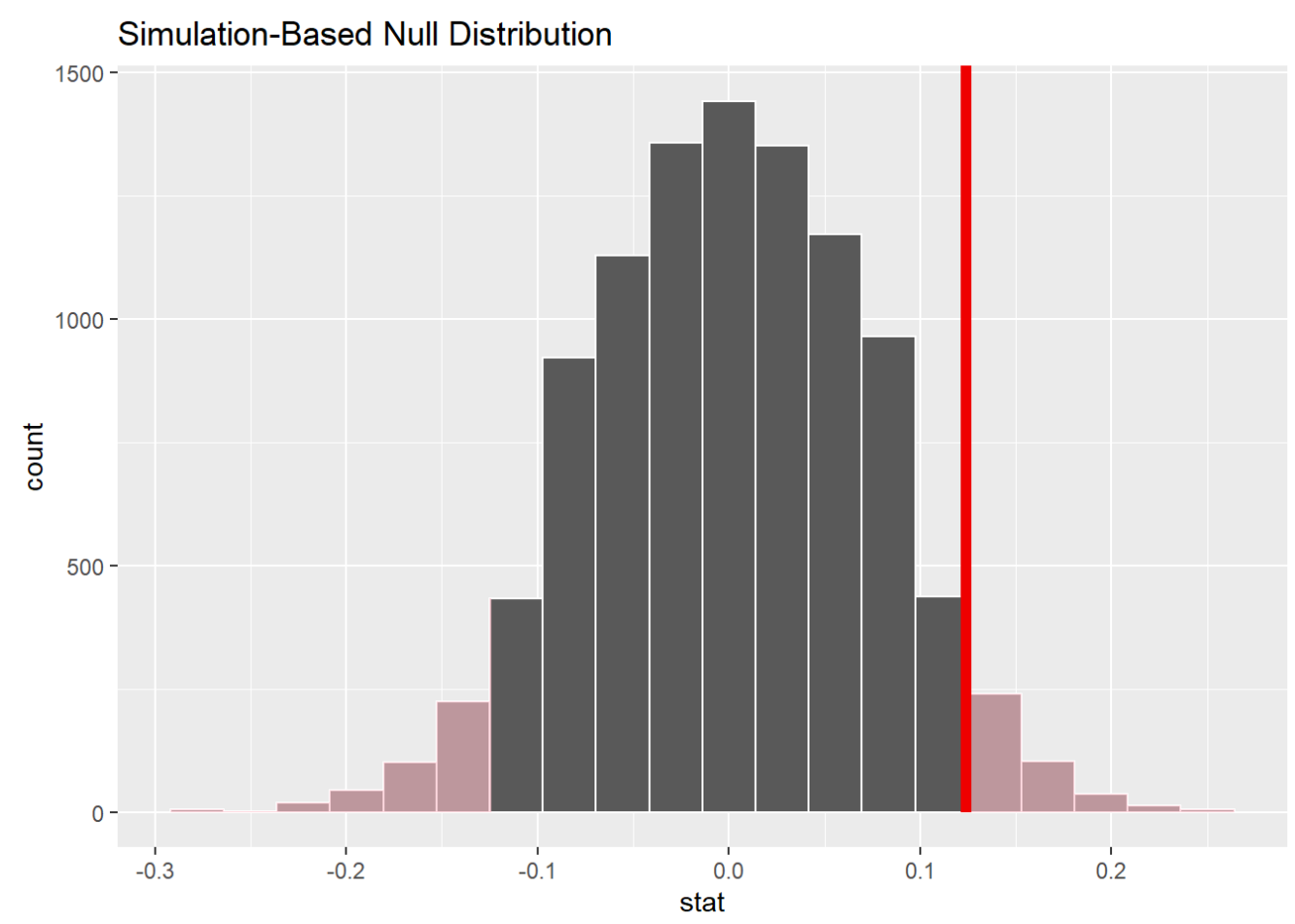

\section{Figure 8}

The degrees of classical belief in free will (CBFW1, CBFW2, and CBFW3)
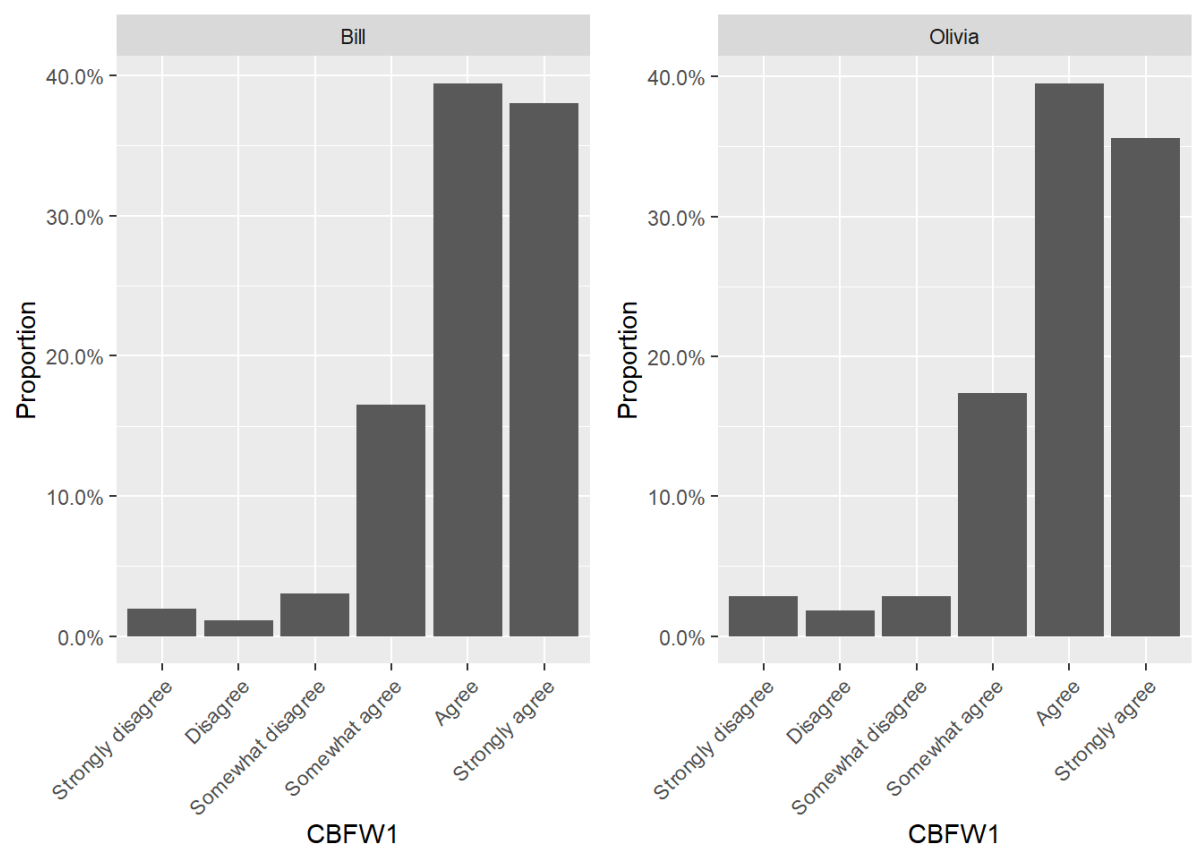

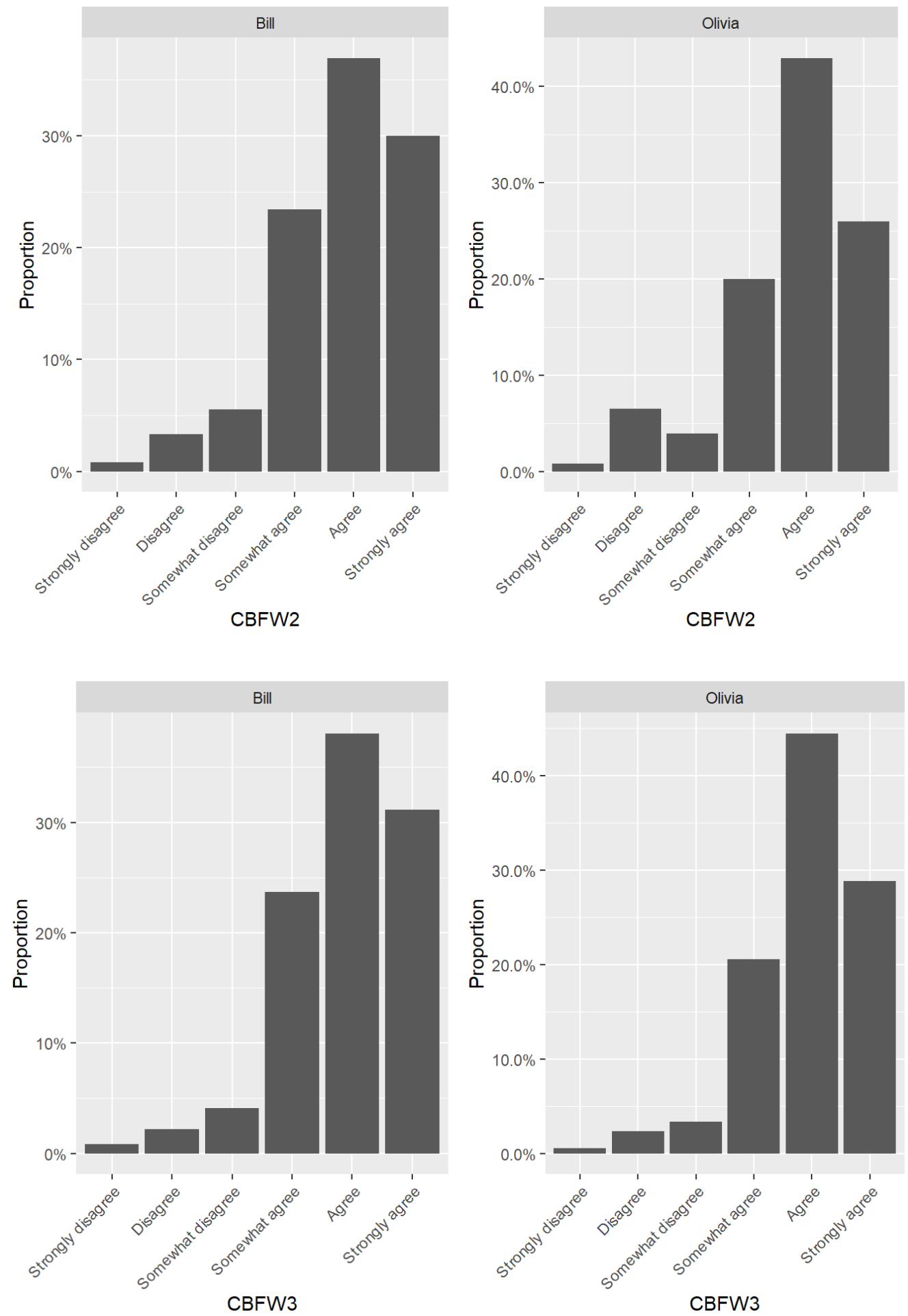


\section{Figure 9}

Check the validity of the assumptions for CBFW1

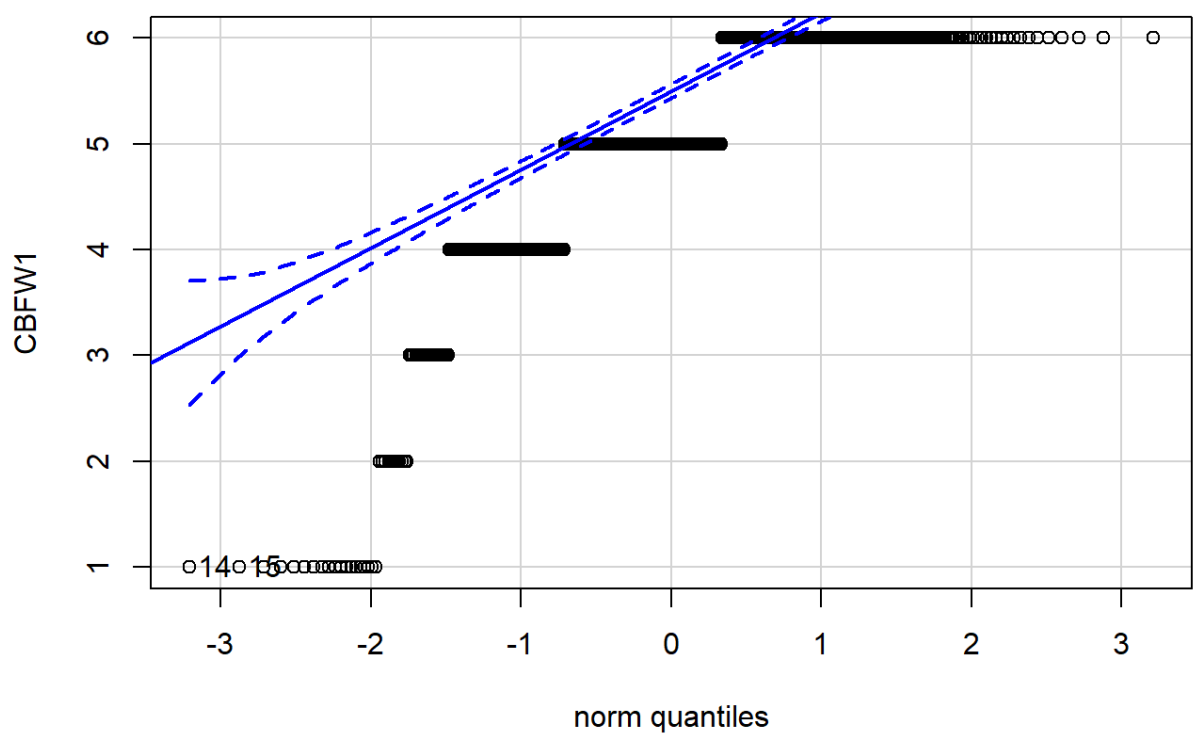

\section{Figure 10}

Check the validity of the assumptions for CBFW2

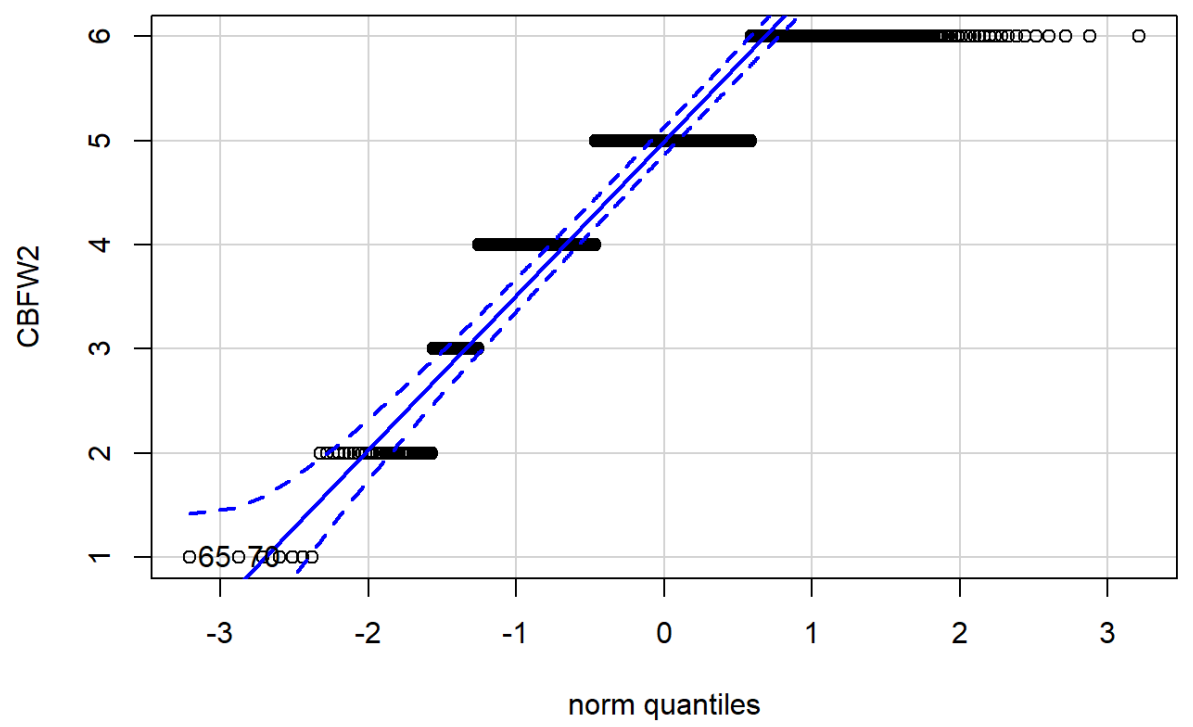




\section{Figure 11}

Check the validity of the assumptions for $C B F W 3$

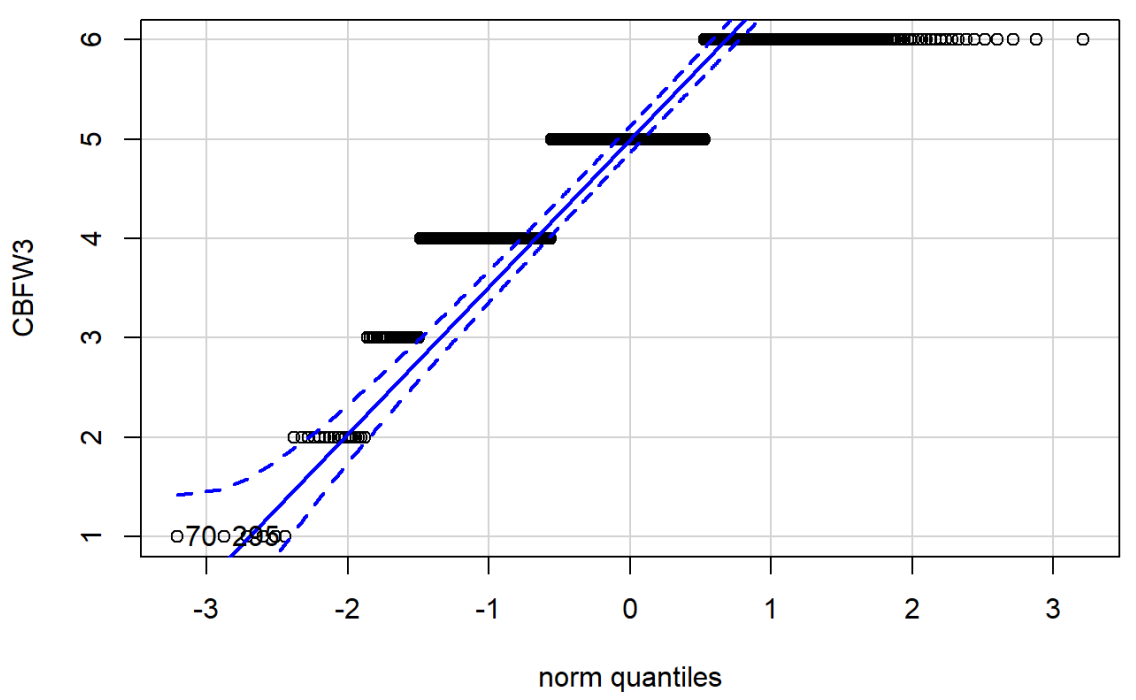

\section{Figure 12}

Check the validity of the assumptions for the CBFW scale

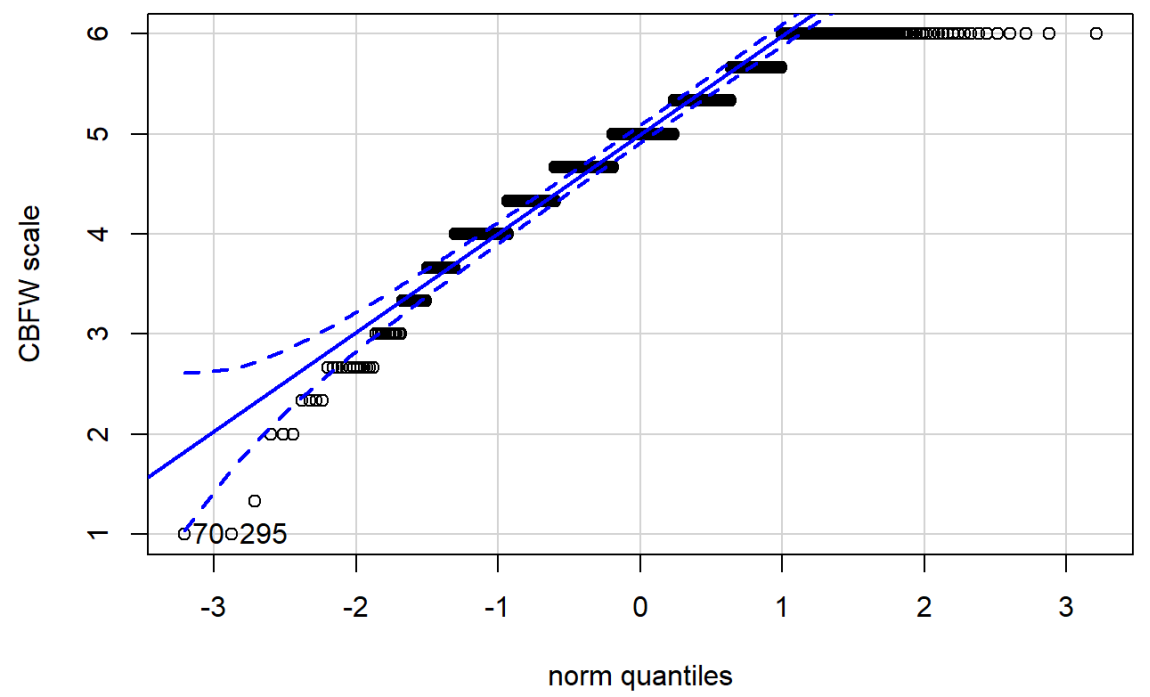




\subsection{Study 2: Observational}

In Study 2, we administered the classical belief in free will item (CBFW) along with a variety of other measures that assess prosocial attitudes and behaviors. Our methods and materials are adapted (Crone \& Levy, 2019; Nichols \& Knobe, 2007; Paulhus \& Carey, 2011) and influenced (e.g., Vohs \& Schooler, 2008) by several prominent studies within the literature on belief in free will. Notably, the build of our second study relies on the results of our first preliminary study — by way of ruling out that there were no sex-related differences or biases with regard to CBFW in Study 1, and more importantly, after comparing and confirming the reliability of the CBFW scale on two different samples (Study 1 and Study 2), we can proceed to examine the relations based on correlational analysis. In addition, we further checked for the same ANCOVA and MANCOVA analyses of Study 1, with the same significance level (0.05) and power (0.8) but with medium effect sizes this time around (see next section, Power analysis). Last but not least, we formed a mediation model to identify the underlying mechanisms involved, and also developed a structural equation model to lay out the overall structural relationships. Both Study 1 and Study 2 were presented in fixed-order (i.e., presented in the same order to all participants) given that we were looking for group (and not individual) differences. Our research instruments can be found in the Supplementary Material.

\section{Power analysis}

In general, a variable measured using a continuous scale has more statistical power for detecting variability among people than that measured using a discrete scale. For that reason, and also to be able to see whether the associations between the measures were positive or negative, we chose to center on correlation coefficients in Study 2. Referring to 
above, we also repeated the previous ANCOVA and MANCOVA in Study 1 (0.25 medium effect size for ANCOVA with 128 required participants and 0.0625 medium effect size for MANCOVA with 180 required participants). Multiple regressions and structural equation modelling (SEM) were also examined. With these in mind, sample size was calculated by G*Power (Faul et al., 2007; 2009), with an effect size of 0.1 (minimal effect size), a power of 0.8 , and a significance level of 0.05 , the number of required participants for Pearson's correlation coefficient (Pearson's $r$ ) came to 193. However, on account of our second study taking more time to complete as well as containing an additional difficult attention check question on top of the previous one used in Study 1, and due to the high number of participants excluded in our first study, we over-sampled by $40 \%$, increasing the number from 193 to a total of 270 participants. After the removal of participants with our exclusion criteria (see Participants), we were left with a total of 197 participants.

\subsection{Methods}

\section{Analyses}

Hierarchical regression. Hierarchical regression is utilized to predict the value of a dependent variable (e.g., the CBFW questions separately) based on two or more predictor variables (e.g., Age, Education, Completion Time). We then use its results to form a mediation model (Figure 13). A mediation model seeks to predict the value of an independent variable (e.g., free will) based on the value of a dependent variable (e.g., donation). This prediction is a hypothesis (c) and once we include a mediator (e.g., education), it is hypothesized that (c) will drop to (c'). Full mediation occurs if the path drops to zero and, if it were to greatly reduce, then it is said that partial mediation has occurred (e.g., Denis, 2020). 


\section{Figure 13}

Single-variable mediation model

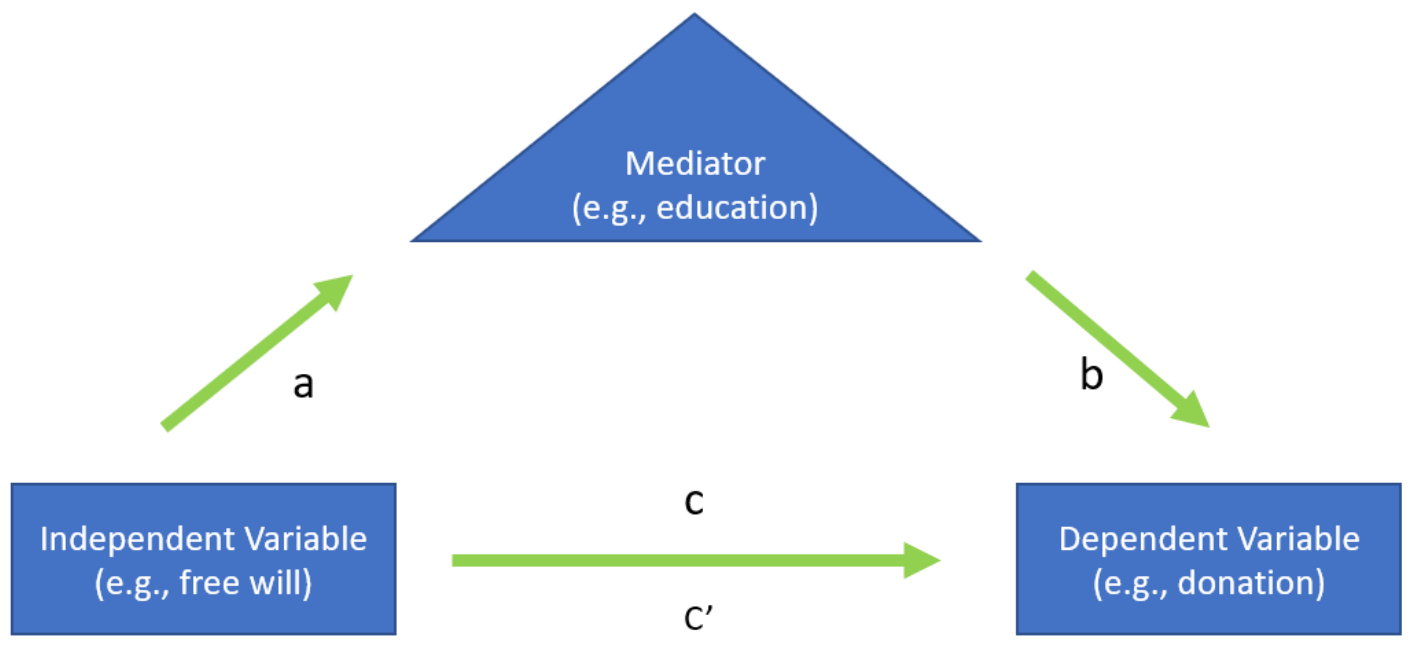

Structural equation modelling (SEM). Structural Equation modelling can be thought of as a combination of factor analysis and multiple regression analysis that also incorporates latent variables (i.e., hypothetical constructs) and is used to analyze structural relationships.

\section{Participants}

The participants were recruited through Amazon's Mechanical Turk. As in Study 1, eligibility was confined to MTurk subjects located in the United States with an approval rating of $95 \%$ and 500 previously approved jobs. Demographic information are shown in Figure 14-17 and Table 11, and the number of participants excluded are summarized in Table 12. Participants were removed if they:
A) provided incorrect information for the Age or Amazon ID questions.
B) failed either of the two attention check questions.
C) did not participate in both tasks (the Dice Cheating Task and Donation Task). 
D) responded to our optional Donation Task without completing the required short survey (this could be interpreted as another attention check question or a form of fraud, and because we did not know which one, we rejected the participants responses).

E) completed the study in the lower fifth percentile (under 100 seconds).

F) selected "not very well" and "well" among the four options on the English Proficiency question: "not very well", “well”, "very well”, and "native speaker/ native-like speaker".

G) did not provide consent in the secondary consent form (since the participants were not told the true purpose of the study at the outset, they were once again asked to provide consent after they read the debriefing form).

\section{Figure 14}

Visualization of demographic information, Sex (Study 2). No participant selected "Not listed/Other" or "Prefer not to say" in Study 2

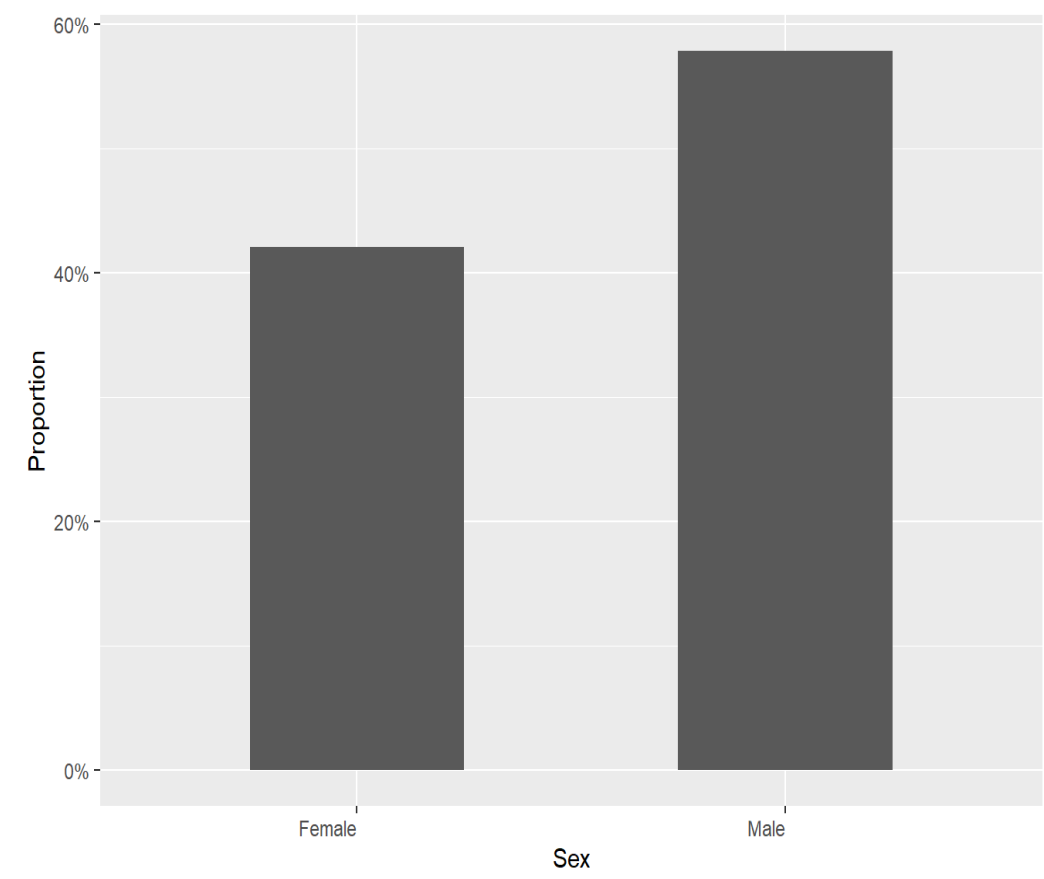




\section{Figure 15}

Visualization of demographic information, Religion (Study 2)

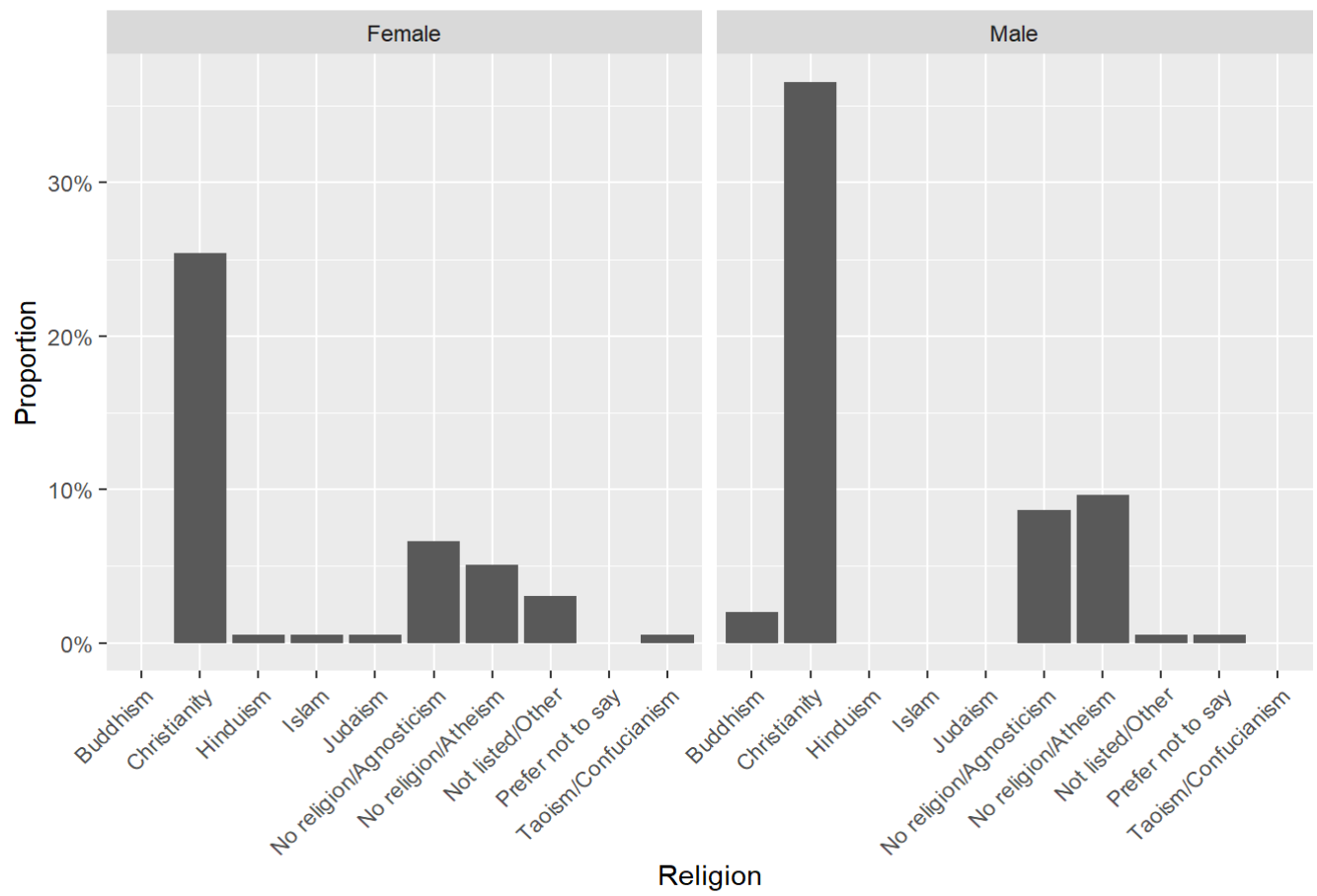

\section{Figure 16}

Visualization of demographic information, Ethnicity (Study 2)

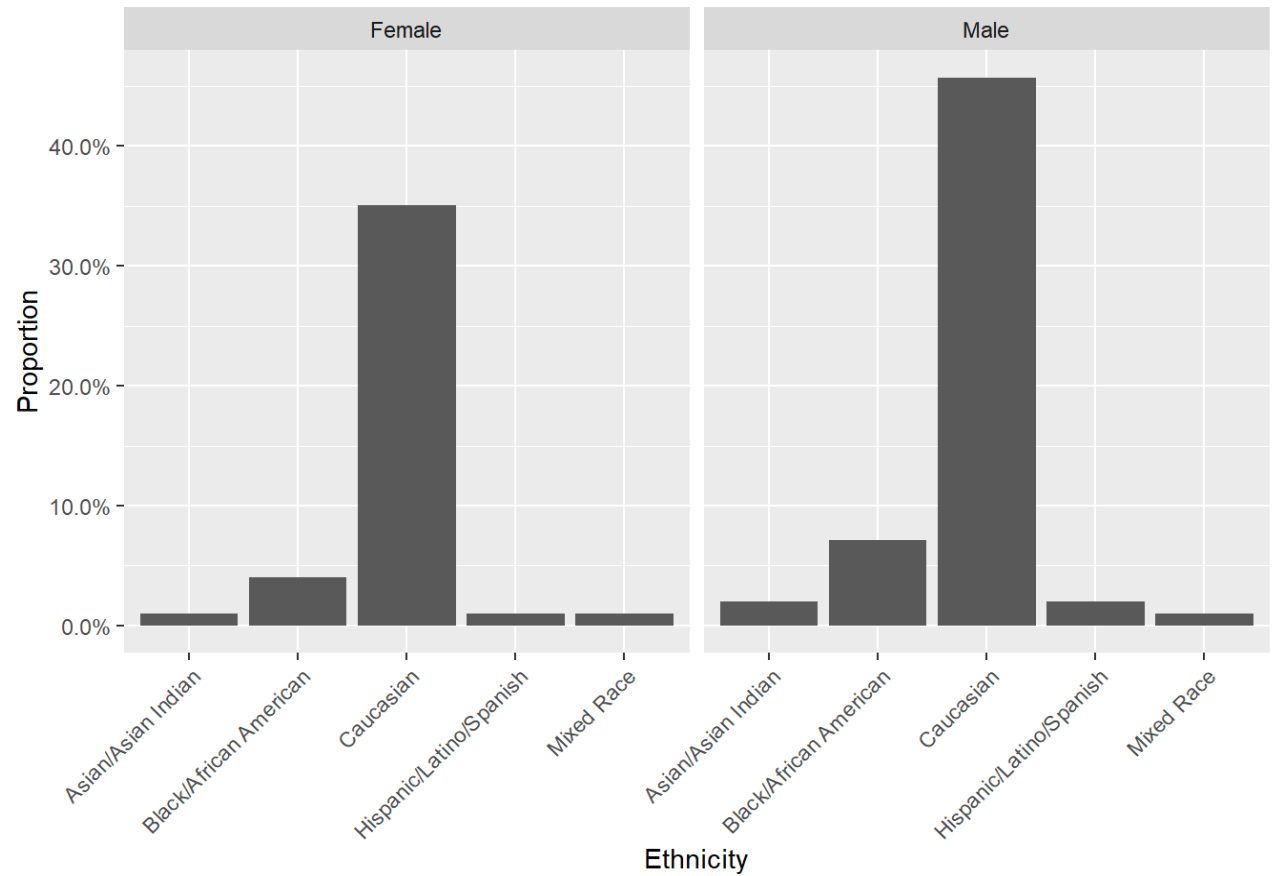




\section{Figure 17}

Visualization of demographic information, Education (Study 2)

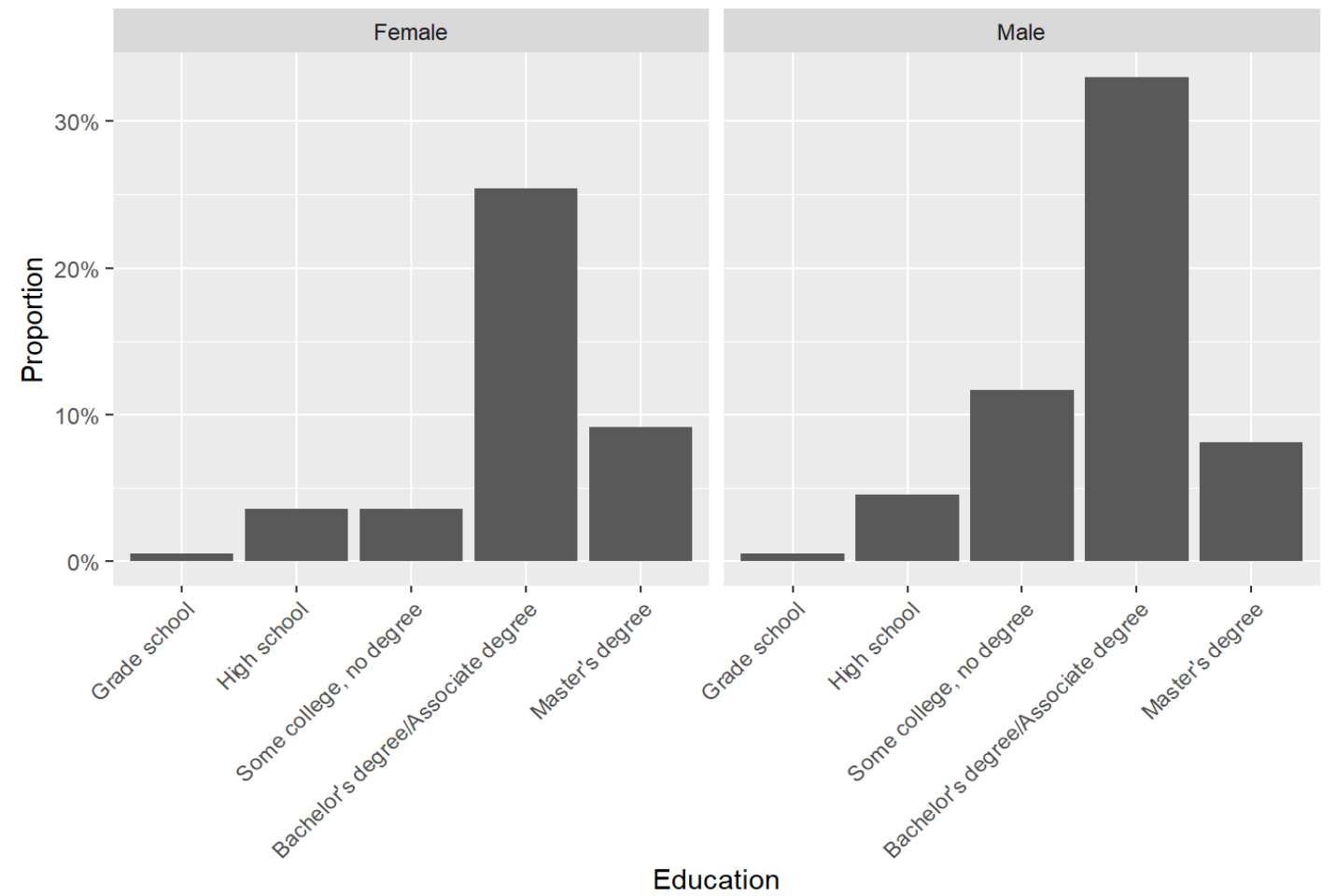

\section{Table 11}

Mean and standard deviation of demographic information, Study 2

Participants Age Female Christian Caucasian

Demographic information 197

$37.4 \pm 9.7 \quad 42.1 \% \quad 61.9 \% \quad 80.7 \%$




\section{Table 12}

Number of participants excluded in Study 2

\begin{tabular}{llcc}
\hline & Removed & Rejected & Total N \\
\hline Attention check (main and optional survey) & 22 & 21 & 43 \\
Lower fifth percentile completion time & 9 & 5 & 14 \\
Did not complete study & 1 & 1 \\
Did not provide consent in follow-up consent form & 2 & 2 \\
Did not participate in Donation Task & 2 & 2 \\
Did not participate in Cheating Task & 2 & 2 \\
Self-reported low English proficiency & 4 & 4 & 51 \\
Lied about completing the secondary survey & & 71 & 119 \\
\hline Altogether & 42 & 40 & 73 \\
\hline Altogether (without overlap) & 33 & & 2 \\
\hline
\end{tabular}

\section{Compensation}

Levels of compensations have been a problem in online studies, and especially on Amazon Mechanical Turk. For this reason, we set base compensations to 1.50 USD, plus two bonus questions $(\$ 1.50$ and $\$ 0.50-1.75)$, this encouraged the participants to take our study more seriously-for a survey that takes around 10 minutes to complete (with an average of 8.3 minutes), which is much higher than the median income of MTurk subjects, approximately two dollars an hour (Hara, Adam, \& Milland, 2018). Compensations were also much higher for Study 1 (\$0.50), which took about 3 minutes to complete (with an average of 2.8 minutes). 


\subsection{Materials}

\section{English level question}

The selected demographics for both studies were limited for people who resided in the United States, therefore, participants were likely to have a more than reasonable grasp of the English language. However, to further confirm our audience and to also ensure the participants were able to understand the items and tasks, we took the further step of adding an English Proficiency item in our second study to remove participants who self-reported low English proficiency.

\section{Classical Belief in Free Will item (CBFW item)}

The CBFW item was the same as in Study 1.

\section{Attitudes toward incarceration}

Granted that libertarians, compatibilists, hard determinists, and hard incompatibilists have different opinions on responsibility, we wanted to see whether a similar contrariety was present in the general public. While assessing attitudes toward retributivism has been a major part of the literature (e.g., Genschow et al., 2017; Krueger et al., 2014; Shariff et al., 2014), the measure that we have proposed here evaluates views on incarceration, and more specifically, it distinguishes participants that agree with the backward-looking motives of imprisonment (punishment) from those that agree with the forward-looking justifications of incarceration (e.g., rehabilitation and isolation from society), and people that agree with both. We have chosen not to shine light on responsibility or moral responsibility, considering they, analogous to free will, are also vague terms. So, concentrating on attitudes toward incarceration has been the theme of this item (since it goes with a clear idea of when people are responsible): 
A 23-year-old, William, is at a party with his friends. He sees a really attractive 22-year-old named Elena. He approaches her several times only to get rejected each time. Not knowing what to do, he gets frustrated and decides to follow Elena home and rape her. William is later arrested and sentenced to 25 years.

Why should William be locked up?

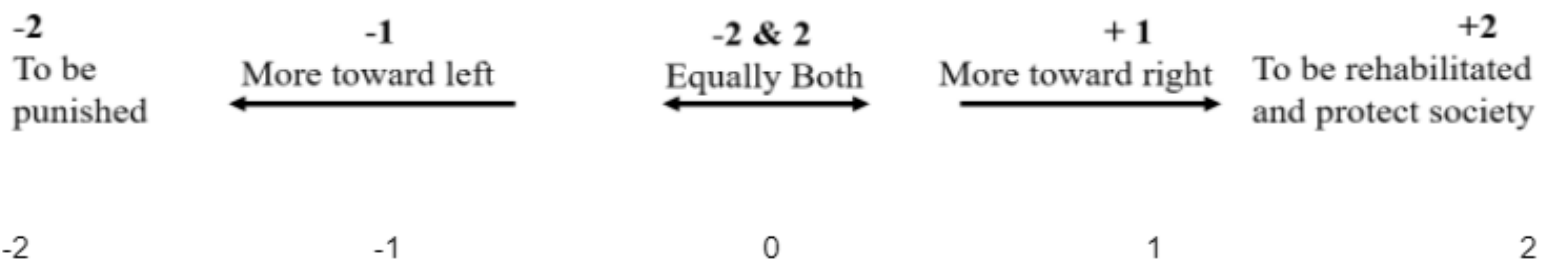

\section{Personal liberties}

To explore an additional angle of prosocial attitudes that may be relevant to BFW, we opted to include attitudes toward human rights, which encompass concepts such as right to life and freedom. The notion of human rights, analogous to other complicated concepts, can be studied from a variety of perspectives. One constructive approach, according to Diaz-Veizades and colleagues (1995), is to view and study human rights through a multidimensional lens. Crowson (2004) rightfully took this to heart and replicated the three factors of Diaz-Veizades and colleagues' Human Rights Questionnaire (HRQ) - the Personal Liberties, Civilian Constraint, and Social Security subscales_-for and toward an improved multidimensional version of the first scale in the field, the Attitudes Toward Human Rights Inventory (ATHRI; Getz, 1985). Participants respond to the questions using a 5-point Likert scale ranging from "Strongly agree" to "Strongly Disagree". The ATHRI has been used in other studies that have explored the relation between human rights and 
various attitudes and beliefs (Hayes, 2004; Livingstone et al., 2006; Narvaez et al., 1999; Sohrabi \& Sohrabi, 2020).

The perspective (subpart) of human rights that we will be looking into in Study 2 is personal liberties. While it might be argued that the Personal Liberties subscale is more controversial than the other two subscales in some respects (Table 13), the statements reflect more obvious ethical and moral concerns that require little-to-no implementation policies, and are close to becoming non-partisan issues; and most importantly, they are mainly personal endeavours to overcome, whereas the two other subscales deal with issues that need further discussions and debates to reach optimal solutions.

Therefore, in this study, we have decided to only administer the Personal Liberties subscale of the ATHRI (Crowson, 2004; Getz, 1985). The objective of the measure is to evaluate tolerance, attitudes toward human rights, and belief in egalitarianism. To our knowledge, no study has investigated the relationship between BFW and attitudes toward personal liberties, or even human rights. However, we have revised some elements of the Personal Liberties subscale of the ATHRI to develop it into a more contemporary measurement so that it can reflect current thinking about human rights (Table 13). Question 5 in the Revised Personal Liberties scale was our second attention check question. Essentially, a construct's reliability depends on the number of items as well as participants in a study, with a minimal subject-to-variable ratio of 5:1 (Bryant \& Yarnold, 1995; see also, Stevens, 2002). Crowson's ATHRI (2004) as well as our Revised Personal Liberties scale exceeded this criterion. 


\section{Table 13}

The Attitudes Toward Human Rights Inventory (Crowson, 2004; Getz, 1985)

ATHRI
Civilian Constraint
1. Laws should be passed to regulate the activities of religious cultures that have come here from Asia. - (Reverse Score)
2. Occasionally it is reasonable to deny the right to vote to some groups; for instance to persons involved in un-American activities
or to members of the Communist party. -
3. People from Communist countries should not be allowed to come here and spread their propaganda. -
4. Books should be banned if they are written by people who have been involved in un-American activities. -
5. Loyal citizens should be given full constitutional rights but disloyal citizens should not expect to be given all those rights. -
Social Security
6. Welfare assistance should be limited to those who are really needy and not given to unemployed counter-culture dropouts. -
7. The government should find ways to ensure a good food supply for the children in our large cities' black neighborhoods.
8. If unemployed people cannot find work, they just are not looking hard enough, and therefore should not be supported by the
Personal Liberties
9. Churches should not change American Indians' beliefs.
10. Teachers who are homosexuals can be good role models for our children, just like anyone else.
11. Birth control information should be made available to the public at large.
12. Homosexuals probably shouldn't be hired for jobs requiring considerable contact with the public since they could carry AIDS.
13. A terminally ill and suffering patient should be able to have the doctor "pull the plug."
14. Abortion is any woman's right.
15. If we let atheists teach in our schools they will try to indoctrinate our children. -

\section{Revised Personal Liberties subscale}

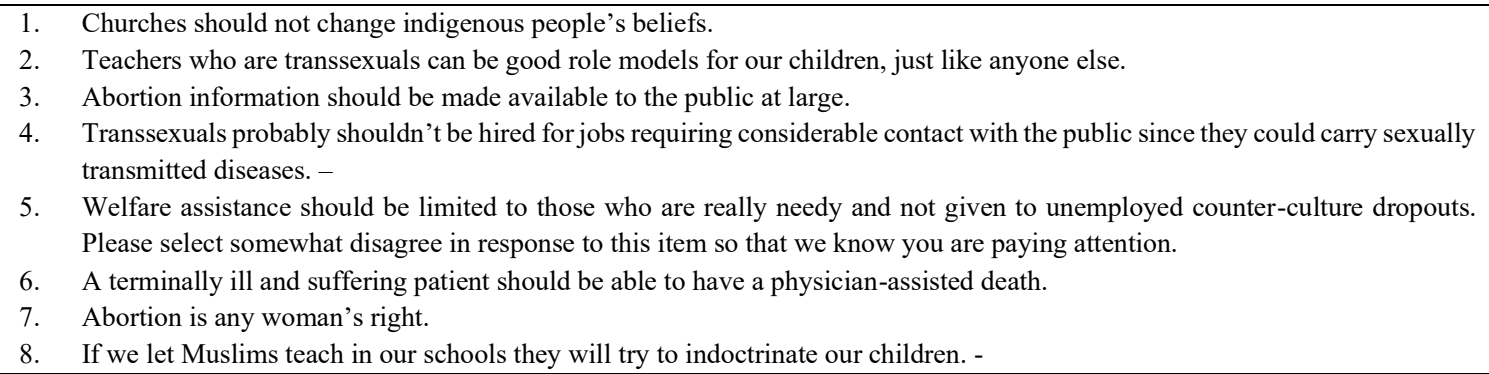

\section{Cheating behavior (Dice Cheating Task)}

Cheating behavior was chosen to measure a type of antisocial behavior. Associated with other actions such as lying and dishonesty, we believe that an individual's decision to cheat or not to cheat may be linked to their beliefs about the level of control they and their fellow human beings have over their decisions (i.e., classical belief). The current cheating task in Study 2, the Dice Cheating Task, has been employed in a recent observational study on BFW (Crone \& Levy, 2019), a task originally conducted offline (Fischbacher \& Heus, 2008). Using cheating behavior as a measurement of antisocial behavior is also consistent 
with Vohs and Schooler's original manipulative study (2008). In Crone and Levy (2019), the participants were asked to roll a real or online dice and report their rolls, they were informed that they would be paid according to the numbers they rolled. Since the study was anonymous, some of the participants were tempted to cheat by reporting higher rolls, but due to probability of dice rolls, the researchers could find out which group, believers or non-believers in free will, earned more money and hence cheated more.

One limitation of Crone and Levy's task was the low amount of potential bonus earnings. In their first study, they offered \$0.01-\$0.06 to each participant, and on their two other studies, they only provided one random participant $\$ 5-\$ 30$. In this study, we substantially increased the bonus to $\$ 0.50-\$ 1.75$ for each participant, with $\$ 0.25$ intervals for each number they roll. Most importantly, we maintained the anonymous aspect of the task by instructing them to search "dice roller" in Google once, and furthermore, informed the participants that the task was optional and the aim of it was to compare the level of enthusiasm between lottery winners and non-winners, thus slightly entailing the value of their true rolls by functioning as a cover stone for the real purpose of the task. Lastly, the decision of setting the Cheating Task and the Donation Task (see below) as optional tasks was made so that the tasks would give the impression of additional work the participants were asked to do in return for additional payment, and this would in turn give them a greater aspect of honesty and charity.

\section{Helping behavior (Donation Task)}

For the measurement of a kind of prosocial behavior, we chose donation, since it is the clearest form of helping behavior a person does without expecting anything in return. We presume that helping behavior, and in particular donation behavior, will be associated with 
the classical belief, given that a major angle of donation revolves around helping people in circumstances wherein you believe them to be in less control over their lives. A donation task was also used in Crone and Levy's study (2019), a well-implemented online study. The researchers offered the participants the opportunity to donate to a charity, but again, either the researcher offered a bonus that was too small or they increased the bonus and awarded one random participant the opportunity to donate to their desired charity among several choices. In the current study, an additional optional short survey was offered to the participants to complete in exchange for a $\$ 1.50$ bonus. The short survey consisted of the Revised Personal Liberties scale and the self-reported English Proficiency question. After their completion of the short survey, the participants were given the opportunity to donate between $\$ 0$ and $\$ 1.50$ of their bonus earnings to the Save the Children Fund. We informed them that we expected to survey a total of 270 people. Therefore, depending on their donations, we could potentially raise up to $\$ 405$. Upon reviewing the results, and according to the participants' decisions, the researchers donated money to the fund. ${ }^{6}$ Save the Children was picked as it is currently one the most scandal-free and unpolitical charities out there.

\section{Analyses}

We have presented the main objectives of the Study 2 in the form of a diagram (Figure 18). This diagram is meant to assist the readers in better understanding the overall layout of Study 2, and also act as a template for our later mediation and structural equation models (see pages 61 and 62). 


\section{Figure 18}

Diagram of the main relationships of Study 2 (in blue); Age, Education, Sex, and BillOlivia are potential influencers (in grey)

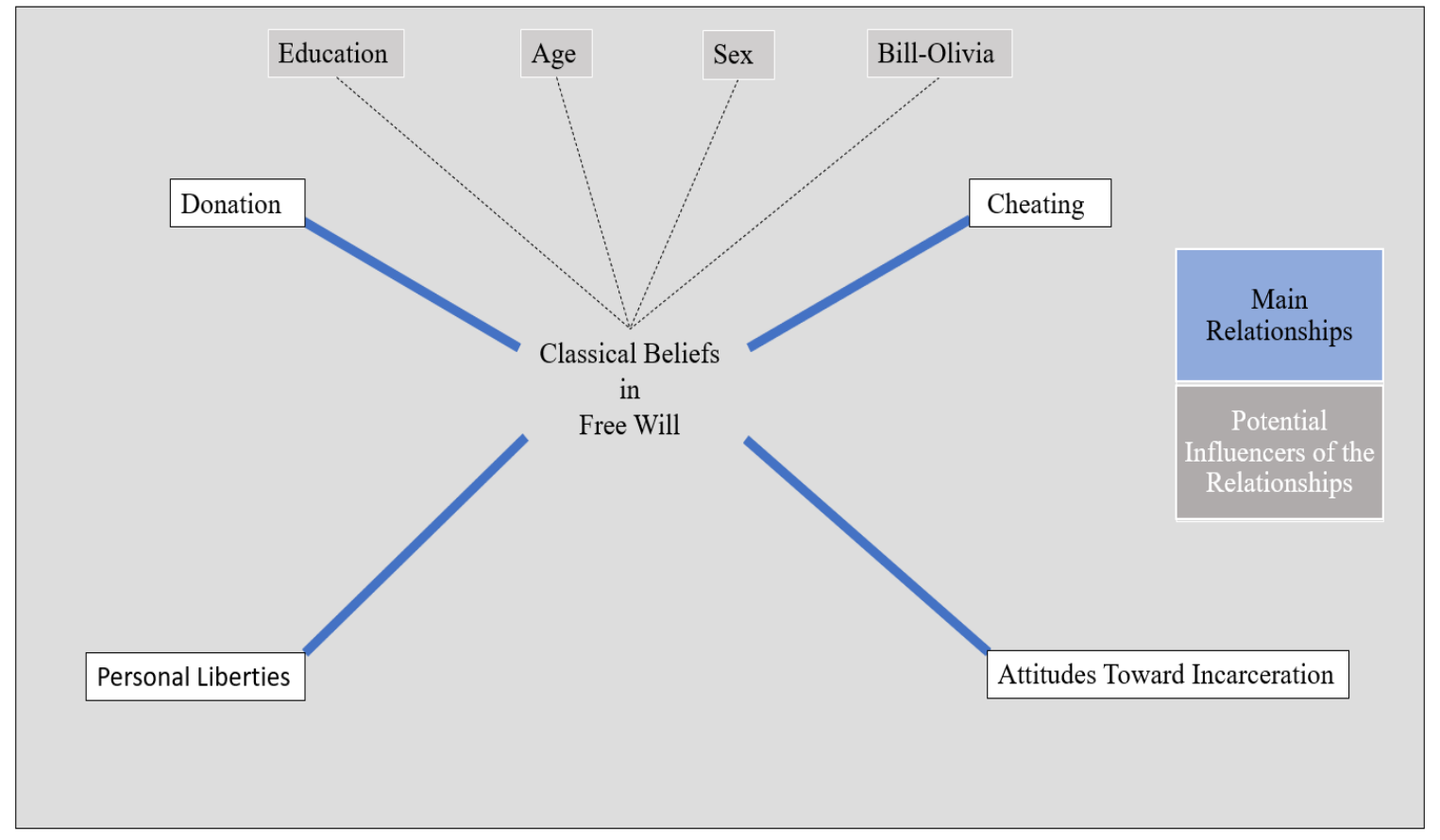

\subsection{Study 2: Results}

Prior to our main analyses for Study 2 , we conducted a reliability analysis on the CBFW scale (Cronbach's Alpha $=.73$ ) and the Revised Personal Liberties scale (Cronbach's Alpha $=.77)$. Both constructs had good psychometric characteristics, with the CBFW scale having identical reliability to Study 1 (Cronbach's Alpha $=.74$ ), and the Revised Personal Liberties scale having a bit higher reliability than the original Personal Liberties subscale (Cronbach's Alpha $=.71$, Crowson, 2004). Next, we moved on to repeat the same ANCOVA and MANCOVA analyses of Study 1, with the exception of the Bill-Olivia dependent variable — we only included the Bill scenario in Study 2 given that we ruled out the potential effects of sex-related biases and differences in Study 1. Analogous to the first study, the ANCOVA results of Study 2 revealed a significant effect of Education $\left(\mathrm{F}_{1,193}=\right.$ 
$3.59 ; p=.0007)$ and also proved the main effect of Sex to be non-significant. Unlike Study 1, there was no significant effect of Age on the CBFW scale, this may be due to the smaller sample size in Study 2. Participants' responses to the CBFW measure are displayed in Table 14 and figure 19.

\section{Figure 19}

Mean and Standard deviation of the degrees of classical belief in free will among females and males

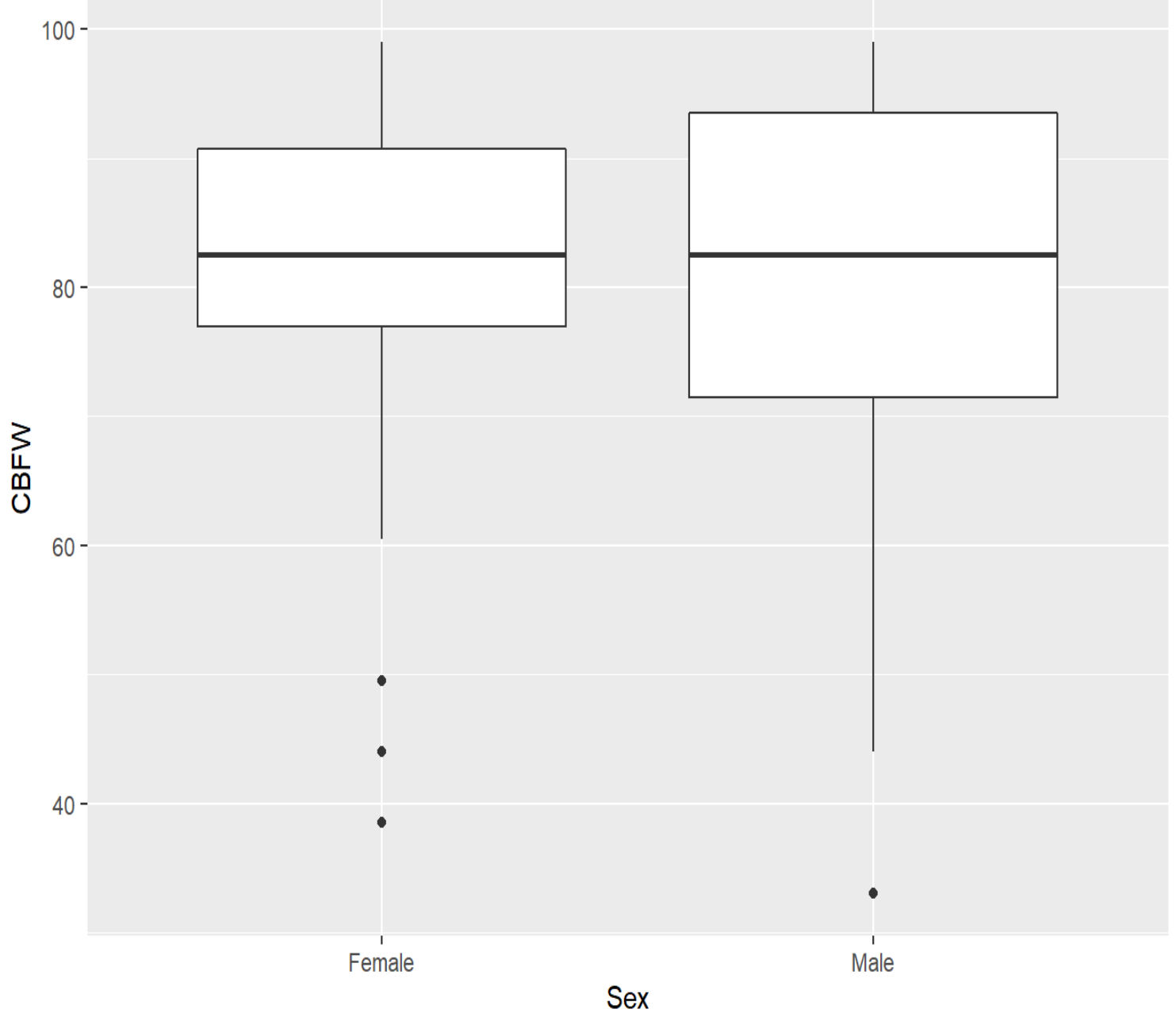




\section{Table 14}

ANCOVA on Sex (independent variable) and the CBFW scale (dependent variable), with Education, Age, and Completion Time as covariates

\begin{tabular}{lccccc}
\hline Source & $d f$ & sumsq & meansq & statistic & p.value \\
& & & & \\
Education & 1 & 8.14 & 8.14 & 12.0 & 0.001 \\
Age & 1 & 0.621 & 0.621 & 0.915 & 0.340 \\
Time & 1 & 0.419 & 0.419 & 0.618 & 0.433 \\
Sex & 1 & 0.477 & 0.477 & 0.702 & 0.403 \\
Residuals & 192 & 130. & 0.679 & NA & NA \\
\hline
\end{tabular}

The MANCOVA analysis on Sex (independent variable) and the three CBFW questions (dependent variables), with Age, Education, and Time as the covariate variables (Table 15) showed that education levels were significantly different for all three CBFW questions $\left(\mathrm{F}_{1.193}=6.870 ; p=0.009 ; \mathrm{F}_{1.193}=6.033 ; p=0.015 ; \mathrm{F}_{1.193}=10.967 ; p=0.001\right)$. Considering CBFW2 was marginally different between Sex $(p=.092)$, we conducted a hypothesis test with 10000 permutations and saw that the effect remained marginal and non-significant $(p$ $=.096$, Figure 20). Importantly, the Box's M test for the MANCOVA analysis for Study 2 proved not to be significant this time $(p=.142)$, reinforcing the earlier statement that Box's M can be sensitive to larger samples, 753 compared to 197 participants (e.g., Tabachnick \& Fidell, 2019). 
Figure 20

Simulation-based null distribution of CBFW2 and Sex (hypothesis test)

Simulation-Based Null Distribution

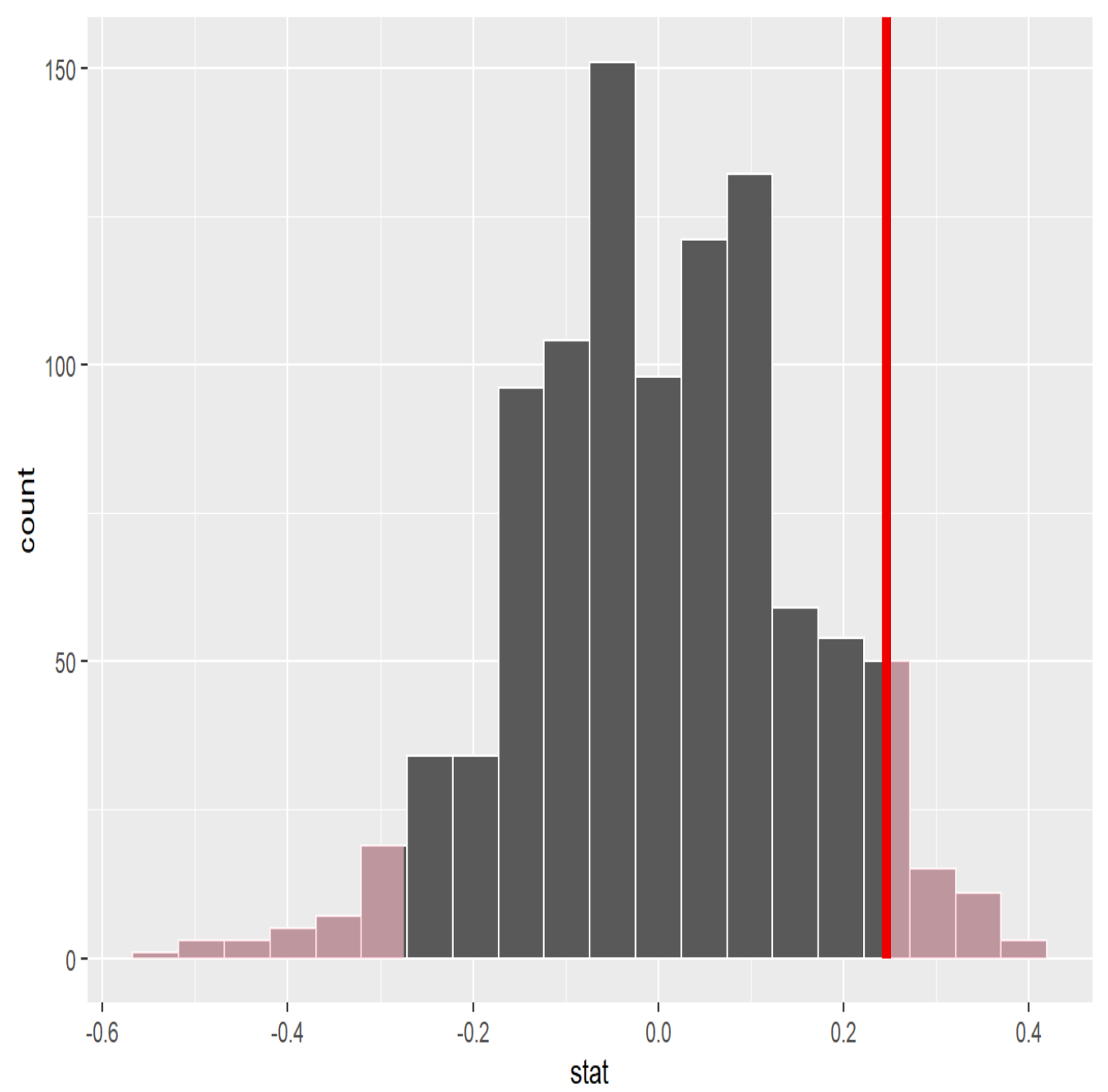




\section{Table 15}

MANCOVA on Sex (independent variable) and the CBFW questions (dependent variables), with Age, Education, and Completion Time as the covariate variables

\begin{tabular}{|c|c|c|c|c|c|c|}
\hline & Dependent Variable & Sum of Squares & $\mathrm{df}$ & Mean Square & $F$ & $p$ \\
\hline \multirow{3}{*}{ Sex } & FW1 & 0.487 & 1 & 0.487 & 0.387 & 0.534 \\
\hline & FW2 & 2.895 & 1 & 2.895 & 2.868 & 0.092 \\
\hline & FW3 & 0.007 & 1 & 0.007 & 0.007 & 0.931 \\
\hline \multirow{3}{*}{ Age } & FW1 & 0.791 & 1 & 0.791 & 0.629 & 0.429 \\
\hline & FW2 & 1.115 & 1 & 1.115 & 1.104 & 0.295 \\
\hline & FW3 & 0.511 & 1 & 0.511 & 0.550 & 0.459 \\
\hline \multirow{3}{*}{ Education } & FW1 & 8.663 & 1 & 8.663 & 6.885 & 0.009 \\
\hline & FW2 & 6.093 & 1 & 6.093 & 6.036 & 0.015 \\
\hline & FW3 & 10.188 & 1 & 10. 188 & 10.977 & 0.001 \\
\hline \multirow{3}{*}{ Time } & FW1 & 0.014 & 1 & 0.014 & 0.011 & 0.915 \\
\hline & FW2 & 0.677 & 1 & 0.677 & 0.671 & 0.414 \\
\hline & FW3 & 2.094 & 1 & 2.094 & 2.257 & 0.135 \\
\hline \multirow{3}{*}{ Residuals } & FW1 & 241.578 & 192 & 1.258 & & \\
\hline & FW2 & 193.809 & 192 & 1.009 & & \\
\hline & FW3 & 178.195 & 192 & 0.928 & & \\
\hline
\end{tabular}

We then proceeded to our main analyses for Study 2, starting with Pearson's correlation coefficient on the CBFW questions, the CBFW scale, the Donation Task, the Cheating Task, the Revised Personal Liberties scale, Incarceration, Age, and Education (Figure 21). The results revealed some interesting and unexpected findings: 
1. First, similar to Study 1, all CBFW questions, as well as the CBFW scale, were significantly negatively correlated with Education $(r=-.19, p=.0071 ; r=-.16, p=$ $.0223 ; r=-.23, p=.0011 ; r=-.24, p=.0006)$. Indicating that laypeople with higher education levels believe less in CBFW.

2. CBFW1, CBFW3, and the CBFW scale were significantly negatively correlated with the Donation Task $(r=-.16, p=.0216 ; r=-.15, p=.0342 ; r=-.18, p=.0125)$. This suggests that more donations came from laypeople with lower degrees of CBFW1 and CBFW3.

3. CBFW2 and the CBFW scale were significantly correlated with the Cheating Task $(r=.17, p=.0156 ; r=.15, p=.0359)$, hinting that laypeople who hold higher levels of CBFW2 cheated more on the Cheating Task.

4. CBFW1 and the CBFW scale were significantly correlated with the Personal Liberties scale $(r=.15, p=.0310 ; r=.17, p=.0162)$. Moreover, CBFW2 and CBFW3 were marginally correlated with the Personal Liberties scale $(r=.13, p=$ $.0615 ; r=.12, p=.0806)$. This means that laypeople with higher degrees of BFW had more positive attitudes toward Personal Liberties.

5. None of the CBFW questions or scale were significantly correlated with Age or Incarceration. Yet Education was significantly correlated with Incarceration $(r=$ $.26, p=.0015)$. All other correlations can be observed in Figure 21. 


\section{Figure 21}

The correlation between the CBFW1, CBFW2, CBFW3, Education, Age, Donation Task, Cheating Task, Incarceration, the Revised Personal Liberties scale, and the CBFW scale

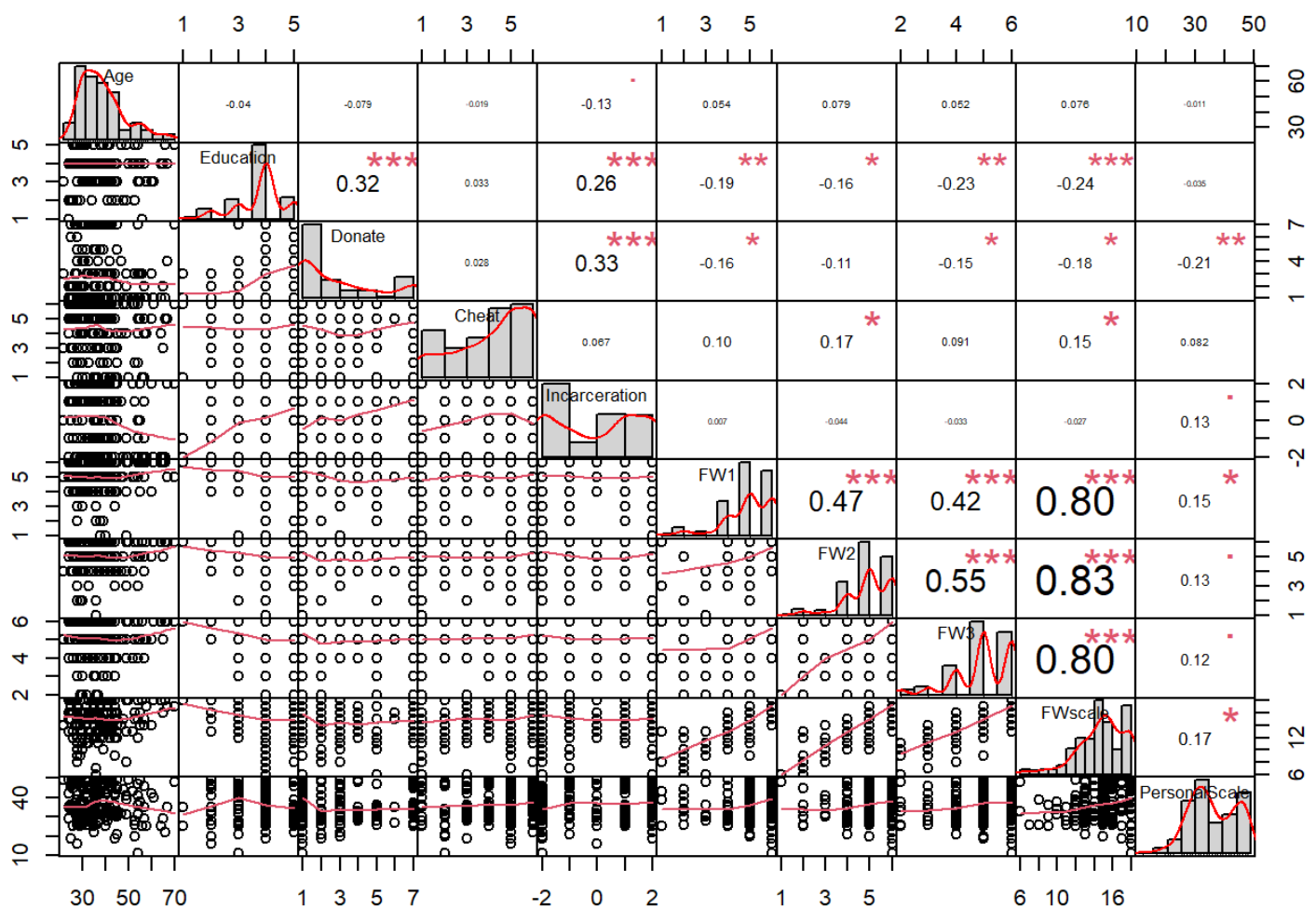

Next, we checked for mediating effects among variables (Table 16) and realized that the relationships between CBFW2 and the Cheating Task as well as CBFW1 and the Revised Personal Liberties scale were not mediated by Education. Additionally, the link between the Revised Personal Liberties scale and CBFW2 and CBFW3 were also not mediated by Education, but were only marginally significant. Moreover, the relationship between the Donation Task and CBFW3 plus CBFW1 and the Donation and Cheating Tasks were partially mediated by Education. Finally, Education had indirect effects on Incarceration and the Donation Task. The mediation model is displayed in Figure 22. 


\section{Table 16}

Hierarchical regression of each $C B F W$ question and the Revised Personal Liberties scale, Incarceration, the Donation Task, and the Cheating Task

\begin{tabular}{|c|c|c|c|c|c|}
\hline IV & $\begin{array}{l}\text { Dependent Variable and } \\
\text { Mediation }\end{array}$ & Estimate & Std. Error & $\mathrm{t}$ value & $\operatorname{PR}(>|t|)$ \\
\hline \multirow{9}{*}{ Donation } & FW1 & -0.3207 & 0.1385 & -2.317 & $0.0216 *$ \\
\hline & FW1 \& & -0.2074 & 0.1349 & -1.537 & 0.126 \\
\hline & Education & 0.7935 & 0.1807 & 4.391 & $1.85 \mathrm{e}-05 * * *$ \\
\hline & FW2 & -0.2464 & 0.1546 & -1.594 & 0.113 \\
\hline & FW2 \& & -0.1360 & 0.1494 & -0.911 & 0.364 \\
\hline & Education & 0.8200 & 0.1805 & 4.543 & $9.71 \mathrm{e}-06 * * *$ \\
\hline & FW3 & -0.3395 & 0.1592 & -2.132 & $0.0342 *$ \\
\hline & FW3 \& & -0.1815 & 0.1566 & -1.159 & 0.248 \\
\hline & Education & 0.7977 & 0.1828 & 4.364 & $2.07 \mathrm{e}-05 * * *$ \\
\hline \multirow{9}{*}{ Cheating } & FW1 & 0.1451 & 0.1029 & 1.410 & 0.16 \\
\hline & FW1 \& & 0.1601 & 0.1049 & 1.526 & 0.128720 \\
\hline & Education & 0.1051 & 0.1406 & 0.748 & 0.455594 \\
\hline & FW2 & 0.2756 & 0.1129 & 2.440 & $0.0156 *$ \\
\hline & FW2 \& & 0.2919 & 0.1145 & 2.549 & $0.01158 *$ \\
\hline & Education & 0.1214 & 0.1384 & 0.878 & 0.38122 \\
\hline & FW3 & 0.1505 & 0.1182 & 1.273 & 0.204 \\
\hline & FW3 \& & 0.1724 & 0.1216 & 1.418 & 0.15787 \\
\hline & Education & 0.1106 & 0.1419 & 0.779 & 0.43689 \\
\hline \multirow{9}{*}{ Personal Liberties } & FW1 & 1.1332 & 0.5216 & 2.172 & $0.031 *$ \\
\hline & FW1 \& & 1.12454 & 0.53281 & 2.111 & $0.0361 *$ \\
\hline & Education & -0.06073 & 0.71385 & -0.085 & 0.9323 \\
\hline & FW2 & 1.0910 & 0.5801 & 1.881 & 0.0615 \\
\hline & FW2 \& & 1.0723 & 0.5894 & 1.819 & 0.0704 \\
\hline & Education & -0.1382 & 0.7122 & -0.194 & 0.8463 \\
\hline & FW3 & 1.0558 & 0.6011 & 1.756 & 0.0806 \\
\hline & FW3 \& & 1.04235 & 0.61940 & 1.683 & 0.094 \\
\hline & Education & -0.06772 & 0.72313 & -0.094 & 0.925 \\
\hline Incarceration & Education & 0.4843 & 0.1283 & 3.774 & $0.000213^{* * *}$ \\
\hline
\end{tabular}




\section{Figure 22}

Mediation model testing for the mediating effect of Education on the relationship between the CBFW questions and the Revised Personal Liberties scale, Incarceration, and the

\section{Cheating and Donation tasks}

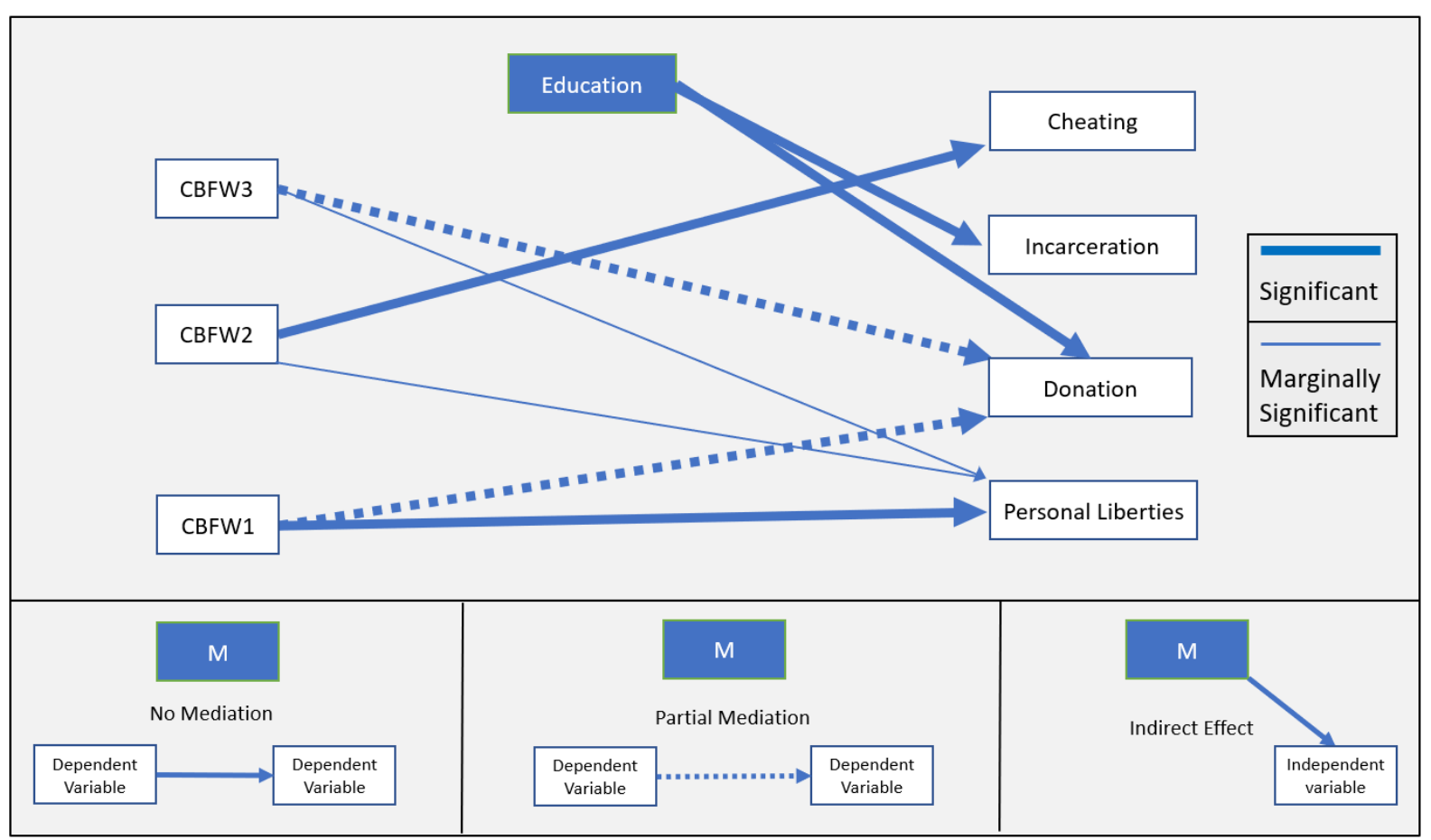

The structural equation model for Study 2 was similar to our mediation model. The model proved to have a good fit, with a non-significant chi-square $(p=0.855)$ and a significant RMSE $(p=0.000)$, Table 17 and Figure 23. In addition, the standardized beta values of our model also showed to confine within the bounds of -1 and 1 (e.g., Deegan, 1978). 


\section{Table 17}

Fit indices for the structural equation model

\begin{tabular}{lllllllll}
\hline Chi Square & GFI & AGFI & NFI & CFI & RMSEA & SRMR & AIC & BIC \\
\hline 0.855 & 0.992 & 0.972 & 0.976 & 1.000 & 0.000 & 0.019 & 5308.3 & 5390.4 \\
\hline
\end{tabular}

\section{Figure 23}

Structural equation model for Study 2, with standardized betas

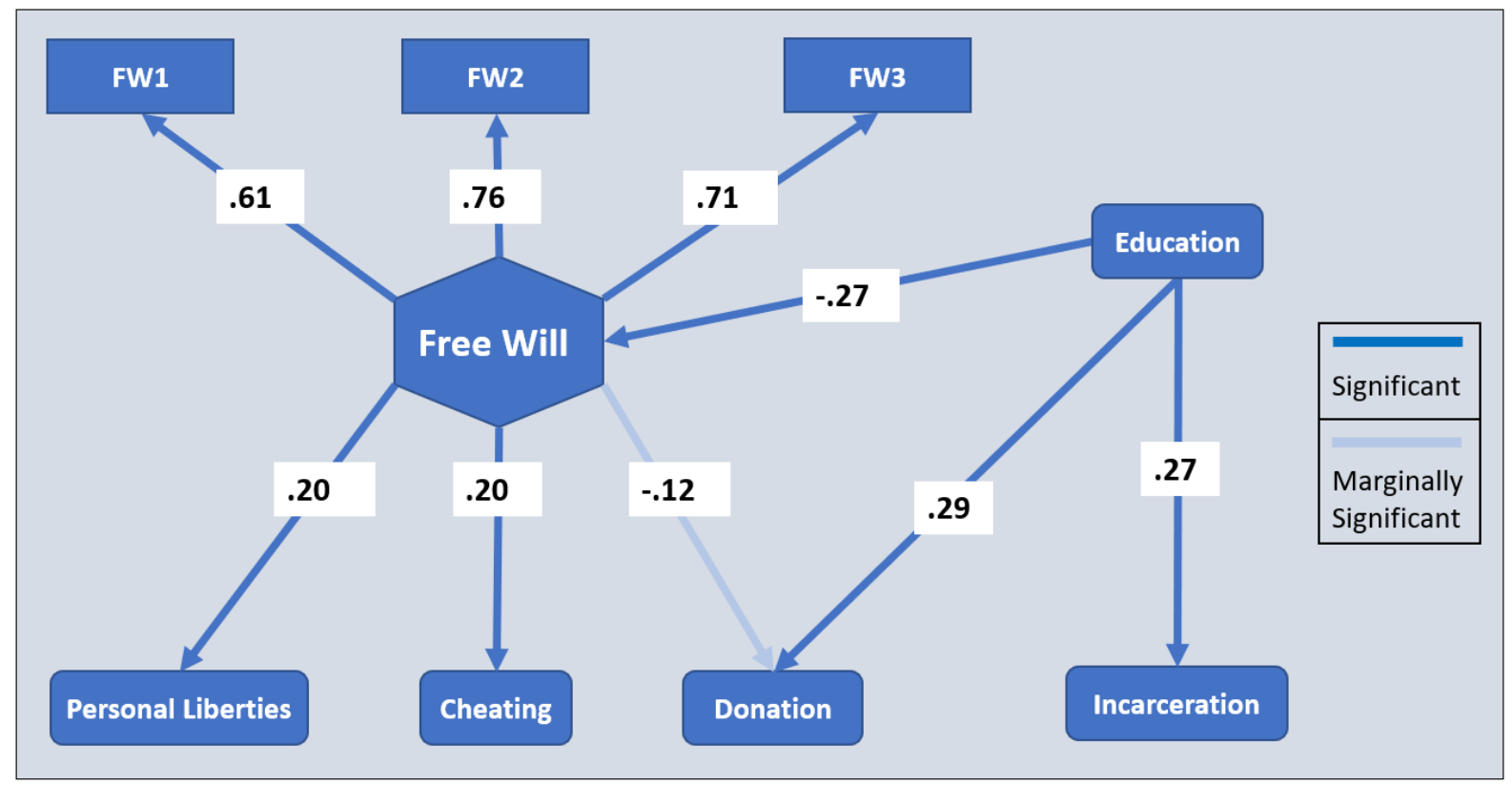

\subsection{Discussion}

The question of whether beliefs in free will (BFW) have social ramifications in the general public is one that we are greatly interested in, and the findings of this thesis are our way of contributing to the answer. We tried every which way to ensure that our results were not spurious, our two attention check questions were very difficult, we set high base and bonus compensations, limited demographic information on Amazon Mechanical Turk (Mturk) to improve the quality of the data, removed participants who self-reported low on 
the English Proficiency question, excluded participants who completed Study 1 and Study 2 in the lower fifth percentile (under 50 and 100 seconds), and also removed participants who knowingly or unintentionally skipped over the secondary survey that was required to partake in the optional Donation Task in Study 2. Moreover, by increasing the potential decisional payoffs, we further tempted the participants in the Cheating Task. Since participants were recruited through MTurk, we could be sure that they would be relying on the payment as part of their income, as opposed to the large number of research projects being conducted on first-and second-year undergraduate students. After excluding participants who failed the abovementioned criteria, we dropped 147 participants in Study $1(16 \%)$ and 73 in Study $2(27 \%)$. The high number of participants excluded in both studies speaks to the value of our remaining sample, while also casting doubt on the many research in social psychology and experimental philosophy that, more often than not, are only able to exude a few percent of their total number of participants. All these considerations allowed us to make confident claims about the validity of our findings.

Our classical belief in free will (CBFW) item consists of three similar questions revolving around our ability to make decisions, yet on different angles. With the first question centering on one person (CBFW1), question two centering on people in many situations (CBFW2), and question three on almost anyone in all situations (CBFW3). This was crucial for we were positive that laypeople's beliefs would vary, and the different correlations between the CBFW questions and our scales and tasks lend empirical support to our theory. In other words, the CBFW questions were not similarly correlated with our items (for instance, only CBFW3 was correlated with the Cheating Task). ${ }^{7}$ First and foremost, the results suggested that the majority of participants had high degrees of CBFW, a finding 
consistent with previous work on free will. Additionally, in order to present a valid construct, we chose to administer two version of our CBFW item (a female and a male scenario) to see whether there were any sex-related differences or biases in the responses. The results suggested that there were no differences and that education was the main predictor. Age was also associated with the classical belief, but only with CBFW1. In particular lower education levels and, in some respects higher age, were correlated with higher degrees of CBFW. In part, we expected this finding-to make use of Voltaire's dictum, "common sense is not so common", and while there are many other ways of acquiring information, some education can be a reasonable facilitator, so the different degrees of BFW among laypeople with different levels of education can be expected.

We then proceeded to our main analyses and found that people with higher levels of CBFW had more positive attitudes toward personal liberties (this relationship was present among all three CBFW questions). How are CBFW related to personal liberties? We reason that personal liberties and CBFW are both associated with an individual's belief that they have free choices. Though, the former is limited to that of an organized society while the latter pertains to our lives. Next, we observed that lower levels of CBFW predicted lower degrees of cheating and higher amounts of total donations (p. 58 and 59). These last findings may seem contradictory to the majority of the literature on BFW (e.g., Baumeister et al., 2009; Vohs \& Schooler, 2008). Though this was not all, also contrasting the literature to an extent (e.g., Genschow et al., 2017; Shariff et al., 2014), our results showed that CBFW is not associated with laypeople's attitudes toward incarceration (retributive or consequentialist). Our suspicion is that perhaps the free will scales employed in the studies were the cause of the correlations they thought they found (as described in section 3.1). For 
example, out of the five questions in the Free Will subscale of the FWI (Nadelhoffer et al., 2014), questions 2 and 5 contain the vague term "free will" and question 1 includes the equally vague term "to do otherwise". But, more seriously, the Free Will subscales of the FAD-4 (Paulhus \& Margesson, 1994) and FAD-Plus (Paulhus \& Carey, 2011) actually include the words and phrases "full responsibility", "at fault", and "punishing". It is a wonder why stronger correlations did not arise! Even so, in theory, it astonishing that laypeople with different degrees of CBFW seem not to have dissimilar views on incarceration, perhaps differences only arise once an individual learns to exercise belief revision - the process of altering one's beliefs in order to incorporate new pieces of information (in the way of the contemporary viewpoints on free will).

The mediating effects of education levels is another thing to look out for in future studies, as demonstrated by the significant correlations between education and the CBFW questions in Study 1 and Study 2. More precisely, from the mediation and structural equation models, we were able to infer that education levels had indirect effects on attitudes toward incarceration and the Donation Task, plus mediating effects on the relationship between the Donation Task and CBFW1 and CBFW2. Now to be clear, we believe it is worth echoing here that these findings are not to be generalized to the main viewpoints on free will (e.g., compatibilism and hard determinism), nor to different cultures. What we can assert, however, is that future studies on laypeople's beliefs in free will should revise the current instruments (section 3.0) before the literature continues to go further down the rabbit hole. 


\subsection{Limitations}

The present study only assessed modest forms of pro- and anti-social behaviors, we believe that there should always be a distinction between actions in highly artificial environments (e.g., labs and online) and those that affect others. By the same token, while a part of our study was aimed at evaluating attitudes toward personal liberties and incarceration, we cannot know whether the participants simply believe or whether they in fact act upon those beliefs, similar to what Carl Rogers called the "ideal self" and the "real self” (Rogers, 1959).

Donation is certainly a good example of a prosocial attitude, yet there are several limitations to it: (i) MTurk subjects have a below-average incomes in the US, (ii) only 19 percent of the population in the US highly trust charities (source: Better Business Bureau Wise Giving Alliance; give.org), (iii) people might prefer to first help the people that are close to them, e.g., family and relatives, and (iv) there may be individuals that prefer to donate to specific charities. Yet, seeing as these limitations apply to all participants (i.e., people who hold different degrees of CBFW), we can deem it a prosocial behavior.

Another limitation of our research is that we only used American participants. This decision was largely made because $75 \%$ of MTurk workers are based in the United States, $16 \%$ in India, 1.1\% Canada, 0.7\% Great Britain, and so forth (difallah et al., 2018), and since our selected demographics were $95 \%$ acceptance rate over 500 separate studies, we may not have been able to obtain the same number of participants from different countries and, as a result, only the United States was chosen. It would certainly be of interest to examine CBFW in other regions of the world. 


\subsection{Conclusion}

The literature on beliefs in free will (BFW) can be summed up with Thomas Alva Edison's famous quote: “A good intention, with a bad approach, often leads to poor results". Well, an area of study that was most certainly based upon good intentions, has not always, but for the most part led to vast numbers of spurious correlations. In this thesis, we present conclusions of two kinds, negative conclusions of previous work and positive conclusions about the real correlations. As stated, future studies in the field have their work cut out for them. There are substantial problems to overcome before any work on BFW can adequately test what they were intended to test. We hope that as this relatively new area of study grows, the problems and challenges that we have raised here will be taken into account and future work in the field will explore alternative methods for investigating BFW - one novel approach, that we have used, is to study classical belief in free will $(\mathrm{CBFW})$, the varied and basic common beliefs that does not require any previous knowledge and/or foundation to the free will debate. Now, there may be other approaches but the one that we have introduced here does the job.

The combination of our two studies' results revealed that the general public tends to have higher as opposed to lower degrees of CBFW. Moreover, between age and education, the latter seems to be the main predictor of the classical belief. Our findings also showed no evidence of sex-related biases or differences with regard to laypeople's degrees of BFW. In Study 2, we explored the implications of CBFW and we were met with some anticipated and not so anticipated findings. First, we saw that higher classical belief predicted higher degrees of cheating as well as lower amounts of donations. But then, on the other hand, CBFW was associated with more positive attitudes toward personal liberties, a subpart of 
human rights. And, last of all, much to our surprise, we did not find any indication of differences between CBFW holders and non-holders' views on incarceration. On account of these findings, we believe that there is good reason to assume that different degrees of classical belief in free will only sometimes influence laypeople's attitudes and behaviors. However, we also believe that far more research is needed before making any strong claims about the implications of degrees of belief in free will on human behavior.

\subsection{Notes}

1. For a detailed overview of the free will debate, see Brook and Stainton (2001, Chapter Six); see also Fischer, Kane, Pereboom, \& Vargas (2007).

2. This concern is amplified by the reason that some studies were unsuccessful in replicating the results of the first manipulative study on free will belief-Vohs and Schoolers' 2008 study (e.g., Nadelhoffer et al., 2020; Open Science Collaboration, 2015; Zwaan, 2013). Likewise, various scholars within the field have raised concerns about their methodologies (e.g., Caruso, 2016; Ewusi-Boisvert \& Racine, 2018; Nadelhoffer et al., 2020).

3. Presenting a male/female scenario would also be a start toward seeing if unreflective laypeople think that some (well to do white males) have more freedom of choice, or freedom of choice in more situations, than, say, women, or gays, or etc.

4. We thought of using a gender-neutral scenario, a Leslie scenario for instance, as prominent people of both genders have had the name; but then, half of the participants would take the neutral name to be that of a male and the other half a female, and this would in turn be an indistinguishable confound since the participants would be responding to two different items. 
5. Since our item differs with previous work in the field, we wanted to be conservative in selecting our effect sizes, and that is why we chose the minimally meaning effect sizes, which is a recommended practice (e.g., Albers \& Lakens, 2018).

6. The final 197 participants donated a sum of $\$ 90.75$ to Save the Children Fund. Due to the 40 rejected participants (without overlap) in Study 2, in which the researchers were not charged by Amazon Mechanical Turk, we were able to donate a total of 153 USD.

7. We would have liked to further explore the varied nature of laypeople's beliefs in free will in this thesis, but lack of time prevented us from doing so and this is left for future work. 


\subsection{Funding}

This work was supported by the Cognitive Science Graduate Scholarship, Carleton University (2019-20).

\subsection{Ethics Clearance}

The current study has received ethics review and clearance by the Carleton University Research Ethics Board (Study 1: CUREB-B, Project \#112740; Study 2: CUREB-B, Project \#114747).

\subsection{Declaration of Conflicting Interests}

The author declared no potential conflicts of interest with respect to the research, authorship, and/or publication of this thesis.

\subsection{Appendix A: Supplemental Materials}

The supplemental materials contain our research instrument, $\mathrm{R}$ Markdown file, and ethics clearance for both Study 1 and Study 2 . They are available at https://osf.io/cva58/?view_only=82b0463d98cb4f458ba102ce27ee5786

\subsection{References}

Aarts, H., \& van den Bos, K. (2011). On the foundations of beliefs in free will: Intentional binding and unconscious priming in self-agency. Psychological science, 22(4), 532-537. Albers, C., \& Lakens, D. (2018). When power analyses based on pilot data are biased: Inaccurate effect size estimators and follow-up bias. Journal of Experimental Social Psychology, 74, 187-195.

Alquist, J. L., Ainsworth, S. E., \& Baumeister, R. F. (2013). Determined to conform: Disbelief in free will increases conformity. Journal of Experimental Social Psychology, 49(1), 80-86. 
Baumeister, R. F., Masicampo, E. J., \& DeWall, C. N. (2009). Prosocial benefits of feeling free: Disbelief in free will increases aggression and reduces helpfulness. Personality and social psychology bulletin, 35(2), 260-268.

Bear, A., \& Knobe, J. (2016). What do people find incompatible with causal determinism? Cognitive Science, 40(8), 2025-2049.

Boudesseul, J., Lantian, A., Cova, F., \& Bègue, L. (2016). Free love? On the relation between belief in free will, determinism, and passionate love. Consciousness and cognition, 46, 47-59.

Brook, A., \& Stainton, R. J. (2001). Knowledge and mind: A philosophical introduction. MIT Press.

Bryant, F. B., \& Yarnold, P. R. (1995). Principal-components analysis and exploratory and confirmatory factor analysis. In L. G. Grimm \& P. R. Yarnold (Eds.), Reading and understanding multivariate statistics. Washington, DC: American Psychological Association.

Buhrmester, M., Kwang, T., \& Gosling, S. D. (2011). Amazon's Mechanical Turk: A new source of inexpensive, yet high-quality data? Perspectives on Psychological Science, $6(1), 3-5$.

Carey, J. M., \& Paulhus, D. L. (2013). Worldview implications of believing in free will and/or determinism: Politics, morality, and punitiveness. Journal of personality, 81(2), $130-141$.

Carmody, P. C., \& Gordon, K. C. (2014). Mere civility, or genuine forgiveness? Prosocial consequences of belief in free will. Interpersona: An International Journal on Personal Relationships, 8(2), 245-256. 
Caruso, G. D. (2016). Free will skepticism and its implications: An argument for optimism. Free will skepticism in law and society.

Casler, K., Bickel, L., \& Hackett, E. (2013). Separate but equal? A comparison of participants and data gathered via Amazon's MTurk, social media, and face-to-face behavioral testing. Computers in human behavior, 29(6), 2156-2160.

Caspar, E. A., Vuillaume, L., Magalhães De Saldanha da Gama, P. A., \& Cleeremans, A. (2017). The influence of (dis) belief in free will on immoral behavior. Frontiers in psychology, 8, 20.

Chandrashekar, S. P. (2020). It's in Your Control: Free Will Beliefs and Attribution of Blame to Obese People and People with Mental Illness. Collabra: Psychology, 6(1).

Clark, C. J., Baumeister, R. F., \& Ditto, P. H. (2017). Making punishment palatable: Belief in free will alleviates punitive distress. Consciousness and Cognition, 51, 193-211.

Clark, C. J., Luguri, J. B., Ditto, P. H., Knobe, J., Shariff, A. F., \& Baumeister, R. F. (2014). Free to punish: A motivated account of free will belief. Journal of personality and social psychology, 106(4), 501.

Cova, F., \& Kitano, Y. (2014). Experimental philosophy and the compatibility of free will and determinism: a survey. Annals of the Japan Association for Philosophy of Science, 22, 17-37.

Crone, D. L., \& Levy, N. L. (2019). Are free will believers nicer people?(Four studies suggest not). Social Psychological and Personality Science, 10(5), 612-619.

Crowson, H. M. (2004). Human rights attitudes: Dimensionality and psychological correlates. Ethics \& Behavior, 14, 3, 235-253. 
Crump, M. J., McDonnell, J. V., \& Gureckis, T. M. (2013). Evaluating Amazon's Mechanical Turk as a tool for experimental behavioral research. PloS one, 8(3), e57410. Deegan Jr, J. (1978). On the occurrence of standardized regression coefficients greater than one. Educational and Psychological Measurement, 38(4), 873-888.

Denis, D. J. (2020). Univariate, Bivariate, and Multivariate Statistics Using R: Quantitative Tools for Data Analysis and Data Science. John Wiley \& Sons.

Dennett, D.C. (2003). Freedom evolves. London: Allen Lane.

Diaz-Veizades, J., Widaman, K. F., Little, T. D., \& Gibbs, K. W. (1995). The measurement and structure of human rights attitudes. The Journal of Social Psychology, 135, 313-328.

Difallah, D., Filatova, E., \& Ipeirotis, P. (2018, February). Demographics and dynamics of mechanical Turk workers. In Proceedings of the eleventh ACM international conference on web search and data mining (pp. 135-143).

Earp, B. D., Everett, J. A., Nadelhoffer, T., Caruso, G. D., Shariff, A., \& SinnottArmstrong, W. (2018). Determined to Be Humble? Exploring the Relationship Between Belief in Free Will and Humility.

Ent, M. R., \& Baumeister, R. F. (2014). Embodied free will beliefs: Some effects of physical states on metaphysical opinions. Consciousness and Cognition, 27, 147-154.

Ewusi-Boisvert, E., \& Racine, E. (2018). A critical review of methodologies and results in recent research on belief in free will. Neuroethics, 11(1), 97-110.

Faul, F., Erdfelder, E., Buchner, A., \& Lang, A.-G. (2009). Statistical power analyses using G*Power 3.1: Tests for correlation and regression analyses. Behavior Research Methods, 41, 1149-1160. 
Faul, F., Erdfelder, E., Lang, A. G., \& Buchner, A. (2007). G* Power 3: A flexible statistical power analysis program for the social, behavioral, and biomedical sciences. Behavior research methods, 39(2), 175-191.

Feldman, G., Baumeister, R. F., \& Wong, K. F. E. (2014). Free will is about choosing: The link between choice and the belief in free will. Journal of Experimental Social Psychology, 55, 239-245.

Feldman, G., Chandrashekar, S. P., \& Wong, K. F. E. (2016). The freedom to excel: Belief in free will predicts better academic performance. Personality and Individual Differences, 90, 377-383.

Fischbacher, U., \& Föllmi-Heusi, F. (2013). Lies in disguise-an experimental study on cheating. Journal of the European Economic Association, 11(3), 525-547.

Fischer, J., Kane, R., Pereboom, D., \& Vargas, M. (2007). Four views on free will. Hoboken, NJ: Wiley.

Frankfurt, H. G. (1969). Alternate possibilities and moral responsibility. Journal of Philosophy, 66(23), 829-839.

Frankfurt, H. G. (1971). Freedom of the Will and the Concept of a Person. Journal of Philosophy, 68(1), 5-20.

Genschow, O., Hawickhorst, H., Rigoni, D., Aschermann, E., \& Brass, M. (2020). Professional Judges' Disbelief in Free Will Does Not Decrease Punishment. Social Psychological and Personality Science.

Genschow, O., Rigoni, D., \& Brass, M. (2017). Belief in free will affects causal attributions when judging others' behavior. Proceedings of the National Academy of Sciences, 114(38), 10071-10076. 
Getz, I. (1985). Moral reasoning, religion, and attitudes toward human rights. Unpublished doctoral dissertation, University of Minnesota, Twin Cities Campus.

Hara, K., Adams, A., Milland, K., Savage, S., Callison-Burch, C., \& Bigham, J. P. (2018, April). A data-driven analysis of workers' earnings on amazon mechanical turk. In Proceedings of the 2018 CHI Conference on Human Factors in Computing Systems (p. 449). ACM.

Harris, S. (2012). Free will. Simon and Schuster

Hayes, M. A. (2004). Students' moral judgment, cultural ideologies, and moral thinking at evangelical Christian liberal arts colleges. Unpublished PhD dissertation, University of Tennessee. https://trace.tennessee.edu/utk_graddiss/4539

Horton, J. J., Rand, D. G., \& Zeckhauser, R. J. (2011). The online laboratory: Conducting experiments in a real labor market. Experimental economics, 14(3), 399-425.

Howell, D. C. (2013). Statistical methods for psychology, 8th Ed. Belmont, CA: Wadsworth

James, W. (2007). 1890. The principles of psychology (Vol. 1). Cosimo, Inc.

Kane, R. (1996). The Significance of Free Will. New York: Oxford University Press.

Kane, R. (1999). Responsibility, luck, and chance: Reflections on free will and indeterminism. The Journal of Philosophy, 96(5), 217-240.

Kondratowicz-Nowak, B., \& Zawadzka, A. M. (2018). Does belief in free will make us feel good and satisfied. Health Psychology Report, 2, 1-9.

Krueger, F., Hoffman, M., Walter, H., \& Grafman, J. (2014). An fMRI investigation of the effects of belief in free will on third-party punishment. Social cognitive and affective neuroscience, 9(8), 1143-1149. 
Li, C., Wang, S., Zhao, Y., Kong, F., \& Li, J. (2017). The freedom to pursue happiness: Belief in free will predicts life satisfaction and positive affect among Chinese adolescents. Frontiers in Psychology, 7, 2027.

Libet, B. (2004). Mind Time: The Temporal Factor in Consciousness. Cambridge, MA: Harvard University Press.

Livingstone, G., Derryberry, W. P., King, A., \& Vendetti, M. (2006). Moral developmental consistency? Investigating differences and relationships among academic majors. Ethics \& Behavior, 16(3), 265-287.

Lynn, M. T., Muhle-Karbe, P. S., Aarts, H., \& Brass, M. (2014). Priming determinist beliefs diminishes implicit (but not explicit) components of self-agency. Frontiers in psychology, 5, 1483.

MacKenzie, M. J., Vohs, K. D., \& Baumeister, R. F. (2014). You didn't have to do that: Belief in free will promotes gratitude. Personality and Social Psychology Bulletin, 40(11), 1423-1434.

Mele, A. (2014). Free will and substance dualism: The real scientific threat to free will. In W. Sinnott-Armstrong (Ed.). Moral psychology, Free will and moral responsibility (vol. 4). Cambridge, MA: MIT Press.

Mercier, B., Wiwad, D., Piff, P. K., Akin, L. B., Robinson, A. R., \& Shariff, A. (2020). Does Belief in Free Will Increase Support for Economic Inequality? Collabra: Psychology, 6(1).

Monroe, A. E., \& Malle, B. F. (2010). From uncaused will to conscious choice: The need to study, not speculate about people's folk concept of free will. Review of Philosophy and Psychology, 1(2), 211-224. 
Monroe, A. E., Dillon, K. D., \& Malle, B. F. (2014). Bringing free will down to Earth: People's psychological concept of free will and its role in moral judgment. Consciousness and cognition, 27, 100-108.

Moynihan, A. B., Igou, E. R., \& van Tilburg, W. A. (2017). Free, connected, and meaningful: Free will beliefs promote meaningfulness through belongingness. Personality and Individual Differences, 107, 54-65.

Mylopoulos, M., \& Lau, H. (2014). Naturalizing free will: Paths and pitfalls. Surrounding Free Will: Psychology, Philosophy, Neuroscience, 123-144.

Nadelhoffer, T., Shepard, J., Crone, D. L., Everett, J. A., Earp, B. D., \& Levy, N. (2020). Does encouraging a belief in determinism increase cheating? Reconsidering the value of believing in free will. Cognition, 203, 104342.

Nadelhoffer, T., Shepard, J., Nahmias, E., Sripada, C., \& Ross, L. T. (2014). The free will inventory: Measuring beliefs about agency and responsibility. Consciousness and cognition, 25, 27-41.

Nahmias, E., Morris, S. G., Nadelhoffer, T., \& Turner, J. (2006). Is incompatibilism intuitive? Philosophy and Phenomenological Research, 73(1), 28-53.

Nahmias, E., Morris, S., Nadelhoffer, T., \& Turner, J. (2005). Surveying freedom: Folk intuitions about free will and moral responsibility. Philosophical Psychology, 18(5), 561584.

Narvaez, D., Getz, I., Rest, J. R., \& Thoma, S. J. (1999). Individual moral judgment and cultural ideologies. Developmental psychology, 35(2), 478.

Nichols, S., \& Knobe, J. (2007). Moral responsibility and determinism: The cognitive science of folk intuitions. Nous, 41(4), 663-685. 
Open Science Collaboration. (2015). Estimating the reproducibility of psychological science. Science, 349(6251).

Paolacci, G., Chandler, J., \& Ipeirotis, P. G. (2010). Running experiments on amazon mechanical turk. Judgment and Decision making, 5(5), 411-419.

Paulhus, D. L., \& Carey, J. M. (2011). The FAD-plus: Measuring lay beliefs regarding free will and related constructs. Journal of Personality Assessment, 93, 96-104.

Paulhus, D. L., \& Margesson, A. (1994). Free Will and Scientific Determinism (FAD-4) scale. Unpublished instrument, University of British Columbia, Vancouver, BC, Canada. Pereboom, D. (2002). Living without free will: The case for hard incompatibilism. In The Oxford handbook of free will.

Rakos, R. F., Laurene, K. R., Skala, S., \& Slane, S. (2008). Belief in free will: Measurement and conceptualization innovations. Behavior and Social Issues, 17, 20-39.

Rigoni, D., Kühn, S., Gaudino, G., Sartori, G., \& Brass, M. (2012). Reducing self-control by weakening belief in free will. Consciousness and cognition, 21(3), 1482-1490.

Rigoni, D., Wilquin, H., Brass, M., \& Burle, B. (2013). When errors do not matter: Weakening belief in intentional control impairs cognitive reaction to errors. Cognition, 127(2), 264-269.

Rogers, C. R. (1959). A theory of therapy, personality, and interpersonal relationships: As developed in the client-centered framework (Vol. 3, pp. 184-256). New York: McGrawHill.

Rose, D., \& Nichols, S. (2013). The lesson of bypassing. Review of Philosophy and Psychology, 4(4), 599-619. 
Sarkissian, H., Chatterjee, A., De Brigard, F., Knobe, J., Nichols, S., \& Sirker, S. (2010). Is belief in free will a cultural universal? Mind \& Language, 25(3), 346-358.

Seto, E., Kim, J., \& Hicks, J. A. (2020). The Illusion of Time: Testing the Bidirectional Relationship Between Belief in Free Will and Temporal Horizons. Social Psychological and Personality Science.

Shariff, A. F., Greene, J. D., Karremans, J. C., Luguri, J. B., Clark, C. J., Schooler, J. W., ... \& Vohs, K. D. (2014). Free will and punishment: A mechanistic view of human nature reduces retribution. Psychological science, 25(8), 1563-1570.

Sohrabi, S., \& Sohrabi, A. (2020). Paranormal belief and attitudes toward human rights. International Journal of Indian Psychology, 8(2), 1477-1485.

Stevens, J. P. (2002). Applied multivariate statistics for the social sciences (4th ed.). Mahwah, NJ: Lawrence Erlbaum Associates, Inc.

Stillman, T. F., Baumeister, R. F., \& Mele, A. R. (2011). Free will in everyday life: Autobiographical accounts of free and unfree actions. Philosophical Psychology, 24(3), 381-394.

Stillman, T. F., Baumeister, R. F., Vohs, K. D., Lambert, N. M., Fincham, F. D., \& Brewer, L. E. (2010). Personal philosophy and personnel achievement: Belief in free will predicts better job performance. Social Psychological and Personality Science, 1(1), 43-50.

Strawson, G. (1986). Freedom and belief. Oxford, England: Oxford University Press.

Stroessner, S. J., \& Green, C. W. (1990). Effects of belief in free will or scientific determinism on attitudes toward punishment and locus of control. Journal of Social Psychology, 130, 789-799. 
Tabachnick, B. G., and Fidell, L. S. (2019). Using Multivariate Statistics, 7th ed. Boston: Pearson.

Thomas, K. A., \& Clifford, S. (2017). Validity and Mechanical Turk: An assessment of exclusion methods and interactive experiments. Computers in Human Behavior, 77, 184197.

Van Inwagen, P. (1989). When is the will free. Philosophical Perspectives, 3(1), 399-422. Vargas, M. (2006). On the importance of history for responsible agency. Philosophical Studies, 127(3), 351-382.

Viney, W., Waldman, D., \& Barchilon, J. (1982). Attitudes towards punishment in relation to beliefs in free will and determinism. Human Relations, 35, 939-950.

Vohs, K. D., \& Schooler, J. W. (2008). The value of believing in free will: Encouraging a belief in determinism increases cheating. Psychological science, 19(1), 49-54.

Vonasch, A. J., Clark, C. J., Lau, S., Vohs, K. D., \& Baumeister, R. F. (2017). Ordinary people associate addiction with loss of free will. Addictive behaviors reports, 5, 56-66.

Willoughby, E. A., Love, A. C., McGue, M., Iacono, W. G., Quigley, J., \& Lee, J. J. (2019). Free will, determinism, and intuitive judgments about the heritability of behavior. Behavior genetics, 49(2), 136-153.

Wisniewski, D., Deutschländer, R., \& Haynes, J. D. (2019). Free will beliefs are better predicted by dualism than determinism beliefs across different cultures. PloS one, 14(9). Zhao, X., Liu, L., Zhang, X. X., Shi, J. X., \& Huang, Z. W. (2014). The effect of belief in free will on prejudice. PloS one, 9(3), e91572. 
Zwaan, R. 2013. The value of believing in free will: a replication attempt. March 18, 2013.

Retrieved from: https://rolfzwaan.blogspot.com/2013/03/the-value-of-believing-in-freewill.html 